\title{
PHOSPHORUS SPECIATION IN SURFACE WATERS BY \\ ION CHROMATOGRAPHY WITH HIGH RESOLUTION
}

MASS SPECTROMETRY DETECTION

by

\section{VLASTIMIL PACKA}

B.Sc. (Inorganic Chemistry), Pavol Jozef Safarik University, Kosice, 1997

M.Sc. (Metallurgy), Technical University, Kosice, 2002

\author{
A dissertation \\ presented to Ryerson University \\ in partial fulfilment of the \\ requirements for the degree of \\ Doctor of Philosophy \\ in the program of \\ Environmental Applied Science and Management
}

Toronto, Ontario, Canada, 2019

(C) Vlastimil Packa, 2019 


\section{AUTHOR'S DECLARATION FOR ELECTRONIC SUBMISSION OF A DISSERTATION}

I hereby declare that I am the sole author of this dissertation. This is a true copy of the dissertation, including any required final revisions, as accepted by my examiners.

I authorize Ryerson University to lend this dissertation to other institutions or individuals for the purpose of scholarly research.

I further authorize Ryerson University to reproduce this dissertation by photocopying or by other means, in total or in part, at the request of other institutions or individuals for the purpose of scholarly research.

I understand that my dissertation may be made electronically available to the public. 


\title{
Phosphorus Speciation in Surface Waters by Ion Chromatography with High Resolution Mass Spectrometry Detection
}

\author{
(C) Vlastimil Packa \\ Doctor of Philosophy \\ Environmental Applied Science and Management \\ Ryerson University, Toronto
}

2019

\begin{abstract}
Phosphorus (P) containing compounds, depending on their origin, can enter freshwater systems in variety of forms. Utilization of bioavailable $\mathrm{P}$, a key nutrient in living organisms, is a crucial factor in biological productivity in aquatic environment ${ }^{1}$. An increase in the $\mathrm{P}$ concentration in water, resulting from both natural and anthropogenic processes, can lead to eutrophication and an excessive growth of vegetative biomass. Determination of organic and inorganic P species in ground, surface and waster is an important part of water quality control and monitoring ${ }^{2}$. Analytical determination of $\mathrm{P}$ compounds, quantification, identification (Chapter 2) and $\mathrm{P}$ speciation process can be problematic due to $\mathrm{P}$ adsorption on storage containers, sulfate interference, presence of acid hydrolysable $\mathrm{P}$ species and colloidal matter, association of both inorganic and organic phosphates with iron, manganese and aluminum, biological uptake of $\mathrm{P}$. Such processes have to be considered when designing an analytical procedure for analysis of $\mathrm{P}$ species. Analytical P compound separation by ion chromatography with mass spectrometry/Orbitrap technology for compound detection (Chapter 3) is a powerful technology with highly sensitive and selective properties capable of performing P speciation in one
\end{abstract}


analytical run. Selectivity of the Orbitrap detector also allows for utilization of isotope dilution technique which can compensate for loss of $\mathrm{P}$ compounds during storage and transportation and thus increase accuracy of measurements and holding time of sample matrices. Analytical techniques used in the past were able to determine broad P-fractions, such as total $\mathrm{P}$, total $\mathrm{P}$ or functional groups of inorganic and organic P compounds. Identification of variety of specific Pcontaining compounds of inorganic and organic origin by the methodology used in this thesis in combination with multivariate statistical analysis can be used to explain the large sets of intercorrelated analytical variables with a smaller set of independent variables (Chapter 4) and help in source identification in water pollution studies ${ }^{3}$. 


\section{FOR}

My wife Zuzana, and our daughters Nicole, Victoria and Natalie 


\section{ACKNOWLEDGEMENTS}

First and foremost, I would like to express gratitude to my supervisors, Dr. Vasile Furdui and Dr. Vadim Bostan for their help, support, and believing in me. They never gave up on me and without their ideas and support this work would not have been possible. It was a tremendous learning experience for me and their support has helped pull me through some strenuous times. I would also like to thank all the committee members Dr. Melania Cristescu, Dr. Andrew Laursen, Dr. Darrick Heyd, Dr. Tuna Baskoy and Dr. Stephen Wiley for taking the time to review this work and offer their suggestions for its improvement.

I am indebted to Dr. Todd Howell from the Environmental and Monitoring Branch of the Ministry of the Environment, Conservation and Parks for his great advice and a valuable perspective on my thesis. His experience in environmental monitoring field has brought a lot of valuable insights into this work. Together with his colleague Dr. Ngan Diep, they supervised Great Lakes sampling program and have delivered thousands of samples for phosphate analysis. My thanks also go out to Dr. Stefanie Maedler from MECP for her help and expert advice in the field of mass spectrometry and to my manager Robert Tooley for his support and editorial work. Thank you to the Inorganic Chemical Analysis Section of MECP for their hard work and effort to deliver analytical results needed for this dissertation especially to Hany Eskander for his total phosphate analysis, Cindy Tat and Mark Duric for their help with sample preparation and capillary chromatography analysis, Shelly Chan, Andrew Senyi and Carlos Jurado for the

colorimetric analysis of phosphate and Sajid Feeroze for total organic carbon analysis.

On a personal note I would like to thank my wife Zuzana and my daughters Nicole, Victoria and Natalie for their support and understanding when I was not always there for them during the busy times dedicated to studies and writing. 


\section{TABLE OF CONTENTS}

Author's Declaration for Electronic Submission of a Dissertation...............................

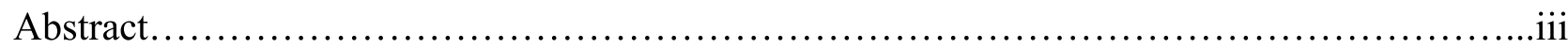

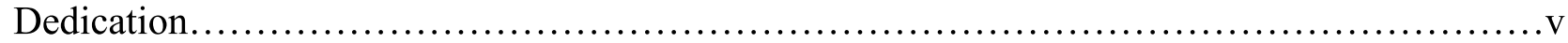

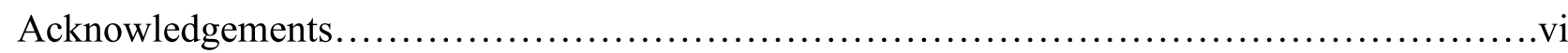

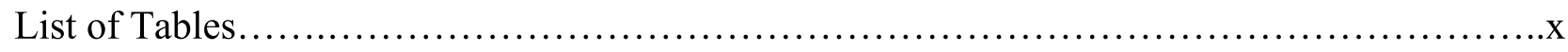

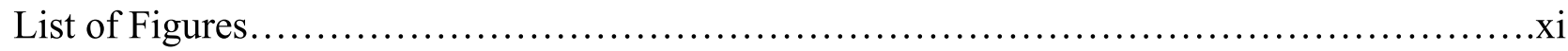

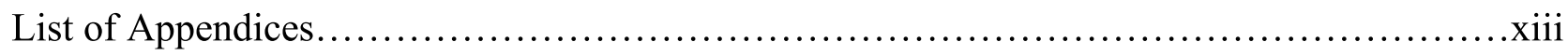

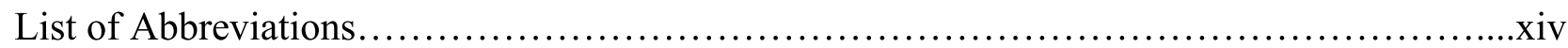

1. Introduction to Phosphorus Speciation and Environmental Applications..................1

$1.1 \quad$ Phosphorus in the Environment..........................................

1.2 Eutrophication of Natural Freshwater Sources ................................

1.3 Eutrophication, Algal Bloom and Environmental Legislation of the Great Lakes ......................................................

1.4 Analytical Determination of Phosphates

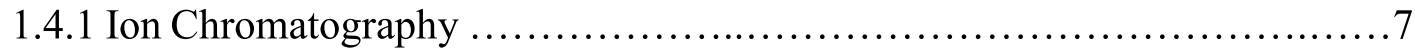

1.4.2 Mass Spectrometry............................................... 8

1.5 Experimental Setup and Methodology

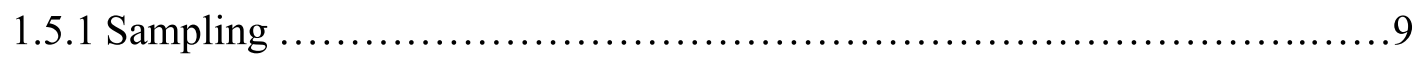

1.5.2 Instrumental Setup - Ion Chromatography........................... 10

1.5.3 Electrospray Ionization Source ..................................... 12

1.5.4 Mass Spectrometry - Orbitrap Technology..........................14

1.6 Research Questions and Hypotheses....................................16

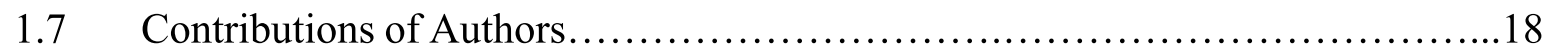

2. Analysis of Phosphorus Species in Water ..................................... 19

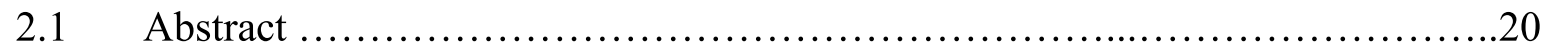

2.2 Introduction 
2.2.1 Phosphorus: Occurrence, Production and Uses .........................20

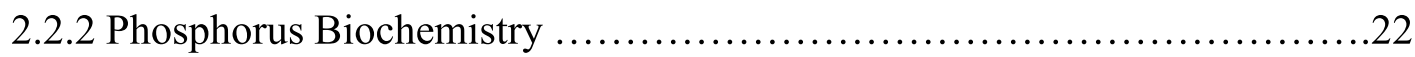

2.2.3 Phosphorus in the Aquatic Environment ...............................24

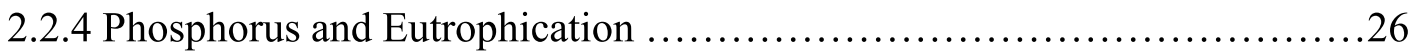

2.3 Phosphorus Analysis

2.3.1 Sample Collection, Treatment and Stability of the Phosphorus Species ....27

2.3.2 Spectrophotometric Methods ...........................................29

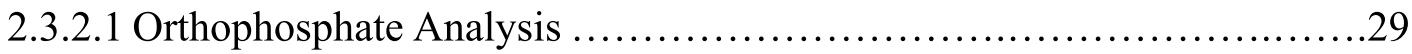

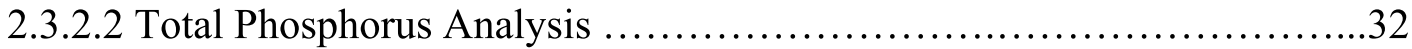

2.3.3 Ion Chromatography and Hyphenated Methods .........................34

2.3.4 Capillary Electrophoresis Methods ...................................36

2.3.5 Inductively Coupled Plasma with Atomic Emission

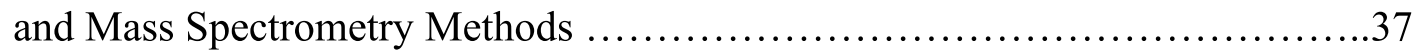

2.3.6 Electrochemical Methods ...........................................40

2.3.7 Nuclear Magnetic Resonance Methods ................................43

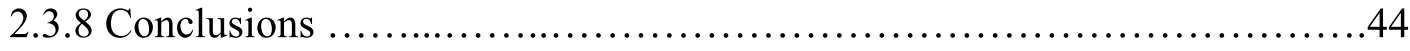

3. Unbiased Measurement of Phosphate and Phosphorus Speciation in Surface Waters .....46

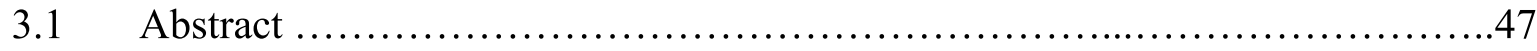

3.2 Introduction

3.2.1 Phosphorus Species in Surface Waters ..............................48

3.2.2 Analysis of Phosphorus Species in Surface Waters ........................49

3.2.3 Phosphate Adsorption on Glassware ..................................50

3.3 Experimental Section

3.3.1 Standards and chemicals ............................................... 51

3.3.2 Field Sampling and Storage Containers ...............................52

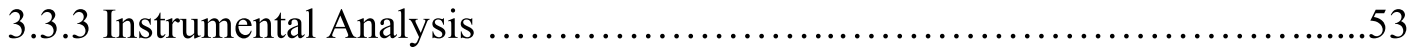

3.3.4 Method A (IC-ESI-MS analysis) .....................................54

3.3.5 Method B (2D-IC-ESI-MS analysis) ................................54

3.4 Results and Discussions

3.4.1 Field Spiking and Isotope Dilution Measurement of Phosphate .............55 
3.4.2 Isotope Dilution, External Calibration and Colorimetric Measurement of

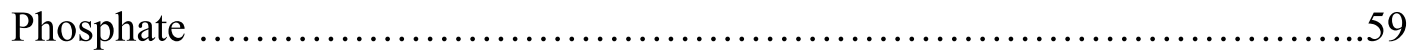

3.4.3 Comparison of Phosphate and Total Phosphorus Results ..................64

3.4.4 Bioavailable Phosphorus Measured in Surface Waters ......................65

3.4.5 Analysis of Phosphate-Containing Metabolites and Condensed Phosphate

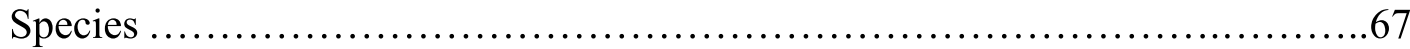

3.4.6 Associated Content ................................................. 71

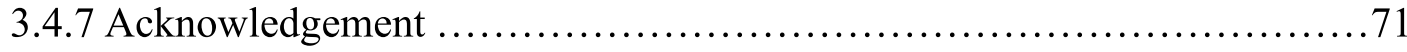

4. Phosphorus Speciation in Toronto Harbour and Rivers ..............................72

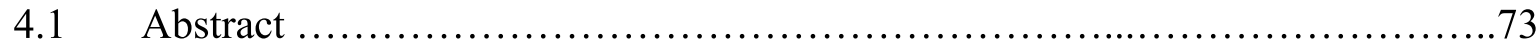

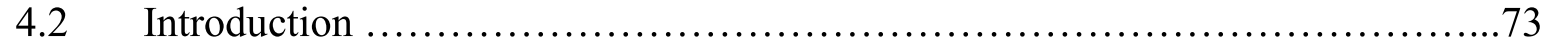

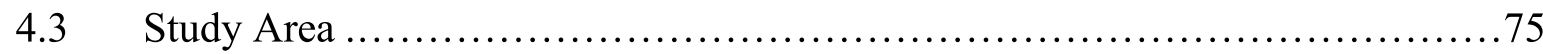

4.4 Experimental Section

4.4.1 Standards and chemicals ............................................ 78

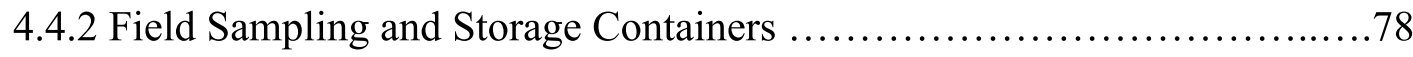

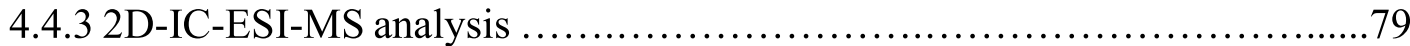

4.4.4 Additional Instrumental Analysis .....................................80

4.4.5 Multivariate Statistical Analysis .................................... 80

4.5 Results and Discussions

4.5.1 Inorganic and organic P-species in river and lake water ................80

4.5.2 PCA and analysis of P-containing metabolites and condensed phosphate

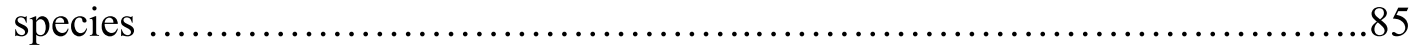

4.5.3 Statistical analysis based on all measured analytical parameters .............86

4.5.4 Statistical analysis based on measured P-species .......................89

4.5.5 Correlation between inorganic and organic P-species ...................92

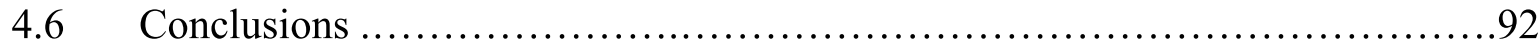

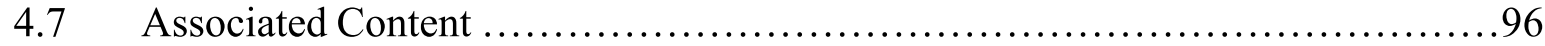

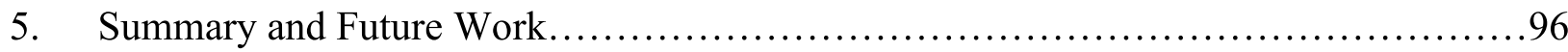

Appendices............................................................ 97

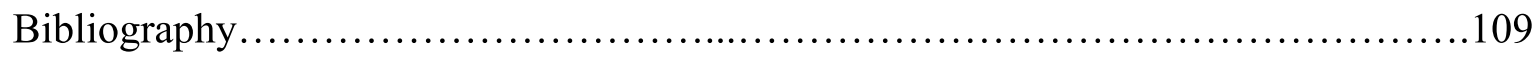




\section{LIST OF TABLES}

2.1 Summary of published procedures for alkaline digestions $\ldots \ldots \ldots \ldots \ldots \ldots \ldots . \ldots 34$ 


\section{LIST OF FIGURES}

1.1 Cyanobacterial bloom in Lake St. Clair .................................... 10

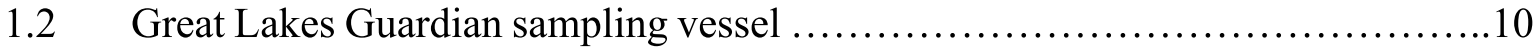

1.3 Electrospray Ionization Source Ion Max …................................13

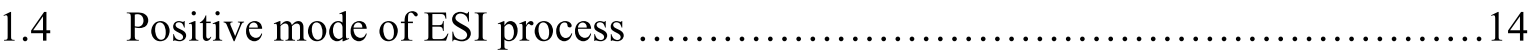

1.5 Schematics of Thermo Scientific Orbitrap Mass Analyzer .......................15

1.6 Schematics of the Orbitrap and the C-Trap ...................................16

2.1 Diagram of $\mathrm{P}$ species in natural waters adapted from Maher and Woo ............26

2.2 Measurements of orthophosphate, acid hydrolyzed polyphosphate and digested total phosphorus using three colorimetric methods

3.1 Phosphate loss (\%) calculated from single measured concentrations in samples

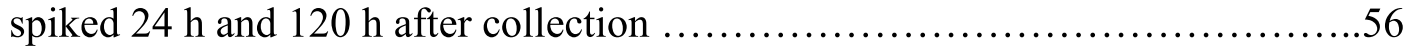

3.2 Phosphate concentration in a surface water sample..........................58

3.3 Comparison of results and bias for Method B (2D-IC-ESI-MS) phosphate results

3.4 Summary of the phosphate concentrations measured in samples

3.5 Correlations between phosphate concentrations measured by

2D-IC-ESI-MS (Method B) and colorimetry with total phosphorus

3.6 Concentrations of phosphate, phosphatase-hydrolyzed phosphate and non-hydrolyzable phosphorus

3.7 Chromatograms of phosphate and phosphate-containing metabolites in a standard mixture analyzed by Method B (2D-IC-ESI-MS) .68

3.8 Concentration ranges of adenosine 5'-monophosphate (AMP) and D-glucose 6-phosphate (Glucose-P) in surface water samples collected in late fall from Lake St. Clair . .70

4.1 Sampling locations in Lake Ontario, Don River, Humber River, Rouge River and Highland Creek

4.2 Average concentrations of inorganic and organic P-containing compounds in tributaries and Lake Ontario

4.3 Concentrations of inorganic P-compounds and P-containing metabolites per Lake Ontario Inner Harbour location compared with conductivity 
4.4 Log concentration ranges of P-metabolites and PPi in river and lake samples

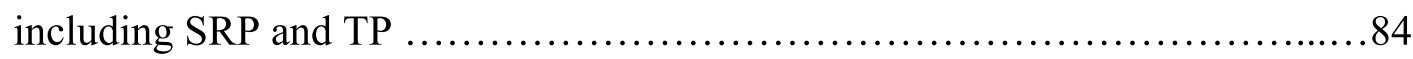

4.5 Concentration ratio of $\mathrm{P}$-containing compounds

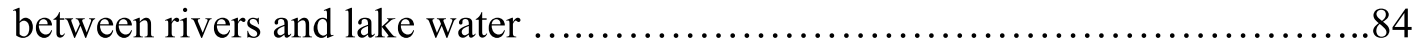

4.6 Loading graphs and Scree diagrams based on all analyzed variables

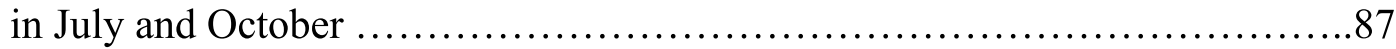

4.7 PCA based on all analyzed variables in July and October .................... 88

4.8 Loading and Scree diagrams using P species sampled in July and October .......90

4.9 PCA based on P-containing compounds in July and October ....................91

4.10 Dendrograms using all analytes July sampling October sampling ...............94

4.11 Dendrograms using P-metabolites only July sampling October sampling ........95 


\section{LIST OF APPENDICES}

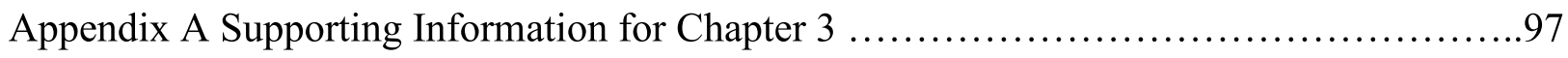

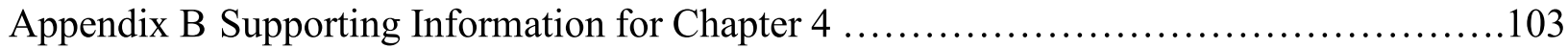




\section{LIST OF ABBREVIATIONS}

\begin{tabular}{|c|c|}
\hline ADP & Adenosine Diphosphate \\
\hline AES & Atomic Emission Spectrometry \\
\hline AMP & Adenosine Monophosphate \\
\hline $\mathrm{AOC}$ & Area of Concern \\
\hline APCI & Atmospheric Pressure Chemical Ionization \\
\hline APHA & American Public Health Association \\
\hline API & Atmospheric Pressure Ionization \\
\hline ATP & Adenosine Triphosphate \\
\hline CE & Capillary Electrophoresis \\
\hline CFA & Continuous Flow Analysis \\
\hline DP & Dissolved Phosphorus \\
\hline Erythrose-P & D-erythrose 4-phosphate \\
\hline ESI & Electrospray Ionization \\
\hline ETV & Electrothermal Vaporization \\
\hline FIA & Flow Injection Analysis \\
\hline Fructose-Bi-P & D-fructose 1,6-biphosphate \\
\hline Fructose-P & D-fructose 6-phosphate \\
\hline FTMS & Fourier Transform Mass Spectrometry \\
\hline Galactose-P & $\alpha$-D-galactose 1-phosphate \\
\hline $\mathrm{GC}$ & Gas Chromatography \\
\hline Glucose-Bi-P & $\alpha$-D-glucose 1,6-biphosphate \\
\hline Glucose-P & D-glucose 6-phosphate \\
\hline GLWQA & Great Lakes Water Quality Agreement \\
\hline $\mathrm{HAB}$ & Harmful Algal Bloom \\
\hline $\mathrm{HCA}$ & Hierarchical Cluster Analysis \\
\hline HDPE & High Density Polyethylene \\
\hline IC & Ion Chromatography \\
\hline ICP & Inductively Coupled Plasma \\
\hline ICR & Ion Cyclotron Resonance \\
\hline
\end{tabular}




$\begin{array}{ll}\text { IEC } & \text { Ion Exclusion Chromatography } \\ \text { IH } & \text { Inner Harbor } \\ \text { IJC } & \text { International Joint Commission } \\ \text { IS } & \text { Internal Standard } \\ \text { ISE } & \text { Ion Selective Electrode } \\ \text { ISO } & \text { International Organization for Standardization } \\ \text { LC } & \text { Liquid Chromatography } \\ \text { MDL } & \text { Method Detection Limit } \\ \text { MS } & \text { Mass Spectrometry } \\ \text { NMR } & \text { Nuclear Magnetic Resonance } \\ \text { OH } & \text { Outer Harbor } \\ \text { P } & \text { Phosphorus } \\ \text { PC } & \text { Principal Components } \\ \text { PCA } & \text { Principal Component Analysis } \\ \text { PGA } & \text { D-(-)-3-phosphoglyceric acid } \\ \text { Pi } & \text { Phosphate Ion } \\ \text { P-metabolites } & \text { Phosphate Containing Metabolites } \\ \text { PPi } & \text { Pyrophosphate } \\ \text { RAP } & \text { Remedial Action Plan } \\ \text { Ribulose-Bis-P } & \text { D-ribulose 1,5 - bisphosphate } \\ \text { Ribulose-P } & \text { D-ribulose 5-phosphate } \\ \text { RSD } & \text { Relative Standard Deviation } \\ \text { SFC } & \text { Supercritical Fluid Chromatography } \\ \text { SIM } & \text { Selected Ion Monitoring } \\ \text { SPME } & \text { Solid Phase Microextraction } \\ \text { SRP } & \text { Soluble Reactive Phosphorus } \\ \text { TDP } & \text { Total Dissolved Phosphate } \\ \text { TOC } & \text { Total Organic Carbon } \\ \text { TP } & \text { Total Phosphorus } \\ \text { TRP } & \text { Uridine 5'- diphosphoglucose } \\ \text { UDP-Glucose } & \end{array}$


USEPA

US Environmental Protection Agency 


\section{CHAPTER 1}

Introduction to Phosphorus Speciation and Environmental Applications of Phosphorus Monitoring 


\section{INTRODUCTION}

\subsection{Phosphorus in the Environment}

Phosphorus $(\mathrm{P})$ is an element with important biological functions and is found in the nature in the fully oxidized state as phosphate. $\mathrm{P}$ is considered as a limiting nutrient for a biological growth primarily in freshwater aquatic environment. Studies of phosphate in the Experimental Lake Area have shown that phytoplankton growth is proportionate to the phosphorus concentration in the water column ${ }^{4} . \mathrm{P}$ is an essential biological element for animal and plant metabolism and energy conversion. Plants can control phosphate concentration in the cells by regulating phosphate metabolism ${ }^{5}$. P is also an important factor in the cell structure. Covalent ester links formed between phosphate and carbohydrate monomers create a rigid cell structure with organically bound phosphate in the cell walls ${ }^{6}$. Phosphate connects with RNA monomers which form DNA and RNA and thus determining the structure of the nucleic acids. Phospholipids bound together by divalent cations are incorporated in the inner walls of the outer cell membranes ${ }^{7}$. Another important role of $\mathrm{P}$ is being an energy carrier. Adenosine triphosphate ATP is the most important energy carrier in the cells ${ }^{8}$. The incorporation of phosphorus into the cell takes place in several steps. Alkaline phosphatase converts organic and inorganic phosphoesters outside the cell, at the cell surface or in the periplasm 9 . Orthophosphate is transported to the cell by the uptake system and converted into ATP. Excess of ortho-phosphate is stored as polyphosphate inside the cell ${ }^{10}$. Polyphosphate stored in the cell can serve as a reservoir of orthophosphate and function in physiological processes of the cell such as growth, cell development and during events of phosphorus deprivation ${ }^{11}$. Not all the $\mathrm{P}$ in the nature is available for biological utilization. The only immediately bioavailable P sources for phytoplankton are 
inorganic phosphate, some phosphorylated sugars and phosphonate ${ }^{12}$. Concentrations of these compounds in natural waters are usually very low due to high affinity of phytoplankton to readily available phosphorus sources ${ }^{13}$. Another source of phosphorus for the phytoplankton is phosphorus released from the dead cells including inorganic phosphate, sugar phosphates, glycerophosphate, polynucleotides and phospholipids ${ }^{14}$. Accurate determination of $\mathrm{P}$ species is crucial for understanding its cycling in the ecosystem and for establishing an effective nutrient management of surface waters. Two main fractions of $\mathrm{P}$ species in natural water are dissolved and particulate $\mathrm{P}$ with both being in the constant dynamic equilibrium ${ }^{15}$. The most frequently determined inorganic forms of P species include phosphate, polyphosphates, cyclic condensed phosphates and also lower oxidation states $\mathrm{P}$ compounds such as phosphinate and phosphonate which may be normally detected only in waste waters ${ }^{16}$. The main classes of organic P species that can be found in the aquatic environment include nucleic acids, phospholipids, inositol phosphates, phosphoamides, phosphoproteins, sugar phosphates, aminophosphoric acids and organic condensed P species ${ }^{17,18}$.

\subsection{Eutrophication of Natural Freshwater Sources}

$\mathrm{P}$ being a part of DNA and RNA is essential for life. Organisms require large amounts of $\mathrm{P}$ to grow rapidly. Supply of $\mathrm{P}$ from the environment is limited as it can't be easily replenished from the atmosphere such as carbon and nitrogen. Large amounts of $\mathrm{P}$ are mined extensively for fertilizer manufacturing to support agricultural crop production ${ }^{19}$. Increasing world population and its need for a food supply demands intensified phosphate rock mining and commercial fertilizer application which causes changes in the $\mathrm{P}$ pathways and rise of bioavailable $\mathrm{P}$ inputs into terrestrial, freshwater and coastal ecosystem ${ }^{20}$. High nutrient inputs can have very negative environmental consequences on the quality of the receiving waters enhancing the abundance of 
algae and aquatic plants ${ }^{21}$. Eutrophication is an accumulation of excessive nutrients such as nitrogen and phosphorus in surface water resulting in changes of water chemical properties. These chemical changes of waters are also a byproduct of light, heat and hydrodynamics resulting from variety of biological, chemical and physical processes ${ }^{22}$. Deterioration of water quality caused by the rapid production of phytoplankton affects normal functioning of the water bodies and is detrimental to aquatic ecology ${ }^{23}$. Original species present in the system can be replaced by opportunistic plant species adapted to the new environmental conditions and thus changing the structure and functioning of the whole aquatic community ${ }^{24}$. Toxic, hypoxiagenerating cyanobacterial harmful blooms, or cyanoHABs, are the most problematic symptoms of nutrient over-enrichment causing serious ecological harm and economic losses. CyanoHABs now affecting ecology of the world's largest water bodies including Lake Victoria (Africa), Lake Erie (US-Canada), Okeechobee (USA), Taihu (China), Kasumigaura (Japan), the Baltic Sea (Europe) and the Caspian Sea (West Asia) ${ }^{25,26}$. The main watershed management tool to control freshwater eutrophication in the last 40 years was primarily mitigation of $\mathrm{P}$ inputs from waste water and nonpoint sources ${ }^{27,28}$. Implementation of P reduction policies have resulted in improvements in aquatic ecology 29,30 but many watersheds have reported little or no improvement in P loss reduction ${ }^{31}$ even after extensive best management practices. In some cases, occurrence of nuisance algal growth increased despite a large reduction in $\mathrm{P}$ concentrations $\mathrm{s}^{32-35}$. It is suggested that a part of the problem is so called "legacy phosphorus" which is a portion of $\mathrm{P}$ within a watershed accumulated along transport pathways. Such an accumulated $\mathrm{P}$ can be remobilized and become a continuing source of $\mathrm{P}$ for years, decades or centuries $^{36,37}$. Annually only $20-30 \%$ of the $\mathrm{P}$ used in agriculture as fertilizer is transported out of the watershed. The remaining $70-80 \%$ accumulates in river sediments, groundwater, lakes and 
estuaries $^{37,38}$ contributing to renewing cycles of algal blooms. Preventing such a complex environmental issue as eutrophication and algal blooms requires more systemic interdisciplinary approach including better understanding of phosphorus dynamics in the aquatic environment. One of the possible contributions to such understanding could be phosphorus identification including speciation of organic P compounds in surface water which are currently not fully understood due to lack of sensitive analytical techniques capable of separation and quantification of these species in surface water matrices.

\subsection{Eutrophication, Algal Bloom and Environmental Legislation of the Great Lakes}

Canada is a country of thousands of lakes. Looking at the map you can't miss magnificent bodies of water located on the US-Canadian border touching 8 US states - Michigan, Wisconsin, Minnesota, Illinois, Indiana Ohio, Pennsylvania and New York and province of Ontario in Canada - The Great Lakes. Lake Superior, Huron, Michigan, Ontario and Erie make up the largest body of fresh water on Earth with the area of 246463 square kilometres and 6 quadrillion gallons of volume accounting for $20 \%$ of the freshwater surface on the planet. The Great Lakes are a home for more than 3500 species of plants and animals including more than 170 species of fish ${ }^{39}$. In province of Ontario they are a source of drinking water for over 10 million people and help generating 80 per cent of the province's electricity driven by hydro-electric plants. Great Lakes also provide fantastic opportunities for recreation and overall, they are responsible for 40 per cent of Canada's economic activity ${ }^{40}$.

But the Great Lakes are headed for a crisis. Their water quality and ecosystem health are rapidly deteriorating as a result of urban growth, harmful pollutants, aquatic invasive species, climate change and especially nutrient pollution ${ }^{40}$. The problem started during the 1960 s when too much 
phosphorus in the lakes and especially in Lake Erie caused massive algal blooms, depleted water of oxygen and thus killing fish, plants and many other aquatic animals. By the late 1960s, Canada and the United States came to a conclusion that immediate action is necessary ${ }^{41}$. The very first policy tool created as a response to the Great Lakes algal and phosphorus pollution problem was Great Lakes Water Quality Agreement (GLWQA). It was signed by Canadian and United States governments on April 15, 1972. GLWQA has established water quality objectives and included commitments to solve municipal and industrial nutrient pollution. It contains 10 Annexes ${ }^{41}$. Annex 4 (Nutrients) is the most relevant part regarding phosphorus management control and algal bloom prevention. As stated in its purpose this annex is supposed "to contribute to the achievement of the general and specific objectives of this agreement by coordinating binational actions to manage phosphorus concentrations and loadings, and other nutrients if warranted, in the Waters of the Great Lakes"41. The GLWQA also states that both countries have to undertake the necessary research to better understand environmental issues such as nutrient distribution, causes of toxic algal blooms, phosphorus sources and forms and its adverse effects, climate change influence, control methods of phosphorus from non-point sources and research soluble reactive phosphorus.

GLWQA was recognized as a global success story in the mid-1980s by mitigating harmful algal bloom problem (HAB) in the Lake Erie. The goal was achieved by implementing legislature to control point sources of phosphorus at industrial establishments and waste water treatment plants. The great portion of phosphorus reduction which is a major cause of an excessive algal bloom was also achieved by banning phosphates in household detergents. The total phosphorus load to the Lake Erie was reduced by $50 \%$ from 29000 MT/year to 14600 MT/year. However, since 1995 the situation has gotten progressively worse. HAB problem is back and it also started affecting 
drinking water sources. Lake Erie has been hit by toxic algal bloom every single year since 2008 . Severity and toxicity of these occurrences are also very high. Toxicity levels of HAB in August 2014 caused a shutdown of drinking water treatment plant in Toledo, Ohio affecting 500000 residents. Algal bloom in July 2015 was the largest on the record in terms of affected area in the Lake Erie.

GLWQA and other phosphorus control relevant legislature regulated only total phosphorus in the past. In order to receive a better insight into algal bloom - phosphorus relationship, the bioavailable phosphorus species analysis and monitoring will provide a valuable information. The most recent GLWQA has changed the approach regarding the issue and the agreement has included dissolved reactive phosphorus - DRP monitoring recommendations and has encouraged scientific research of new methods of identification of DRP.

\subsection{Analytical Determination of Phosphates}

\subsubsection{Ion Chromatography}

Ion chromatography is a part of a high-performance liquid chromatography which separates ions and polar molecules based on their affinity to the ion exchanger. It uses high performance analytical columns filled with small diameter homogenous particles. Very first commercially available ion chromatograph was available in $1975^{42}$. Three main separation methods used today in ion chromatography are: Ion chromatography - supressed or non-supressed, ion exclusion chromatography (IEC) and ion pair chromatography. The stationary phases or ion exchangers which are used to separate analytes are macromolecular solids with cross-linked space structure. They can be divided into anion exchangers, with functional groups containing cationic 
counterion able to exchange anions and cation exchangers with functional groups containing anionic counterion for exchange of cations present in the solution. Functional groups in cation exchangers are acidic: sulfonic $\left(-\mathrm{SO}_{3} \mathrm{H}\right)$, carboxylic $(-\mathrm{COOH})$, iminodiacetic $\left(-\mathrm{n}\left(\mathrm{CH}_{2} \mathrm{COOH}\right)_{2}\right)$, phenolic $\left(-\mathrm{C}_{6} \mathrm{H}_{4} \mathrm{OH}\right)$, phosphonic $\left(-\mathrm{PO}_{3} \mathrm{H}_{2}\right)$ and phosphinic $\left(-\mathrm{PO}_{2} \mathrm{H}\right)$. Anion exchange functional groups are alkaline : quarternary ammonium $\left(-\mathrm{NR}_{3}{ }^{+}\right)$, tertiary and secondary protonated amines $\left(-\mathrm{NR}_{2} \mathrm{H}^{+},-\mathrm{NRH}_{2}^{+}\right)$and sulfonic groups $\left(-\mathrm{SR}_{2}^{+}\right)^{43}$. Parameters of the eluents used in ion chromatography such as type, $\mathrm{pH}$ and flow rate are very important factors of the method development. Sodium carbonate and sodium bicarbonate solutions are the most commonly used in the isocratic systems when the concentration of the eluent is constant during the run. In the gradient system when the concentration of the eluent changes during chromatographic separations $\mathrm{KOH}$ and $\mathrm{NaOH}$ solutions are mostly used ${ }^{44}$. Conductometric detection is the most common detection system in ion chromatography. The biggest challenge in ion chromatography in the past was to determine the concentration of analytes in the presence of high conductivity background of an eluent as the eluent is also an electrolyte. The problem was solved by placing a conductivity suppression column which was later replaced by the suppressor in front of the detector increasing conductivity of the analytes and decreasing the conductivity of the eluent background $^{43}$.

\subsubsection{Mass Spectrometry}

Mass spectrometry is an analytical technique of separation of ions based on their $(\mathrm{m} / \mathrm{z})$ mass to charge ratio. It requires the conversion of the analytes of interest into positively or negatively charged ions. The ions generated in the ion source are transported into mass analyzer and they sorted out according to their $\mathrm{m} / \mathrm{z}$ and the signal obtained is recorded by the detector ${ }^{45}$. There are many ionization techniques used in the environmental applications. The most common ones are 
electron ionization, chemical ionization, field ionization/field desorption, fast atom bombardment, thermospray ionization, electrospray ionization, atmospheric pressure chemical ionization, inductively coupled plasma and laser desorption ${ }^{43}$. Electrospray ionization is an atmospheric pressure ionization utilizing a strong electric field generated by applying a high voltage $(3-6 \mathrm{kV})$ to the spraying capillary with a counter electrode. Accumulated charge on the sample droplet causes solvent to evaporate and disintegrate with ion desorption ${ }^{46}$. Depending on the conditions used the ions can be protonated $[\mathrm{M}+\mathrm{zH}]^{\mathrm{z}}$ in the positive mode or deprotonated $[\mathrm{M}-\mathrm{zH}]^{\mathrm{z}-}$ in the negative mode settings. The addition of ammonium hydroxide in the negative mode and formic acid in the positive mode will enhance the ionization process ${ }^{43}$. Fourier transform mass spectrometry (FTMS) are using analyzers like Ion Cyclotron Resonance (ICR) or Orbitrap, offering a significant increase in mass resolution and accuracy. The FTMS have an ion trap where ions oscillate around a central spindle electrode and $\mathrm{m} / \mathrm{z}$ ratio is calculated from the frequency of oscillations along the axis of the electric field ${ }^{47}$. The Orbitrap is an ion trap analyzer that consists of a central electrode and two outer electrodes and it can serve as both an analyzer and a detector. Different ions oscillate around the central electrode at different frequencies which are measured and recorded as Fourier transform mass spectra ${ }^{48}$.

\subsection{Experimental Setup and Methodology}

\subsubsection{Sampling}

Environmental sampling can be a source of a great variability therefore it is important to consider various aspects where we can see a danger of variances such as sampling location, the number and type of samples and the actual sampling procedure. Lake St. Clair, Thames River, Lake Erie and Lake Ontario were the sampling locations of choice for the phosphorus 
speciation $^{49}$. Lake St. Clair is a shallow mesotrophic lake with the maximum depth of less than $6 \mathrm{~m}$ and recurring instances of a cyanobacterial algal bloom (Fig.1.1). Thames River is the largest Canadian tributary of the Lake St. Clair identified as a priority tributary under Annex 4 Nutrients of the Great Lakes Water Quality Agreement. The samples were taken from the 96 stations between June and October 2017. The sampling depth was between 1-3m inshore and $>3$ $\mathrm{m}$ nearshore taken by the sampling boats ${ }^{49}$ (Fig.1.2).
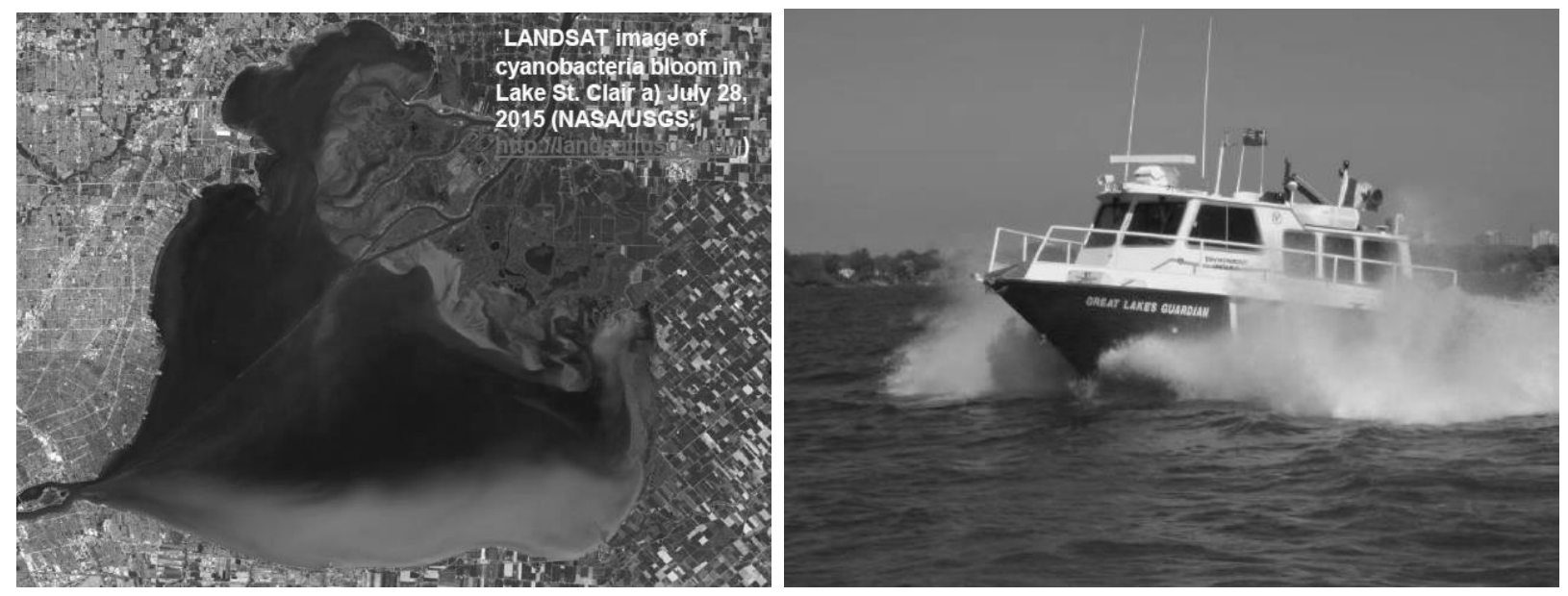

Fig.1.1 Cyanobacterial bloom in Lake St.Clair Fig.1.2 Great Lakes Guardian sampling vessel

\subsubsection{Instrumental Setup - Ion Chromatography}

As an instrumental setup the 2-dimensional ion chromatography was used to separate phosphate species from the matrix. Ion Chromatograph: Dionex ICS-5000+ consisted of AS-AP autosampler, 2x DP dual pump modules, 2x EG eluent generators, DC dual column compartment and $2 \times$ AXP-MS auxiliary pumps.

\section{Column assembly 1 :}

Guard Column: IonPac AG18, 4 mm id x 50 mm 
Separation Column: IonPAc AS18, $4 \mathrm{~mm}$ id x $250 \mathrm{~mm}$

The Dionex ${ }^{\mathrm{TM}}$ IonPac ${ }^{\mathrm{TM}}$ AS18-4 $\mu \mathrm{m}$ Column in combination with the Dionex IonPac AG18- $4 \mu \mathrm{m}$ Guard Column is designed for the analysis of inorganic anions in less than 10 minutes using an isocratic or gradient hydroxide eluent delivered with an Eluent Generator ${ }^{50}$.

\section{Column assembly 2:}

Guard Column: IonPac AG24, 2 mm id x $50 \mathrm{~mm}$

Column: IonPac AS24, $2 \mathrm{~mm}$ id x $250 \mathrm{~mm}$

Concentrator IonPAc TAC-ULPI, 5mm x $23 \mathrm{~mm}$

The Dionex ${ }^{\mathrm{TM}}$ IonPac AS-24 - 2mm Analytical and AG24 2 mm Guard Columns are hydroxide selective anion exchange columns designed for separation of environmental ions. The Ionpac AS24 is a low bleed column designed to be used for ion chromatography separation coupled with Mass Spectrometry (IC/MS/MS) ${ }^{50}$. Dionex IonPac anion concentrator columns are designed primarily for high-purity water analysis. The concentrator column retains anions from a measured volume of aqueous sample matrix, concentrating the analyte species and lowering detection limits by 2-5 orders of magnitude ${ }^{50}$.

\section{$\underline{\text { DP Dual Pump }}$}

Pressure Lower Limit: 200 psi

Pressure Upper Limit: 3000 psi

Pump 1 Flow Rate: $1 \mathrm{~mL} / \mathrm{min} \quad$ Pump 2 Flow Rate: $\quad 300 \mu \mathrm{L} / \mathrm{min}$

Pump 3 Flow Rate: $200 \mu \mathrm{L} / \mathrm{min}$

Analytical pumps offer the option of mechanical gradients (proportioning valve) yielding linear, concave and convex gradients. Dual independent seal wash prolongs seal life and removes crosscontamination in dual-channel systems ${ }^{50}$. 
$\underline{\text { AS-AP Autosampler }}$

Injection Volume: $1000 \mu \mathrm{L}$

$\underline{\text { DC Dual Column Compartment }}$

Suppressor 1: AERS-500 $4 \mathrm{~mm}$

Suppressor 2: AERS-500 $2 \mathrm{~mm}$

Electrolytically Regenerated Suppressors minimize peak dispersion and improve peak efficiency, particularly when coupled with $4 \mu \mathrm{m}$ columns. These suppressors were developed in concert with the high efficiency $4 \mu \mathrm{m}$ ion-exchange columns, which use higher flow rates to achieve faster separations while retaining optimal resolution, or equivalent flow rates to achieve higher resolutions while retaining sample throughput ${ }^{50}$.

\subsubsection{Electrospray Ionization Source}

All mass spectrometers require an ionization source to generate ions. The ionization setup is based on atmospheric pressure electrospray ionization (API) source IonMax from ThermoScientific. The source includes 2 nitrogen inlets, a vaporizer cable for APCI probe heaters and an $8 \mathrm{kV}$ cable for the electrospray needle ${ }^{51}$. 


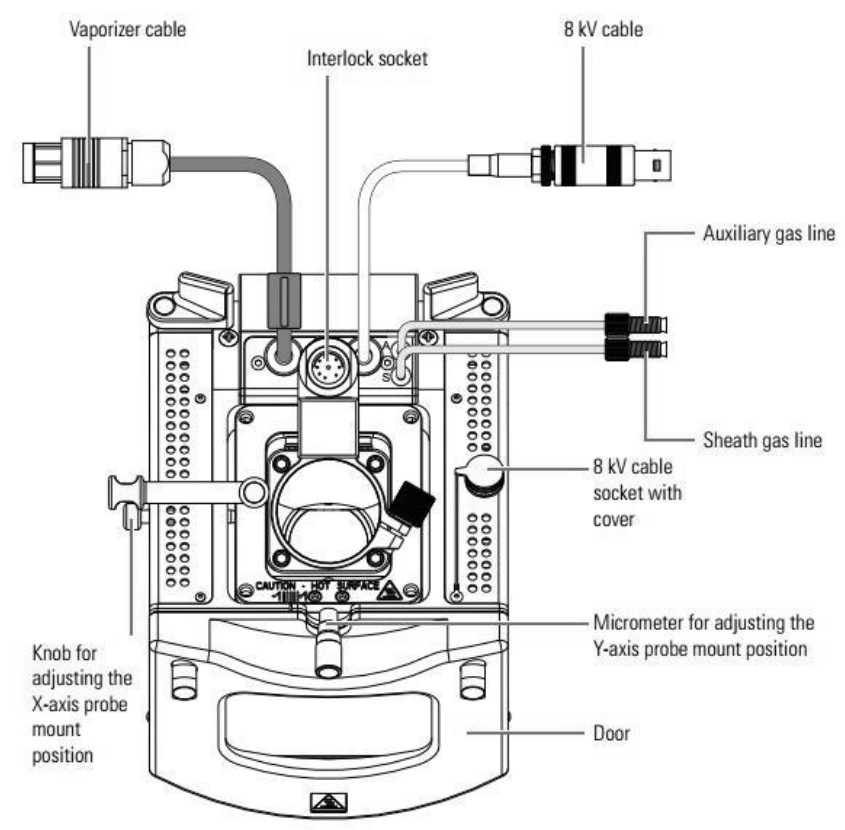

Fig.1.3 Electrospray Ionization Source IonMax.

In ESI the ions in solution are transferred to gaseous phase as follows:

1. The sample enters the high voltage ESI needle

2. The needle sprays the solution in a form of electrically charged fine droplets

3. As the droplets evaporate their surface electrical charge increases

4. After reaching the Rayleigh stability limit the droplets divide into even smaller droplets due to electrostatic repulsion.

5. The process is repeated many times until the sample ions are changed into a gas phase and enters a mass spectrometer. 


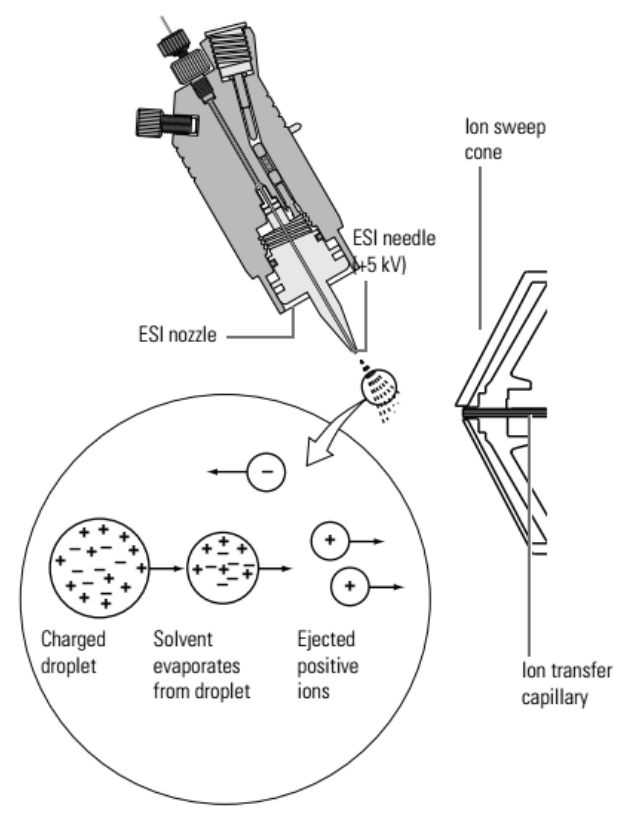

Fig.1.4. Positive mode of ESI process

ESI can be operated in positive or negative polarity mode depending on the ions analyzed.

Acidic molecules form negative ions and basic ions form positive ions in the solution ${ }^{51}$.

\subsubsection{Mass Spectrometry - Orbitrap Technology}

Mass Spectrometer: Q Exactive hybrid quadrupole-Orbitrap mass spectrometer

Ion Source: IonMax, Sheeth Gas Flow Rate: 16.0, Auxiliary Gas Flow Rate: 5.0, Spray Voltage:

$3.3 \mathrm{kV}$, Capillary Temperature: $320^{\circ} \mathrm{C}$, S-Lens RF Level: 50.0, Auxiliary Gas Heater

Temperature: $200^{\circ} \mathrm{C}$, Total Run Time: 40 min, Scan Type: Full MS- SIM (Selected Ion

Monitoring), Polarity: negative, Resolution: 70 000, Scan Range: 50 - 700 m/z, AGC Target:

3e6, Maximum IT: $200 \mathrm{~ms}$

RF lens ion optics contains 18 electrodes. It captures entire expansion from ion transfer tube and focuses ion beam through conductance limiting aperture. In the QExactive the advanced active 
beam guide and hyperquad mass filter are a quadrupole assembly with square rods that function as ion guides.

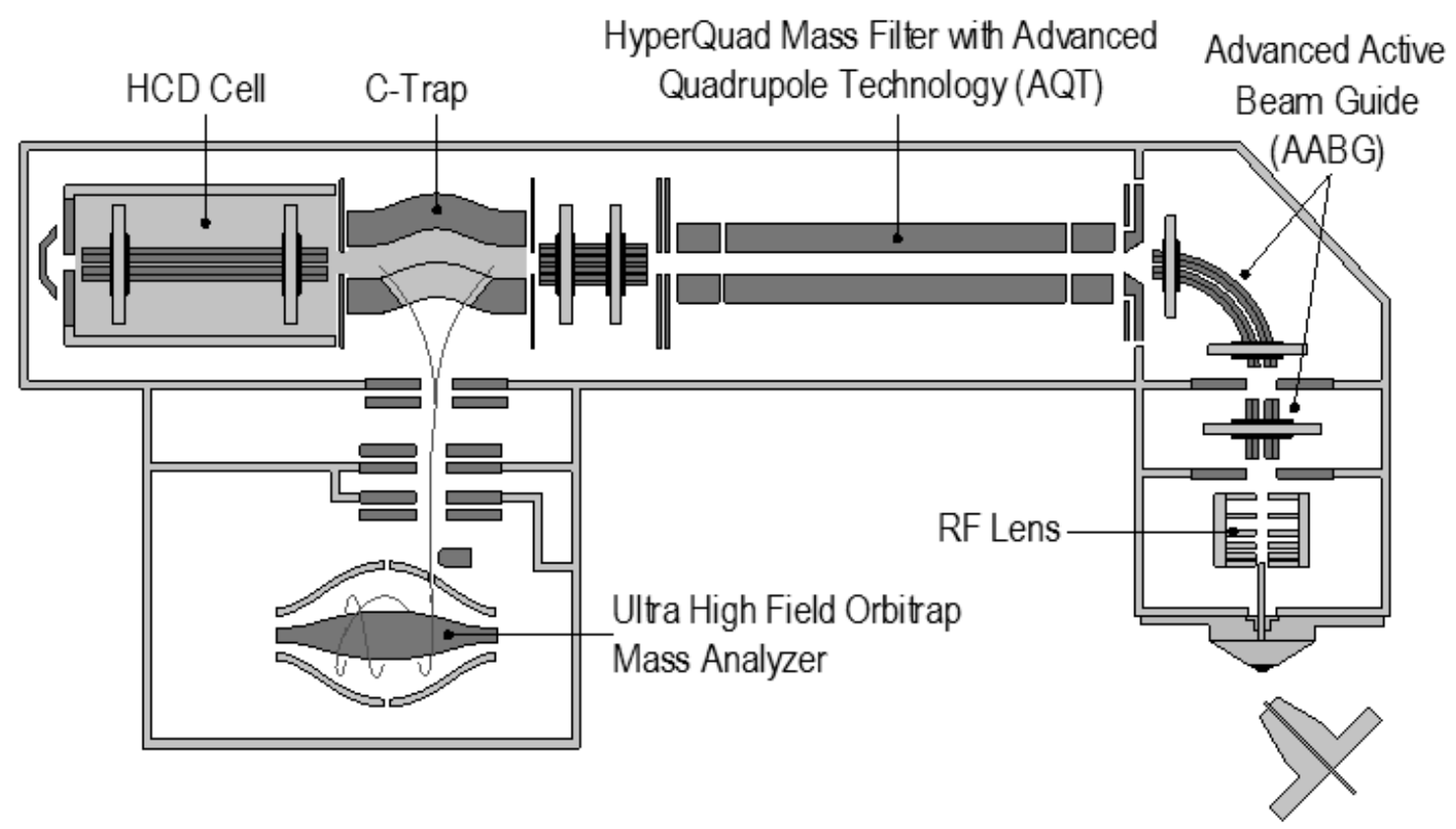

Fig.1.5 Schematics of ThermoScientific Orbitrap Mass Analyzer

RF lens ion optics contains 18 electrodes. It captures entire expansion from ion transfer tube and focuses ion beam through conductance limiting aperture. In the QExactive the advanced active beam guide and hyperquad mass filter are a quadrupole assembly with square rods that function as ion guides. The bent flatapole is curved to prevent neutrals from passing into the Orbitrap. In combination these multipoles focus and transfer the ion beam between the ion source and the orbitrap through successively higher vacuum regions ${ }^{52}$. The ion guides decrease the kinetic energy of the transmitted ions and ensure that ions travel in a stable manner towards the detection region. Ions are stored and cooled in the RF-only C-trap. After trapping the RF is ramped down and DC voltages are applied to the rods creating a field across the trap pushing ions towards the detector. If fragmentation is required the ions are guided into a higher energy 
collision induced dissociation HCD cell where precursor ions are fragmented by the gained energy and collisions with nitrogen.

The detector - orbitrap mass analyser consists of a spindle-shape central electrode surrounded by a pair of bell-shaped outer electrodes. The orbitrap employs electric fields to capture and confine ions. The ions oscillating frequencies along the $\mathrm{z}$-axis depend on the $\mathrm{m} / \mathrm{z}$ and the field curvature. The Fourier transform obtains the frequencies of the axial oscillations and therefore $\mathrm{m} / \mathrm{z}$ ratios of the ions ${ }^{52}$.

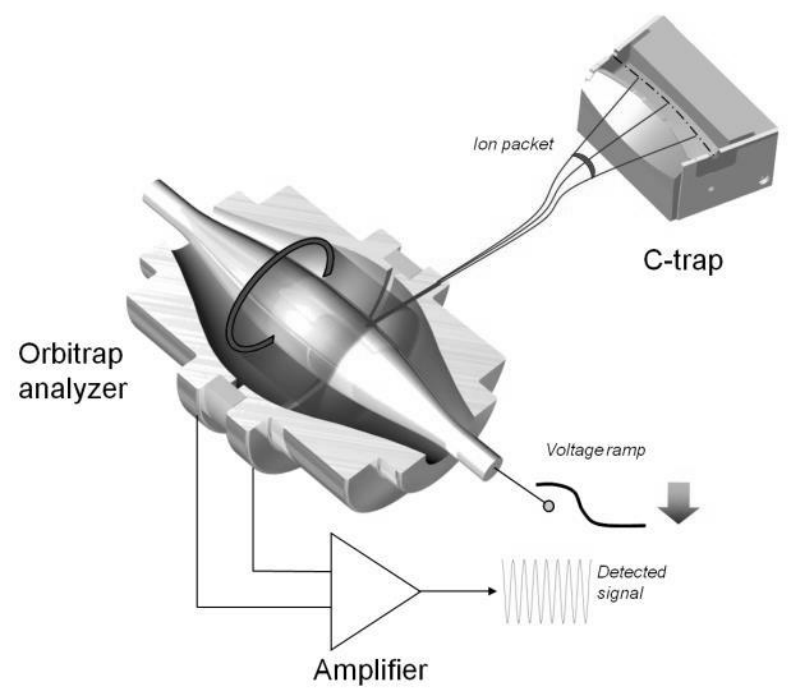

Fig.1.6 Schematics of the Orbitrap and the C-Trap.

\subsection{Research Questions and Hypotheses}

The main goal of this thesis was development of a methodology for identification and quantification of low-level inorganic and organic species of phosphorus in surface water using Ion Chromatography with Mass Spectrometry/ Orbitrap detection. Currently the most commonly 
used analytical approach of phosphorus analysis can mostly identify broader classes of phosphorus species in natural waters.

Quantification of specific trace-level phosphorus metabolites in water column require utilization of novel and more sensitive analytical methodologies. The data obtained by such methodologies including concentrations of bio-available P-containing metabolites would potentially contribute to explaining P utilization in aquatic environment and multivariate statistical analysis of such data could identify sources of $\mathrm{P}$ pollution.

Thus, in Chapter 2 past and current analytical techniques of $\mathrm{P}$ analysis are reviewed. Advantages and disadvantages of the methods are discussed as well as their utilization for an efficient $\mathrm{P}$ analysis and method detection capabilities.

Chapter 3 describes development of a novel method of P-speciation and shows its advantages compared to currently used methods of analysis. Ion chromatography coupled with mass spectrometry approach used in this thesis is superior to other techniques by employing an option of isotope dilution to compensate for P-species adsorption loss after sampling contributing to an accurate trace-level P-measurement.

Chapter 4 shows how the data acquired by this method can be used to statistically evaluate Psources in the aquatic environment. Multivariate statistical analysis was used to better understand differences between various P-sources including quantification of bioavailable P-metabolites in river and lake samples. 


\subsection{Contributions of Authors}

Chapter 2 was accepted for publication in Encyclopedia of Water: Science, Technology and Society, edited by Patricia A. Maurice. Copyright c 2020 JohnWiley \& Sons, Inc as Packa, V., Bostan, V., Furdui, V. Analysis of Phosphorus Species in Water. Manuscript was written by VP and edited by VF and VB.

Chapter 3 was published as Packa, V.; Maedler, S.; Howell, T.; Bostan, V.; Diep, N.; Tooley, R.; Furdui, V. I., Unbiased Measurement of Phosphate and Phosphorus Speciation in Surface Waters. Environmental Science \& Technology 2018.

DOI: $10.1021 /$ acs.est.8b05089

Hypotheses and experimental design were carried out by VP and supervised by VF and SM. Experiments, data analyses and manuscript preparation were carried out by VP and supervised by VF, VB, TH and SM. Sampling schedule was designed and carried out by TH and ND. Manuscript was supervised and edited by VF, VB, SM, TH, ND and RT. 


\section{CHAPTER 2}

\section{Analysis of Phosphorus Species in Water}

Chapter 2 was published in Encyclopedia of Water: Science, Technology and Society, edited by

Patricia A. Maurice. Copyright c 2020 JohnWiley \& Sons, Inc. as Packa, V., Bostan, V., Furdui, V. Analysis of Phosphorus Species in Water. 


\subsection{Abstract}

A limiting nutrient for aquatic ecosystems, the natural and anthropogenic sourced phosphorus is present in surface waters. Monitoring of phosphorus in water samples and reduction procedures were developed to minimize the occurrence of harmful algal blooms. Phosphate is the most frequent phosphorus species in water, being present in anionic form (inorganic phosphate) or attached to a carbon-based molecule (organic phosphate). Although various methods have been developed for phosphate and total phosphorus analysis, the spectrophotometric and ion chromatographic methods remain the most frequently used. Other methods discussed are based on capillary electrophoresis, inductively coupled plasma coupled to atomic emission spectrometry, electrochemical and nuclear magnetic resonance techniques. The simultaneous analysis of various phosphorus species was possible by coupling chromatographic separations with mass spectrometry, using either electrospray or inductively coupled plasma ionization.

\subsection{Introduction}

\subsubsection{Phosphorus: Occurrence, Production and Uses}

Phosphorus is an element essential for life. It can exist in three main allotropic forms: white, black and red. A polyatomic nonmetal, phosphorus has a single naturally occurring stable isotope, ${ }^{31} \mathrm{P}$, and is not found in elemental form in nature due to its high reactivity ${ }^{53}$. In 1669 , searching for the mythical "philosopher's stone", the German physician Hennig Brandt discovered elemental phosphorus while carrying out alchemical experiments with urine. The presence of phosphorus in plants was detected for the first time by Albino in $1688^{54}$. Almost a hundred years later, in 1769, phosphorus was recognized as an essential ingredient in bones of animals and humans by Gahn and Scheele. The first detection of phosphorus in a mineral 
(pyromorphite, a lead phosphate) was made by Gahn in $1779^{55}$. The name given to the element was taken from the Greek word phosphorous, or "bearer of light", from the glow of white phosphorus when exposed to oxygen ${ }^{56}$. Phosphorus is located in the $15^{\text {th }}$ group of the periodic table (new IUPAC classification, also previously known as group V of main elements) and belongs to the nitrogen family of elements, known also as pnictogens (nitrogen, arsenic, antimony, bismuth and a synthetic element named moscovium). White phosphorus is very poisonous to humans with a lethal oral dose of $1 \mathrm{mg} / \mathrm{kg}$ of body weight and as little as $0.2 \mathrm{mg} / \mathrm{kg}$ may produce adverse effects ${ }^{57}$. It is absorbed by the liver and chronic exposure can cause necrosis of the teeth and jaw bones ${ }^{58}$. A characteristic property of phosphorus is the availability of its unfilled $3 d$ orbitals $\left(1 \mathrm{~s}^{2}, 2 \mathrm{~s}^{2}, 2 \mathrm{p}^{6}, 3 \mathrm{~s}^{2}, 3 \mathrm{p}^{3}\right)$ to form $\mathrm{p} \pi-\mathrm{d} \pi$ bonds with oxygen and nitrogen. Because of its smaller radius, phosphorus forms tetrahedral $\mathrm{PO}_{4}{ }^{3-}$ anions and chain polyacids $\mathrm{H}_{n+2} \mathrm{P}_{\mathrm{n}} \mathrm{O}_{3 \mathrm{n}+1}(\mathrm{n}=2-17){ }^{59}$. Phosphorus is the eleventh most abundant element in the earth's crust with the concentrations to the extent of $1120 \mathrm{ppm}\left(\mathrm{mg} \mathrm{kg}^{-1}\right)$. It exists in the terrestrial minerals as orthophosphate with the exception of schriebersite $(\mathrm{Fe}, \mathrm{Ni})_{3} \mathrm{P}$, which is present in meteoric iron ${ }^{60}$. There are around 200 known crystalline phosphate minerals. The major source of phosphorus in rocks is the apatite mineral family $\mathrm{Ca}_{10}\left(\mathrm{PO}_{4}\right)_{6}(\mathrm{OH}, \mathrm{F}, \mathrm{Cl})_{2}$, with common members as fluorapatite $\mathrm{Ca}_{5}\left(\mathrm{PO}_{4}\right)_{3} \mathrm{~F}$, chloroapatite $\mathrm{Ca}_{5}\left(\mathrm{PO}_{4}\right)_{3} \mathrm{Cl}$ and the most important for industrial applications, hydroxyapatite $\left.\mathrm{Ca}_{5}\left(\mathrm{PO}_{4}\right)_{3} \mathrm{OH}\right)^{61}$ used to produce phosphate fertilizers. Phosphoric acid can be obtained using the original Brandt's method, isolation from urine by distillation, process improved by Robert Boyle in 1680, when the fine white sand was added to the mixture to remove volatiles. Later, when the bone ash was used as a raw phosphorus material, sulfuric acid was added to produce phosphoric acid, which was first concentrated and 
then heated with coke to produce phosphorus ${ }^{55}$. In 1890, Readman improved the efficiency of the process by using an electric furnace ${ }^{62}$ based on the following process:

$$
2 \mathrm{Ca}_{3}\left(\mathrm{PO}_{4}\right)_{2}+6 \mathrm{SiO}_{2}+10 \mathrm{C} \rightarrow 6 \mathrm{CaSiO}_{3}+10 \mathrm{CO}+\mathrm{P}_{4}
$$

Most of the industrially produced phosphorus is converted into phosphoric acids and their salts.

Phosphoric acid is used in production of superphosphates (phosphorus fertilizers for crops) from phosphate minerals and alternate phosphate sources like guano deposits ${ }^{63}$.

\subsubsection{Phosphorus Biochemistry}

Phosphorus oxidation states range from -3 to +5 . However, in nature phosphorus almost exclusively exists in the +5 -oxidation state and plays a significant role in living organisms. Prebiotic phosphorus chemistry plays a central role in attempting to shed light on the origin of life on Earth. Phosphorus rich minerals such as brushite $\left[\mathrm{CaHPO}_{4} .2 \mathrm{H}_{2} \mathrm{O}\right]$, apatite $\left[\mathrm{Ca} 5\left(\mathrm{PO}_{4}\right)_{3} \mathrm{OH}\right]$, struvite $\left[\mathrm{MgNH}_{4} \mathrm{PO}_{4} \cdot 6 \mathrm{H}_{2} \mathrm{O}\right]$, lungeburgite $\left[\mathrm{Mg}_{3} \mathrm{~B}_{2}\left(\mathrm{PO}_{4}\right)_{2}(\mathrm{OH})_{2} .8 \mathrm{H}_{2} \mathrm{O}\right]$ and schreibersite $\left[(\mathrm{Fe}, \mathrm{Ni})_{3} \mathrm{P}\right]$ were sources of ortho $\left[\mathrm{PO}_{4}{ }^{3-}\right]$, pyro $\left[\mathrm{P}_{2} \mathrm{O}_{7}{ }^{4-}\right]$ and tripoly $\left[\mathrm{P}_{3} \mathrm{O}_{10}{ }^{5-}\right]$ phosphates necessary for incorporation into organic molecules in the early stages of life creation $^{64}$. Westheimer reviewed the role of phosphorus in living systems emphasizing the importance of phosphoric acid and its role in nucleic acids ${ }^{65}$. Phosphates are ionized at physiological $\mathrm{pH}$ due to a low first $\mathrm{pK}_{\mathrm{a}} \sim 2$ which allows conservation of phosphate metabolites within a cell membrane ${ }^{65,66}$. Organic phosphate esters are involved in biochemical reactions as energy carriers, coenzymes or as intermediates. They are involved in photosynthesis, carbohydrate and lipid metabolism, the nitrogen cycle and in other biochemical reactions involving energy transfer. Organic phosphate species belong to a few broad compound classes. For example, orthophosphate monoesters, which have one ester linkage, include sugar 
phosphates, mononucleotides and inositol phosphates. Adenosine Triphosphate (ATP) is the most important energy carrier and is present in all life forms as a metabolic mediator between high energy phosphate donors and low energy phosphate acceptors. Creatine phosphate and phosphoenol pyruvate also belong to main reservoirs of biochemical energy. Nutrient degradation with highly exergonic phosphoryl-transfer reactions are coupled to the formation of ATP from adenosine diphosphate (ADP) and orthophosphate with the help of enzymes known as kinases. Kinases catalyze the transfer of phosporyl groups between ATP and other molecules ${ }^{67}$. Phosphates required for the phosphorylation of adenosine 5'-diphosphate (ADP) to ATP in algae can be stored in the cells by conversion to polyphosphates ${ }^{8}$. Orthophosphate diesters have two esters per phosphate and are represented by phospholipids, RNA and DNA ${ }^{68}$. The sugarphosphate backbone is responsible for the primary structure of the nucleic acids. Phosphate from one nucleotide monomer connected to the sugar (deoxyribose or ribose) of the following nucleotide, continue in this alternating sequence with long chains in DNA and RNA structure. The cell membranes also consist of phospholipids which are bound together by divalent cations ${ }^{7}$. Animal bone formation, buffering function in urine and blood are also metabolic functions of inorganic phosphates. Catabolic processes in which the nutrients are broken down the released energy is transferred to phosphorus containing energy carriers. The stored energy is subsequently used during anabolic biosynthetic processes where the products from catabolism are reassembled back into proteins, lipids, polysaccharides and other molecules ${ }^{69}$. Inorganic polyphosphates contain a phosphoanhydride bond which is energetically similar to that of ATP and is used as a phosphate reserve ${ }^{70}$. Orthophosphate is transported to the cell by the uptake system and converted into ATP by adding a phosphate ion to ADP. The excess of orthophosphate is stored as polyphosphate inside the cell ${ }^{10}$. Microorganisms accumulate reserve phosphorus compounds 
in the form of polyphosphates and in some archae and bacteria phosphorus is stored even as magnesium phosphate during phosphorus excess periods in the environment ${ }^{71}$. Some strains of cyanobacteria can store phosphorus as polyphosphates for the events of external phosphorus shortage. Such ability gives the cyanobacteria a competitive advantage over the other phytoplankton when the phosphorus availability is low ${ }^{11}$. Phosphorus plays an important factor in structure of certain cells. For instance, carbohydrate monomers and phosphate forms covalent ester links creating a rigid structure of the prokaryotes cells, where the organically bound phosphate is found in the cell walls ${ }^{8}$. Pyrophosphate is a waste product of the macromolecular biosynthesis ${ }^{72}$. The incorporation of phosphorus into the cell takes place in several steps. Alkaline phosphatase converts organic and inorganic phosphoesters outside of the cell, at the cell surface or in the periplasm ${ }^{9}$.

Another important role of polyphosphates in living organisms are chelation of metal ions (e.g. $\mathrm{Cd}^{2+}$ ), decreasing their toxicity and also as a buffer against alkali ions ${ }^{73}$.

\subsubsection{Phosphorus in the Aquatic Environment}

Phosphorus in natural waters is present in a variety of chemical forms that migrate between particulate and dissolved fractions, according to a dynamic equilibrium ${ }^{16}$.

$$
\mathbf{P}_{\text {dissolved }} \rightleftarrows \mathbf{P}_{\text {particulate }}
$$

Orthophosphate $\left(\mathrm{H}_{2} \mathrm{PO}_{4}{ }^{-}\right.$and $\mathrm{HPO}_{4}{ }^{2-}$ at normal aquatic $\left.\mathrm{pH}\right)$ is a dominant form of dissolved inorganic phosphorus in natural waters with concentrations often at $1 \mu \mathrm{g} \mathrm{L}^{-1}$ as $\mathrm{P}$ or below, usually being below detection limits of the most current methods of analysis ${ }^{74}$. An extensive steady-state phosphorus radiobioassay study of 56 lakes in North America confirmed that orthophosphate was often present in picomolar $(\mathrm{pM})$ concentrations and was order of 
magnitudes lower than measured by widely used analytical methods ${ }^{75}$. Other naturally occurring forms of inorganic phosphorus include condensed phosphates such as polyphosphates (chain phosphates), metaphosphates (cyclic phosphates) and ultraphosphates (branched cyclic structures) ${ }^{76}$. Polyphosphates are bioavailable and are produced by a wide range of microorganisms and also by human activities. Pyrophosphate and other polyphosphates usually escape detection by standard colorimetric analytical methods but can be quantified by ${ }^{31} \mathrm{P}$ nuclear magnetic resonance spectroscopy and enzymatic essay studies ${ }^{77}$. Polyphosphate chain length effect on phosphatase-mediated hydrolysis mechanisms was investigated with the use of ${ }^{31} \mathrm{P}$ NMR monitoring the dynamic changes of $\mathrm{P}$ molecular configuration during polyphosphate hydrolysis ${ }^{78}$. Determination of linear and cyclic polyphosphates by chromatography and electrophoresis methodologies were reviewed by Rosset et al. ${ }^{79}$. Inorganic particulate phosphorus can also release orthophosphate in certain conditions. Iron(III) phosphate or Fe(III) complexes have a major role in cycling the phosphorus within the aquatic environment. Hydrated ferric oxides tend to adsorb dissolved phosphates from the water column and co-precipitate in the sediments. During anaerobic conditions, due to iron reduction, phosphorus can be released from the hydrated ferric oxides from sediments into the water column ${ }^{16}$. Absorption of phosphorus on humic-Fe compounds were studied by Franco and Heath ${ }^{80}$. The research suggested that phosphate adsorbed to oxyhydroxide colloids or ferric-organic colloids can be released and made available to planktonic organisms by photoreduction of iron in the presence of sunlight or by phosphatase activity independently of light intensity. Further studies regarding the biogeochemical cycling of colloidal ferrous oxides in freshwater was investigated by McKnight and Duren ${ }^{81}$. Organic phosphorus species occurring in water due to biological processes include sugar phosphates, phosphate metabolites (AMP, ADP, ATP), phytate and its degradation 
products, inositol phosphates and also anthropogenic organophosphorus species such as alkyl substituted phosphonic acids, alkylphosphates and bisphosphonates used as herbiceds, pesticides and detergents ${ }^{82}$. Organic and inorganic phosphorus species in natural water samples including phosphate monoesters, phosphate diesters, polyphosphates, phosphonates and myo-inositol hexakisphosphate were detected by ${ }^{31} \mathrm{P}$ NMR spectroscopy ${ }^{83-85}$. Dissolved organic phosphorus species make up to $15-30 \%$ of the total phosphorus in lake waters. During summer periods and high biological activity, these compounds may comprise up to $90 \%$ of the total soluble phosphorus ${ }^{86,87}$. A diagram of the phosphorus species in natural waters was adapted from Maher and $\mathrm{Woo}^{88}$ and presented in Figure 2.1.

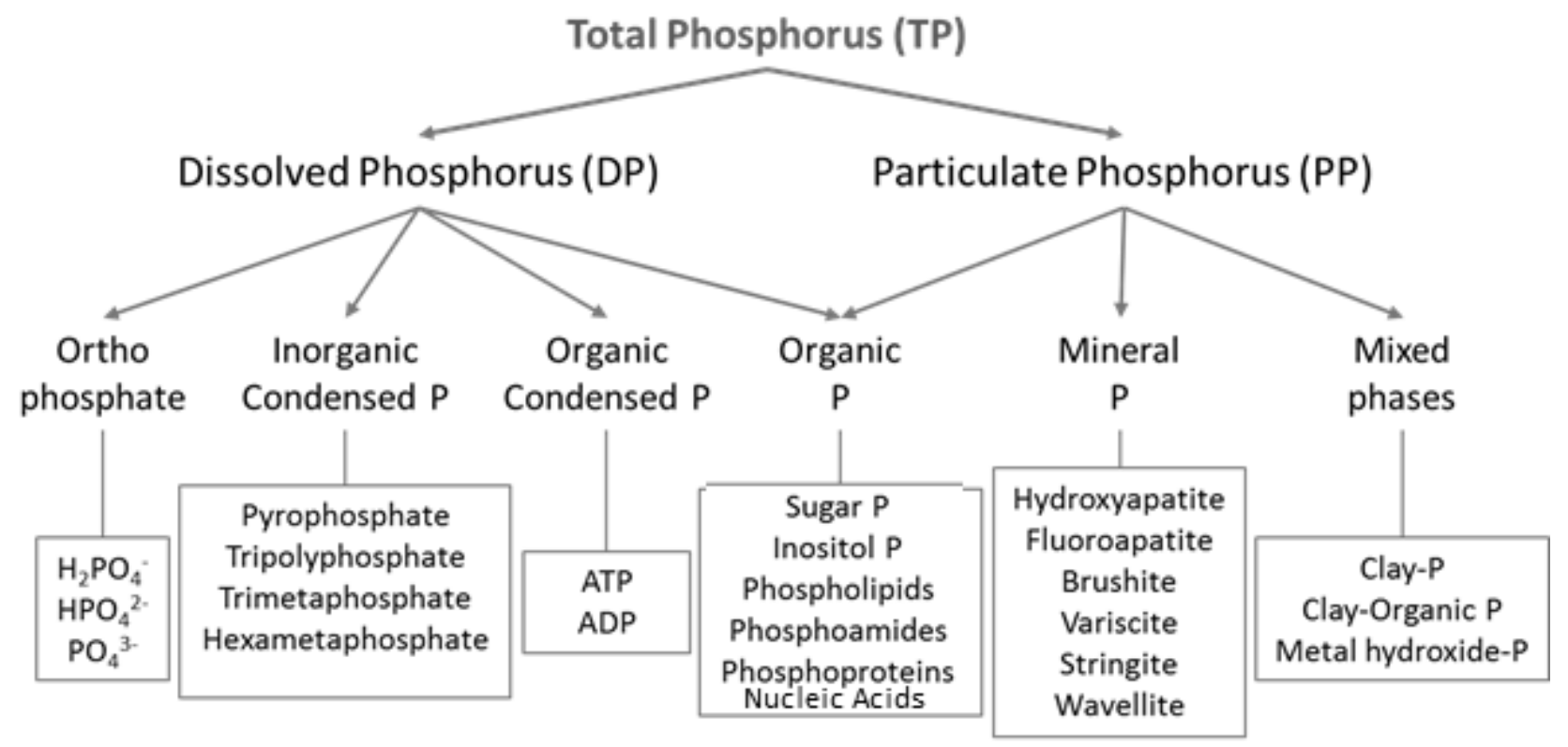

Figure 2.1: Diagram of $\mathrm{P}$ species in natural waters adapted from Maher and Woo ${ }^{88}$

\subsubsection{Phosphorus and Eutrophication}

Eutrophication of freshwater causes excessive algal growth, depletion of oxygen in deeper regions of aquatic systems, loss of aquatic life, deterioration of aquatic habitat and threat of toxin contamination in drinking water supplies caused by algal blooms. Eutrophication of surface 
waters is usually related to the transfer of exogenous forms of phosphorus into surface waters. Phosphorus is often a limiting factor for algal growth in surface waters due to fact that it can't be replenished from atmospheric sources like nitrogen and carbon. Studies conducted in the Experimental Lake Area have shown that growth of phytoplankton is proportionate to the concentrations of phosphorus in the water column ${ }^{4,89}$. Further enrichment bioassay studies of phytoplankton growth and its relationship to phosphorus as a limiting factor in freshwater showed that combined nitrogen and phosphorus enrichment enhanced algal growth more substantially than only addition of phosphorus or nitrogen separately ${ }^{90,91}$. Phosphorus is an essential element and is crucial to metabolism and energy conversion in animals and plants. Plants control the phosphate concentration in the cell by regulating phosphate metabolism ${ }^{5}$. The only immediately available phosphorus sources for phytoplankton are inorganic phosphate, some phosphorylated sugars and phosphonates ${ }^{12}$. Total bio-available phosphorus is a combination of immediately available phosphorus and phosphorus which can be utilized using desorption, dissolution and enzymatic degradation ${ }^{92}$. Orthophosphate and small organic phosphate esters are readily available for phytoplankton uptake. Concentrations of these compounds in natural waters are usually very low, due to high affinity of phytoplankton to readily available phosphorus sources ${ }^{13}$. Another source of phosphorus for the phytoplankton is phosphorus released from the dead cells. The main forms of such phosphorus are inorganic phosphate, sugar phosphates, glycerophosphate, polynucleotides and phospholipids ${ }^{14}$.

\subsection{Phosphorus Analysis}

\subsubsection{Sample Collection, Treatment and Stability of the Phosphorus Species}

Sampling procedure can be a source of analytical variability and obtaining a representative and stable sample is paramount in analysis of phosphorus species. Sampling from natural aquatic 
systems is subjected to seasonal variabilities in phosphorus discharge from anthropogenic sources. The highest phosphorus loadings can correlate with agricultural run-offs during the incidents of increased precipitation, snow melting or irrigation ${ }^{93}$. Phosphorus variations can be caused also by phosphorus species leaching from the benthos during anaerobic conditions created in the hypolimnion of a lake. The phosphate is brought to the surface when the surface temperature decreases in the fall and the hypolimnion is mixed with the surface water ${ }^{94}$. Storing surface water samples for 4 hours at $4{ }^{\circ} \mathrm{C}$, Lambert et al. ${ }^{95}$ found no significant change in total phosphorus (TP) measurements, but observed 25-54\% decreases in total dissolved phosphorus, total reactive phosphorus and dissolved reactive phosphorus. Samples preserved with $\mathrm{H}_{2} \mathrm{SO}_{4}$ at $\mathrm{pH}<2$ can be stored at $4{ }^{\circ} \mathrm{C}$ for up to 28 days ${ }^{96}$ prior to TP analysis. Preliminary treatment is often necessary for the overall effectiveness of the analyses with dependence on the purpose of the phosphorus species determination and complexity of the sample. Differentiation between dissolved and suspended phosphorus species requires filtration, preferably carried out at the time of the sample collection. Polycarbonate or cellulose acetate membrane filters ${ }^{97}$ with $0.45 \mu \mathrm{m}$ or $0.2 \mu \mathrm{m}$ pore size are recommended. However, $0.2 \mu \mathrm{m}$ pore size filter is preferred to remove efficiently the bacteria and plankton ${ }^{98}$. Some bacteria, viruses and colloidal phosphorus can pass through $0.2 \mu \mathrm{m}$ filter and thus be present in both dissolved and particulate fractions ${ }^{93}$. Further studies on filterability of the freshwater bacteria on $0.1 \mu \mathrm{m}$ filters were conducted by Wang et al. 99 . "Reactive phosphorus" by definition is the phosphorus measured by colorimetric analyses without previous hydrolysis or digestion of the sample and including dissolved and suspended forms of orthophosphate and also condensed phosphates. The fraction termed "acid-hydrolysable phosphorus" is the portion of organic phosphates converted to orthophosphate by acid hydrolysis at boiling temperatures. "Organically bound phosphorus" is the fraction converted into 
orthophosphate by a destructive oxidation ${ }^{100}$. Analysis of the total phosphorus in water samples requires digestion with oxidizing reagents. The digestion procedures will be discussed in the chapter 2.3.4 (Total Phosphorus Analysis). However, it is necessary to point out that persulfate digestion produces high concentrations of sulfate which interferes with ion chromatography measurements of phosphate and further sulfate removal techniques are required. Other sample treatment techniques such as removal of interfering matrix anions (off-line or on-line procedures), column-switching systems and preconcentration are commonly used in chromatographic separations of inorganic non-condensed phosphorus species ${ }^{82}$.

\subsubsection{Spectrophotometric Methods}

\subsubsection{Orthophosphate Analysis}

In the early 1900s, Schreiner presented a method of determination of phosphate in waters using ammonium molybdate as a coloring agent. The most common phosphate analysis in water samples is a spectrophotometric (colorimetric) method, a modification of the original Murphy and Riley method using the ascorbic acid as a reducing agent ${ }^{101}$. Phosphorus analysis by colorimetry involves two general steps: conversion of the phosphorus species into orthophosphate and subsequent colorimetric determination of the orthophosphate. The International Organization for Standardization (ISO) published method $15681^{102,103}$ for determination of orthophosphate by flow injection analysis (FIA) and continuous flow analysis (CFA). The methods are suitable for the determination of orthophosphate for concentration ranges between 10 and $1000 \mu \mathrm{g} \mathrm{L}^{-1}$ as P. Samples are mixed with sodium dodecyl sulfate (surfactant) and acidic solution of molybdate and antimony reagents, with molybdenum blue being subsequently produced by the ascorbic acid reduction of a phospho-antimony-molybdate 
complex and measured at $880 \mathrm{~nm}{ }^{103,104}$. Method ISO 15681 suggest that samples with orthophosphate concentrations lower than $100 \mu \mathrm{g} \mathrm{L}^{-1}$ as P should be stored in glass containers, while samples with higher concentrations can be also stored in plastic containers. Interferences affecting spectrophotometric determination of the orthophosphate include arsenates $\left(100 \mu \mathrm{g} \mathrm{L}^{-1}\right.$ as As is equivalent to approx. $30 \mu \mathrm{g} \mathrm{L}^{-1}$ as $\mathrm{P}$ ), silicates (at 60 times higher concentrations than $\mathrm{P}$ ), fluoride (above $50 \mathrm{mg} \mathrm{L}^{-1}$ ), nitrite (above $5 \mathrm{mg} \mathrm{L}^{-1}$ for samples not acidified when collected), suspended particles blocking the light from the lamp ${ }^{102}$. Another widely used method for orthophosphate is the vanadomolybdophosphoric acid method. The orthophosphate reacts with ammonium molybdate in the presence of vanadium under acidic conditions and produce a yellow vanadomolybdophosphoric acid, which is measured at $470 \mathrm{~nm}$. The positive interferences for this method are silica and arsenate (when sample is heated) and negative interferences caused by arsenate, fluoride, thorium, bismuth sulfide, thiosulfate, thiocyanate and excess molybdate ${ }^{100,105}$. Stannous chloride method is based on reduction of molybdophosphoric acid with $\mathrm{SnCl}_{2}$, when an intensely colored molybdenum blue complex is produced and measured at $650 \mathrm{~nm}$ or $690 \mathrm{~nm}$ 100, 106. For samples containing less than $10 \mu \mathrm{g} \mathrm{L}^{-1}$ as $\mathrm{P}$ the stannous chloride method provides better sensitivity than the vanadomolybdophosphoric acid method. Ascorbic acid reduction method is recommended for analyzing samples with orthophosphate concentrations between 1 $\mu \mathrm{g} \mathrm{L}^{-1}$ and $100 \mathrm{mg} \mathrm{L}^{-1}$ as P. Using data provided by Standard Methods ${ }^{100}$, the performance of the three colorimetric methods in measuring orthophosphate is summarized in Figure 2.2. 

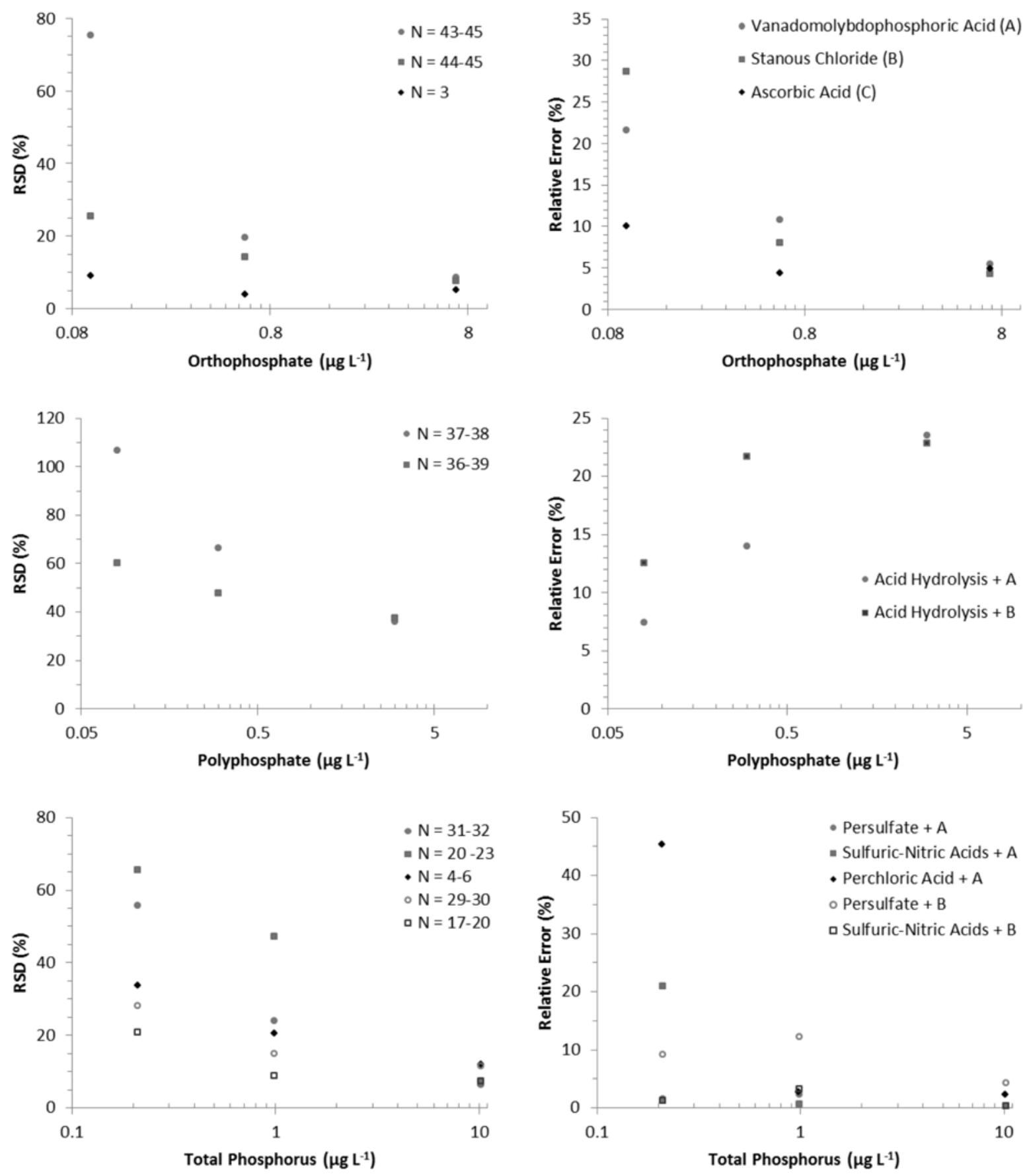

Figure 2.2: Measurements of orthophosphate, acid hydrolyzed polyphosphate and digested total phosphorus using three colorimetric methods ( $\mathrm{A}, \mathrm{B}$ and $\mathrm{C}$ ). Comparison of the results is based on the relative standard deviation (RSD) and relative error values provided in table 4500-P:I. of Standard Methods, $22^{\text {nd }}$ edition ${ }^{100}$, with $\mathrm{N}$ being the number of participating laboratories $(\mathrm{N})$. 


\subsubsection{Total Phosphorus Analysis}

Digestion of water samples releases phosphorus from all organic phosphorus species and condensed inorganic phosphate. Colorimetric analysis is usually measuring the orthophosphate in the digested samples, being reported as TP. The persulfate digestion by autoclaving at $120^{\circ} \mathrm{C}$ was proposed by Menzel and Corwin in $1965^{107}$ and it is still one of the simplest approach. In 1974 US Environmental Protection Agency (US EPA) published method 365.4 for TP analysis ${ }^{108}$, with sulfuric acid digestion at 160 and $380{ }^{\circ} \mathrm{C}$ in the presence of a mercury catalyst $\left(\mathrm{HgSO}_{4}\right)$. If this digestion is still in use, the recent implementation of the Minamata Convention on Mercury ${ }^{109}$ encourages its replacement with mercury free alternatives. The 1978 version of the US EPA method (365.3) introduced the acid persulfate digestion. Standard methods published by the American Public Health Association (APHA) provides digestion procedures with nitric acidsulfuric acid, perchloric acid and persulfate, known also as peroxodisulfate ${ }^{100}$. An integrated inline UV-assisted acid persulfate digestion was also published in ISO method $15681^{102,103}$. Alkaline persulfate digestion was proposed by Valderrama ${ }^{110}$ in 1981 as a method for simultaneous measurement of TP and total nitrogen. Similar alkaline persulfate digestion methods have been published ${ }^{100,110-113}$, with differences in sample volume and in concentrations of persulfate used for digestion (see Table 1). Ormaza-González and Statham ${ }^{114}$ concluded that alkaline persulfate digestion method following Valderrama's procedure has poor recoveries for polyphosphates, metaphosphates, and ATP, while other similar alkaline digestion methods achieve very good recoveries for ATP (Table 1). The UV based digestion was efficient in releasing phosphorus from sugars, monoesters and phosphonates, but not efficient for the digestion of polyphosphate, metaphosphate and ATP ${ }^{114}$. The results obtained with an in-line automated system with UV-assisted acid persulfate digestion were about $5 \%$ biased low when 
compared with manual digestion, mainly due to $90-95 \%$ recoveries for pyrophosphate and trimethylphosphate ${ }^{100}$. Due to settling down of the particles in the test tube prior to injection, the method may not be fit also for analyzing samples with high levels of suspended sediments. Lambert and Maher ${ }^{115}$ found no significant differences between alkaline persulfate and nitricsulfuric acid digestion. In a recent study, Dayton et al. ${ }^{116}$ confirmed that acid persulfate digestion is much more efficient than alkaline persulfate digestion ${ }^{114}$, particularly for samples containing suspended sediments. The perchloric acid digestion was more efficient than acid persulfate digestion for water samples with high-suspended sediment levels ${ }^{117,118}$, but it is labor intensive and require special safety conditions. Using data provided by Standard Methods ${ }^{100}$, the performance of five different digestion methods is summarized in Figure 2.2. Arsenate present at higher concentration than phosphorus and suspended sediments in unfiltered digested solutions can interfere in the colorimetric measurement of the orthophosphate ${ }^{96}$. In samples with high levels of iron, the phosphorus can be lost by precipitation.

Zhou and Struve found that neutralization and settling time after digestion affect the TP analysis results, especially for samples with very low TP level even in the absence of visible sediments ${ }^{119}$. For reduced variability in the interlaboratory studies, they also suggested the need of a standardized method providing digestion solution concentrations $\left(\mathrm{H}_{2} \mathrm{SO}_{4}\right.$ and $\left.\mathrm{K}_{2} \mathrm{~S}_{2} \mathrm{O}_{8}\right)$ and detailed treatment procedures following the sample digestion until colorimetric analysis. 


\begin{tabular}{|l|c|c|c|c|c|}
\hline & Valderrama & $\begin{array}{c}\text { Ebina et } \\
\text { al. }\end{array}$ & $\begin{array}{c}\text { Hosomi } \\
\text { and Sudo }\end{array}$ & $\begin{array}{c}\text { Standard } \\
\text { Methods }\end{array}$ & USGS \\
\hline Sample Volume & 30 & 5 & 10 & 6 & 10 \\
\hline $\begin{array}{l}\text { Digestion Solution } \\
\text { Volume }\end{array}$ & 4 & 5 & 2 & 1.25 & 5 \\
\hline$\left[\mathbf{K}_{2} \mathbf{S}_{2} \mathbf{O}_{8}\right](\mathbf{m g} / \mathbf{m L})$ & 5.6 & 10 & 6.67 & 11 & 13.5 \\
\hline$\left[\mathbf{N a O H}_{\mathbf{n}}(\mathbf{m g} / \mathbf{m L})\right.$ & 1.65 & 1.5 & 1.5 & 1.66 & 2 \\
\hline$\left[\mathbf{H}_{3} \mathbf{B O}_{3}\right] \mathbf{( m g / m L )}$ & 3.53 & - & - & - & - \\
\hline ATP Recovery (\%) & $\approx 68$ & 98.1 & - & 103 & - \\
\hline AMP Recovery (\%) & - & 100.8 & 94 & - & - \\
\hline
\end{tabular}

Table 2.1: Summary of published procedures for alkaline digestions (Valderrama ${ }^{110}$, Ebina et al. ${ }^{113}$, Hosomi and Sudo ${ }^{112}$, Standard Methods ${ }^{100}$ and USGS ${ }^{111}$ ). Recoveries for adenosine $5^{\prime}$ triphosphate (ATP) and adenosine 5'-monophosphate (AMP) were provided from the same references, except for Valderrama ${ }^{110}$ and Hosomi and Sudo ${ }^{112}$ methods.

\subsubsection{Ion Chromatography and Hyphenated Methods}

Ion chromatography (IC) with conductivity detection was first used to measure inorganic anions and cations by Small et al. in $1975^{44}$. Surface and waste stream waters were analyzed in 15-20 min, measuring anions $\left(\mathrm{F}^{-}, \mathrm{Cl}^{-}, \mathrm{Br}^{-}, \mathrm{I}^{-}, \mathrm{NO}_{3}{ }^{-}, \mathrm{NO}_{2}{ }^{-}, \mathrm{SO}_{4}{ }^{2-}, \mathrm{SO}_{3}{ }^{2-}\right.$ and $\left.\mathrm{PO}_{4}{ }^{3-}\right)$ and cations $\left(\mathrm{Li}^{+}, \mathrm{Na}^{+}\right.$, $\left.\mathrm{K}^{+}, \mathrm{Rb}^{+}, \mathrm{Cs}^{+}, \mathrm{NH}_{4}^{+}, \mathrm{Ca}^{2+}, \mathrm{Mg}^{2+}\right)$. The weak acidic character and the complex dissociation equilibrium of phosphate ions make IC analysis more challenging than for other strong acidic anions ${ }^{120}$. Although phosphate ions were not considered, Gjerde et al. ${ }^{121}$ decreased the analysis time and improved sensitivity by using a macroporous anion exchange column with very low exchange capacity and low conductivity eluents (benzoate, phatalate, sulfobenzoate, perchlorate and malonate). Using IC with conductivity detection, Rosset et al. ${ }^{79}$ successfully separated a mixture of cyclic and condensed phosphates in less than 30 minutes. Comparing phosphate measurements by suppressed ion chromatography and colorimetry (molybdenum blue complex) Xie et al. ${ }^{120}$ found that organic phosphorus compounds were less susceptible to hydrolysis when analyzed by IC and the presence of polyvalent metal ions (e.g. $\mathrm{Al}^{3+}$ and $\mathrm{Fe}^{3+}$ ) caused lower 
phosphate concentrations when measured by IC. US EPA (method 300.1) and Standard Methods (section 4110) published IC analysis procedures for phosphate ${ }^{100,122}$. Samples are analyzed after a filtration through $0.45 \mu \mathrm{m}$ filter ${ }^{100}$ and separated on an anion exchange column. Continuous suppression ensures significantly decreased conductivity of the eluent and conversion of the analyzed anions into their acid forms, which have higher conductivity than the eluent. Using a carbonate-bicarbonate eluent, separation of all major anions was achieved in 10 minutes with a method detection limit of orthophosphate at $14 \mu \mathrm{g} \mathrm{L} \mathrm{L}^{-1}$ as $\mathrm{P}$.

McDowell et al. ${ }^{123}$ used atmospheric pressure chemical ionization (APCI) mass spectrometry (MS) to analyze hypophosphite $\left(\mathrm{m} / \mathrm{z}=65\right.$ for $\left.\mathrm{H}_{2} \mathrm{PO}_{2}{ }^{-}\right)$, phosphite $\left(\mathrm{m} / \mathrm{z}=81\right.$ for $\left.\mathrm{H}_{2} \mathrm{PO}_{3}{ }^{-}\right)$and phosphate $\left(\mathrm{m} / \mathrm{z}=97\right.$ for $\left.\mathrm{H}_{2} \mathrm{PO}_{4}^{-}\right)$in water. Detection limits for hypophosphite was $26 \mu \mathrm{g} \mathrm{L}^{-1}$ as $\mathrm{P}$, for phosphite $12 \mu \mathrm{g} \mathrm{L}^{-1}$ as $\mathrm{P}$ and for phosphate $11 \mu \mathrm{g} \mathrm{L}^{-1}$ as $\mathrm{P}$. Development of the high capacity ion chromatography columns allowed the detection and quantification of ultra-low concentrations of phosphorus anions in environmental samples. Ivey and Foster ${ }^{124}$ used IC separation coupled to electrospray ionization (ESI) MS for detection of phosphorus oxyanions. Large volume injection $(800 \mu \mathrm{L})$ and sample pre-treatment (Dionex Ag OnGuard II cartridges) allowed decreasing the detection limit for hypophosphite $\left(0.34 \mu \mathrm{g} \mathrm{L}^{-1}\right.$ as $\left.\mathrm{P}\right)$ and phosphite $(0.62$ $\mu g \mathrm{~L}^{-1}$ as $\mathrm{P}$ ), but the Ag cartridge removed also the phosphate ions from the sample. Using a high capacity IC column (Dionex AS-11HC), large injection volume $(500 \mu \mathrm{L})$ and suppressed conductivity, Han et al. ${ }^{125}$ lowered the detection limit for phosphites to $0.062 \mu \mathrm{g} \mathrm{L}-1$ as P. The results were confirmed using also a two-dimensional IC separation with suppressed conductivity and confirmed ion identities with IC-ESI-MS. In an ESI-MS study of dehydration reactions from inorganic oxyanions with aminopolycarboxylates (e.g. imidodiacetic acid, nitrilotriacetic acid), Kojima et al. ${ }^{126}$ found that a direct measurement $\left(\mathrm{m} / \mathrm{z}=97\right.$ for $\left.\mathrm{H}_{2} \mathrm{PO}_{4}{ }^{-}\right)$is the only option 
available for phosphate ions. With a combination of two IC columns and a third concentrator column located between the two separation columns, Wang et al. ${ }^{127}$ determined low level anions in seawater, including phosphate at a detection limit of $23 \mu \mathrm{g} \mathrm{L}-1$ as $\mathrm{P}$.

\subsubsection{Capillary Electrophoresis Methods}

Capillary electrophoresis (CE) has been used for the analysis of ionic aqueous species including phosphate. It requires only a small sample volume, usually in the picoliter to nanoliter range ${ }^{128,}$ 129. The first electrophoretic separation of inorganic anions was reported in $1967{ }^{130}$. CE separations are relatively fast, requiring only $10 \mathrm{~min}^{131}$. Arce et al. ${ }^{129}$ coupled FIA with CE and measured trace level concentrations of phosphate and other inorganic anions and cations. On-line automated monitoring systems for cations and anions were developed for a water purification plant. Using UV detection $(214 \mathrm{~nm})$ phosphate was eluted in 9 min and obtained a detection limit of $32 \mu \mathrm{g} \mathrm{L}^{-1}$ as $\mathrm{P}^{129}$. Mayrhofer et al. ${ }^{132}$ used a combination of CE with a contactless conductivity detector, achieving a 3 minutes elution of phosphate with sorbate as a background electrolyte and a detection limit of $23 \mu \mathrm{g} \mathrm{L}^{-1}$ as P. A similar FIA-CE separation was published by Kuban et al. ${ }^{133}$ for on-site simultaneous determination of inorganic anions and cations in drainage water from the artificially aerated Lake Sempach (Switzerland). The method achieved peak area repeatability of $1 \%$ and a detection limit for phosphate of $65 \mu \mathrm{g} \mathrm{L}^{-1}$ as P. Gaudry et al. ${ }^{134}$ developed a novel CE method for rapid simultaneous measurement of 23 environmental inorganic cations and anions including phosphate. The method used a sequential injection CE with capacitively-coupled contactless conductivity detector. Oppositely charged ions from a single sample plug were simultaneously injected on two separate capillaries for independent separation and detection. Rapid analysis time was achieved in only 3.5 min with phosphate eluting at $2.4 \mathrm{~min}$, with a detection limit of $20 \mu \mathrm{g} \mathrm{L} \mathrm{L}^{-1}$ as $\mathrm{P}$ and phosphate analytical range 
between 0.5 and $10 \mathrm{ppm}^{134}$. In the mid-2000s, CE had seen significant improvements in the area of indirect photometric detection through the use of dyes as probes and LED light sources and software capable of simulating separations and designing of background electrolytes providing optimal separation conditions and improved sensitivity of analysis ${ }^{135}$.

\subsubsection{Inductively Coupled Plasma with Atomic Emission and Mass Spectrometry Methods}

Inductively coupled plasma (ICP) either combined with atomic emission spectrometry (AES) or MS have been used to determine TP in water samples. In 1980, Sugimae ${ }^{136}$ analyzed phosphorus in river, sewer and domestic waste water by ICP-AES. Positive interferences produced by argon and NO were minimized by source parameter optimization. The spectral level increase from 1000 $\mathrm{mg} \mathrm{L} \mathrm{L}^{-1} \mathrm{Mg}$ was equivalent to $2 \mathrm{mg} \mathrm{L}^{-1} \mathrm{P}$ but using a preliminary cation-exchange procedure eliminated the interference. A detection limit of $130 \mu \mathrm{g} \mathrm{P} \mathrm{L}^{-1}$ was achieved and the results were in a good agreement with the colorimetrically obtained results. Fujino et al. ${ }^{137}$ reported difficulties in direct determination of low level phosphorus in natural water, due to $\mathrm{Si}$ and $\mathrm{Fe}$ spectral interferences. Solvent extraction in 1-octanol with $\mathrm{HCl} / \mathrm{MoO}_{4}{ }^{2-}$ complexing agent removed interfering elements and preconcentrated phosphorus, achieving a detection limit of $50 \mu \mathrm{g} \mathrm{L}^{-1}$ as $\mathrm{P}$. Samples analyzed were from Lake Biwa (Japan) and ranged in concentrations between 12 and 32 $\mathrm{mg} \mathrm{L}^{-1}$. Various modes of ICP-AES sampling and influence of anions and metal species in determination of phosphorus were investigated by Wennrich et al. ${ }^{138}$. Using electrothermal vaporization, the method achieved a phosphorus detection limit of $44 \mu \mathrm{g} \mathrm{L}^{-1}$ as $\mathrm{P}$ at $178.27 \mathrm{~nm}$. Pneumatic nebulization and addition of methanol-ethanol mixture into aqueous samples improved detection limits of the studied nonmetals. Using axial determination at $213 \mathrm{~nm}$ with $\mathrm{Ga}$ as an internal standard and matrix-matched calibration standards (added $\mathrm{K}, \mathrm{Mg}$ and $\mathrm{Ca}$ ) reduced the matrix effect of $\mathrm{Na}$ and $\mathrm{Ca}$ in ground water samples from $20-30 \%$ to about $3 \%{ }^{139}$. The detection 
limit improved from 30 to $12 \mu \mathrm{g} \mathrm{L}^{-1}$ as Pby measuring at $213 \mathrm{~nm}$ instead of $178 \mathrm{~nm}$, due to a decreased matrix effect and a negligible $\mathrm{Cu}$ interference. Hydride generation technique was tried to determine phosphorus by ICP-AES, with phosphate reduced to calcium phosphide by aluminum powder, followed by reaction with $\mathrm{HCl}$ in a graphite furnace atomizer. The argon plasma generated phosphine gas $\left(\mathrm{PH}_{3}\right)$ was measured at $213.6 \mathrm{~nm}$ with an order of magnitude improvement of the detection limit from the direct nebulization approach ${ }^{140}$. Introducing the sample by electrothermal vaporization (ETV), Okamoto et al. ${ }^{141}$ lowered the detection limit to $2.6 \mu \mathrm{g} \mathrm{L}^{-1}$ as $\mathrm{P}$ measured by ICP-AES. The loss of phosphorus during drying and ashing was suppressed by using a tungsten boat furnace, with phosphate forming stable tungsten phosphate species.

Much lower detection limits than ICP-AES were achieved with ICP-MS methodology. The advantages of the ICP-MS include a wide dynamic range, specificity, sensitivity and multielement detection capability. A decrease in excitation and ionization efficiencies by the water mist introduced into the nebulizer is responsible for poor sensitivities. Polyatomic interferences on phosphorus $\left({ }^{31} \mathrm{P}^{+}\right)$include ${ }^{14} \mathrm{~N}^{16} \mathrm{OH}^{+},{ }^{15} \mathrm{~N}^{16} \mathrm{O}^{+}$and ${ }^{12} \mathrm{C}^{1} \mathrm{H}_{3}{ }^{16} \mathrm{O}^{+141}$. Cantarero et al. ${ }^{142}$ measured TP and dissolved phosphorus (DP, filtered through $0.45 \mu \mathrm{m}$ membrane filter) in agricultural

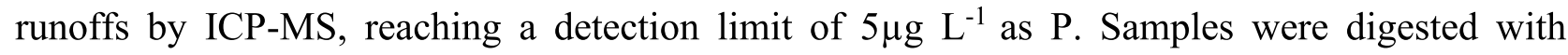
ammonium persulfate and sulfuric acid. The colorimetry and ICP-MS TP results were in good agreement. Speciation techniques require separation, identification and characterization of the phosphorus species. Separation techniques coupled to ICP-MS for phosphorus speciation include chromatographic methods (e.g. liquid chromatography (LC), gas chromatography (GC) and supercritical fluid chromatography (SFC)) and electrophoretic methods (e.g. CE and gel electrophoresis) ${ }^{143,}{ }^{144}$. Hyphenated ICP-MS techniques were effectively used for phosphorus speciation analysis ${ }^{143-145}$. 
Phospholipids, a group of organic phosphorus species, were extracted in organic solvents LC separated and measured using ICP-MS ${ }^{146}$. The optimized method used mobile phase splitting prior to nebulization for reduced solvent load to plasma, spray chamber cooling to $-5{ }^{\circ} \mathrm{C}$ and carrier gas flow adjusted to maximize condensation of the organic vapors. Helium was used as collision gas to reduce polyatomic interferences and the absolute detection limits ranged between 0.2 and 1.2 ng for the analyzed phospholipids. Bisphosphonates, previously known as biphosphonates $\left(\mathrm{HO}_{3} \mathrm{P}-\right.$ $\mathrm{CR}_{1} \mathrm{R}_{2}-\mathrm{PO}_{3} \mathrm{H}$ ), are a group of compounds analogues to pyrophosphate. They were initially used as complexing agents in water treatment, detergent additives ${ }^{147}$ and treatment of the osteoporosis ${ }^{148}$. Being water soluble ionic compounds, ion-exchange chromatography is the most suitable separation technique, although challenges still exist due to chelation with metal ions and a loss of column performance ${ }^{149,}{ }^{150}$. Kovacevic et al. ${ }^{150}$ separated bisphosphonates on a Dionex AS-7 IC column using diluted nitric acid as eluent and ICP-MS for detection. Polyatomic interferences at $\mathrm{m} / \mathrm{z} 31$, influence of plasma parameters on phosphorus and background signal were investigated. Detection limits achieved for two bisphosphonates, alendronic acid $\left(0.2 \mathrm{mg} \mathrm{L}^{-1}\right)$ and etidronic acid $\left(0.5 \mathrm{mg} \mathrm{L}^{-1}\right)$ were higher than those achieved using pre- or post-column derivatization methods ${ }^{150-}$ 152.

Following the 1970s ban on toxic and persistent organochlorine pesticides, the agrochemical industry used less persistent but more acutely toxic organophosphorus pesticides. Fidalgo-Used et al. ${ }^{153}$ developed a method for determination of organophosphorus pesticides in spiked river samples by solid phase microextraction (SPME) coupled to GC-MS and GC-ICP-MS for separation and detection. Their experimental setup proved that SPME is an effective technique for the extraction and preconcentration of trace level organophosphorus pesticides in river water samples. Better detection limits were obtained by SPME-ICP-MS $\left(0.09-143 \mathrm{ng} \mathrm{L}^{-1}\right)$ than by 
SPME-GC-MS (0.8-504 ng L-1). The use of GC-ICP-MS offered a higher potential for monitoring organophosphorus pesticides in complex environmental samples ${ }^{153}$. Glyphosate (N(Phosphonomethyl)glycine), is a phosphonate compound used as a broad-spectrum herbicide with low toxicity to mammals, but its overall environmental impact is not fully understood yet. Trace levels of glyphosate and phosphate in water were measured by IC coupled to ICP-MS ${ }^{154}$, using an anion exchange column (Dionex AS16) and $20 \mathrm{mM}$ citric acid eluent. The glyphosate and phosphate were detected separately by ICP-MS at $\mathrm{m} / \mathrm{z}=31$. This sensitive method had a wide dynamic range and low detection limit $\left(0.7 \mu \mathrm{g} \mathrm{L}^{-1}\right)$ for both analytes, without using preconcentration or chemical derivatization. Similar detection limits were reported by Wigfield et al. ${ }^{155}$.

\subsubsection{Electrochemical Methods}

In 2012, Berchmans et al. ${ }^{156}$ reviewed the electroanalytical methods used for inorganic phosphate analysis, which include potentiometry, voltammetry and amperometry . Although detection limits are not as low as for MS and colorimetry methods, the simplicity and capability of miniaturizing the electrochemical instrumentation allowed their use as field and remote sensing instrumentation. However, their low sensitivity, frequent equipment recalibrations and drifts caused by temperature fluctuation are limiting their applications.

In 1947, Flatt and Brunisholz ${ }^{157}$ determined phosphate in aqueous solutions by potentiometric titration with silver nitrate when $\mathrm{Ag}_{3} \mathrm{PO}_{4}$ precipitate is formed. The silver phosphate ion selective electrode (ISE) developed by Novozamsky and van Riemsdijk ${ }^{158}$ was capable of measuring phosphate with detection limit at $30 \mu \mathrm{g} \mathrm{L}{ }^{-1}$ as P.Despite the major interference observed from chloride ions, it was one of the first direct potentiometric detection of phosphate. In a 
potentiometric flow-through detector with a metallic copper electrode, Alexander et al. ${ }^{159}$ investigated the electrode response to phosphates (orthophosphate, pyrophosphate and tripolyphosphate) and inorganic anions. In a similar setup with a lead (II) ISE, orthophosphate and tripolyphosphate were reproducibility measured with non-linear calibration curves ${ }^{160}$. Improved selectivity was obtained using FIA with cadmium ISE, when $\mathrm{Cd}^{2+}$ from the reagent stream precipitated phosphate as $\mathrm{Cd}_{3}\left(\mathrm{PO}_{4}\right)_{2} \quad{ }^{161}$. Incorporating bis(p-methylbenzyl)tin dichloride, dibenzyltin dichloride, and bis(p-chlorobenzyl)tin dichloride in plasticized polymer membranes Glazier and Arnold ${ }^{162}$ achieved a high level of selectivity for dibasic phosphate, hypothesized as the result of Sn-C hyperconjucation within the organotin compound. Chen et al. ${ }^{163}$ developed a FIA with cobalt wire ISE for potentiometric determination of phosphate $\left(31 \mu \mathrm{g} \mathrm{L} \mathrm{L}^{-1}\right.$ as $\mathrm{P}$ detection limit) . Marco et al. ${ }^{164}$ measured phosphate in waste waters and fertilizer samples using FIA with cobalt wire ISE,compensating the significant positive chloride interference by independently measuring chloride and using a chloride selectivity coefficient. A low-level detection of dibasic phosphate in wastewater samples ( $93 \mu \mathrm{g} \mathrm{L}^{-1}$ as $\mathrm{P}$ ) was achieved with a potentiometric cobalt-based screen-printing sensor fabricated by electroplating cobalt on the surface of a screen-printing electrode. The interferences of $\mathrm{pH}$, dissolved oxygen and other anions were examined ${ }^{165}$. A potentiometric detector for phosphate, resistant to turbidity and color interference, was developed by $\mathrm{Li}$ et al. ${ }^{166}$ using $\mathrm{Zn}^{2+}$ and $\mathrm{Cu}^{2+}$ complexes with 2,6-bis(bis(2-pyridylmethyl)aminomethyl)-4methylphenol as a receptor and o-mercaptophenol as an indicator.

Voltametric measurements of orthophosphate can be based on the reduction of the ammonium phosphomolybdate complex, inhibition of the redox reaction of potassium hexacyanoferrate or the inhibition of an enzyme-based glucose electrode. The process is inhibited by the oxygen atoms around the central phosphorus atom ${ }^{167}$. Fogg and Bsebsu proposed differential-pulse voltammetric 
determination of orthophosphate as molybdovanadophosphate at a glassy carbon electrode ${ }^{168}$ and by direct injection of phosphate into molybdate reagent ${ }^{169}$. Effective blank background elimination was possible with phosphate detection limit at $31 \mu \mathrm{g} \mathrm{L}^{-1}$ as P. A similar analytic procedure with a glassy-carbon electrode was used for the determination of phosphate, silicate, arsenate and germanate as $\beta$-heteropolymolybdates ${ }^{170}$. Recently, Barus et al. ${ }^{171}$ developed a phosphate sensor using square wave voltammetry. The system does not require addition of any reagents as they are formed in situ $\left(\mathrm{H}^{+}\right.$and $\left.\mathrm{MoO}_{4}{ }^{2-}\right)$. An optimized prototype electrochemical cell requires only 5 minutes of complexation time and has a concentration range between 15 and 125 $\mu \mathrm{g} \mathrm{L} \mathrm{L}^{-1}$ as $\mathrm{P}$.

Amperometric sensors measure the current produced by the target analyte at an electrode with a constant voltage. The reduction of ferrocene based macrocyclic synthetic receptor and the reduction of a phosphomolybdate complex were used as indirect amperometric measurements of the orthophosphate ${ }^{167}$. Simultaneous determination of phosphate and pyrophosphate by amperometric detection with immobilized enzyme reactors was proposed by Yao and Wasa ${ }^{172}$. The injected sample was split into two channels, with one channel going through the immobilized pyrophosphate reactor prior to a co-immobilized nucleoside-phosphorylase-xanthine oxidase reactor to obtain orthophosphate ( $31 \mu \mathrm{g} \mathrm{L} \mathrm{L}^{-1}$ as $\mathrm{P}$ detection limit). The second channel passed only through the latter reactor to obtain sum of orthophosphate and pyrophosphate $\left(62 \mu \mathrm{g} \mathrm{L}^{-1}\right.$ as $\mathrm{P}$ detection limit). The authors also used a novel bioamperometric flow-injection system with a 16way switching valve to simultaneously determine orthophosphate and 12 purine phosphate nucleotides. Samples were passed through two channels, acid phosphatase immobilized reactor and a delay coil to separate the peaks corresponding to the two sample portion injected ${ }^{173}$. Cheng et al. ${ }^{174}$ achieved lower detection limits with amperometric detection of phosphate $(0.3 \mu \mathrm{M})$. In 
this FIA system the adsorption of phosphate at the electrode was triggered by the activation of a barrel plated nickel electrode (Ni-BPE) in alkaline media, forming a $\mathrm{Ni}(\mathrm{OH})_{2} / \mathrm{NiO}(\mathrm{OH})$ film. Upon the addition of phosphate, the current suppression of the glucose signal at Ni-BPE was observed. The proposed analytical system is an electrochemical sensor that can detect phosphate with good sensitivity and selectivity. A novel phosphate and bicarbonate sensing method was proposed by Honda and Moromitzu ${ }^{175}$ by electrochemical oxidation, with a detecting electrode obtained from amorphous $\mathrm{RuO}_{2}-\mathrm{Ta}_{2} \mathrm{O}_{5}$ catalysts, formed on a titanium substrate.

\subsubsection{Nuclear Magnetic Resonance Methods}

Nuclear magnetic resonance is one of the most powerful non-invasive experimental techniques available for providing atomic and molecular structure information based on changes in resonance frequency of the intramolecular magnetic field around an atom in a molecule ${ }^{176}$. Dissolved phosphorus species such as orthophosphate, phosphonates, orthophosphate monoesters and di-esters were detected by ${ }^{31} \mathrm{P}-\mathrm{NMR}$ spectroscopy in lake and river water after ultrafiltration and reverse osmosis of 250-500 mL samples. Soluble unreactive phosphorus was analyzed also with the use of praseodymium ethylenediamine tetraacetate, alkaline bromination degradation procedures and adjustment of sample $\mathrm{pH}{ }^{177}$. Cade-Menun et al. ${ }^{178}$ developed a procedure for characterization of dissolved and particulate phosphorus species from river waters. Detected phosphorus species included orthophosphate, phosphonates, myo-inositol hexakisphosphate and orthophosphate di-esters. Further investigation is required due to possible alteration of the phosphorus forms when using lyophilization of the samples in NaOH-EDTA solutions. A thorough speciation of dissolved and particulate phosphorus forms in the eutrophic Lake Mendota (Wisconsin, USA) by ${ }^{31}$ P-NMR spectroscopy was performed by Read et al. ${ }^{179}$. The results showed that particulate phosphorus species contained phosphonate, orthophosphate 
mono- and di-ester, orthophosphate, pyrophosphate and polyphosphate. Dissolved phosphorus contained all particulate phosphorus forms with orthophosphate being the dominant species. Biochemical regression analysis of the results provided insight into mechanisms of phosphorus dynamics. Similar ${ }^{31}$ P-NMR study of the dissolved and particulate phosphorus species in an eutrophic lake was done in the shallow Lake Taihu, China ${ }^{180} \cdot \mathrm{D}_{2} \mathrm{O}$ was added into the supernatant to reach $10 \%$ proportion required for signal lock prior to the analysis. The ${ }^{31} \mathrm{P}-\mathrm{NMR}$ spectra were measures at $161.84 \mathrm{MHz}$ on an Agilent AV400 spectrometer, with orthophosphate and phosphate monoesters as the dominant phosphorus species in both fractions. While phosphonate was detected in dissolved fraction, pyrophosphate was mainly found in the particulate phosphorus fraction. At this time there is no NMR standard method for phosphorus species analysis. Chemical shifts of phosphorus species are affected by $\mathrm{pH}$ and salt concentrations, a challenge for data reproducibility ${ }^{181}$. More than 50 phosphorus compounds were analyzed under standardized conditions in order to establish a P-compounds library for easier repeatability of the experiments and ${ }^{31}$ P-NMR identification of the compounds ${ }^{181}$. Forms and lability of phosphorus species in algae and aquatic macrophytes were investigated by ${ }^{31} \mathrm{P}$ NMR coupled with enzymatic hydrolysis using alkaline phosphatase ${ }^{182}$. Eleven phosphorus species were identified in the mono- and di-ester region as well as orthophosphate, pyrophosphate and phosphonates.

\subsubsection{Conclusions}

As a direct result of nutrient control policies introduced by many countries, there is a decline in total phosphorus loadings in natural waters, with more than $50 \%$ reduction of TP observed in Lake Erie since $1967^{183}$. Similar decreases in TP were reported in a long-term study of Boreal lakes in Sweden ${ }^{184}$. However, algal blooms are still occurring, and the climate changes may 
influence the frequency of these events. As the composition of the nutrient pool impacts the harmful algal blooms ${ }^{185}$, phosphorus speciation methods with trace and ultra-trace level detection limits will be required. Currently, FIA spectrophotometric methods are the major analytical technique of choice in the environmental analysis of orthophosphate and total phosphorus. The electrochemical methods support remote sensing with real time results access, but some still require improvements in detection limits to match current environmental levels of phosphate in surface waters.. Most of the developed methods are analyzing orthophosphate and total phosphorus. There is a need for developing new methods able to measure organic phosphate species. ${ }^{31} \mathrm{P}$ NMR was capable of analyzing classes of P-species, however there is a lack of methods capable of analyzing specific phosphate compounds. Although not a very popular technique yet, the IC-ESI-MS instrumentation provide the required low-level detections and a possibility to analyze simultaneously a large number of specific phosphorus species. Compared to other analytical methods IC-ESI-MS provides high sensitivity and selectivity required for analysis of both inorganic and organic phosphate species in surface water matrices at various levels. Increasing availability and decreasing cost of instrumentation will support development of highly selective and sensitive analytical methodologies for phosphorus speciation. 


\section{CHAPTER 3}

\section{Unbiased Measurement of Phosphate and Phosphorus Speciation in Surface Waters}

Chapter 3 was published as Packa, V.; Maedler, S.; Howell, T.; Bostan, V.; Diep, N.; Tooley, R.; Furdui, V. I., Unbiased Measurement of Phosphate and Phosphorus Speciation in Surface Waters. Environmental Science \& Technology 2018.

DOI: $10.1021 /$ acs.est. 8 b05089 


\subsection{Abstract}

Trace-level phosphate analysis and phosphorus speciation in surface water remained challenging due to adsorption and phosphate uptake by microorganisms. In this study a two-dimensional ion chromatography separation coupled to electrospray ionization high-resolution mass spectrometry (2D-IC-ESI-MS) allowed isotope dilution quantitation of phosphate with simultaneous analysis of eleven phosphate-containing metabolites and two inorganic condensed phosphates. Samples were collected from Lake St. Clair, Lake Ontario and Georgian Bay (ON, Canada). Comparative experiments showed lower phosphate results for samples not immediately spiked and for external calibration quantitation. Field spiking with ${ }^{18} \mathrm{O}$-labeled phosphate combined with isotope dilution quantitation allows measurement of the phosphate levels existent at the collection time instead of the phosphate concentrations remaining in the samples at the analysis time. This is a significant advantage against the traditional colorimetric and ion chromatographic (IC) analysis methods, which are unable to compensate for the adsorption loss occurring in standards and samples, especially when phosphate is present at levels below $20 \mu \mathrm{g} \mathrm{L}^{-1}$ as $\mathrm{P}\left(61 \mu \mathrm{g} \mathrm{L}^{-1}\right.$ as $\left.\mathrm{PO}_{4}{ }^{3-}\right)$. Two phosphate-containing metabolites, adenosine 5'-monophosphate (AMP) and D-glucose 6phosphate (Glucose-P), were detected in a subset of samples collected from Lake St. Clair, with no statistically significant correlation between them and the simultaneously measured phosphate. Directly bioavailable P (phosphate), indirectly bioavailable P (phosphatase-hydrolyzed P) and non-bioavailable $\mathrm{P}$ (non-hydrolizable $\mathrm{P}$ ) fractions were quantified by measuring phosphate, phosphate after phosphatase addition and total phosphorus. The proposed 2D-IC-ESI-MS method developed for a QExactive MS instrument with field spiking of the internal standard provides accurate phosphate results and eliminates quantitation errors caused by phosphate adsorption. This 
setup allows simultaneous collection of targeted and non-targeted analysis data and thus the detection of trace polar organic phosphorus metabolites as well.

\subsection{Introduction}

\subsubsection{Phosphorus Species in Surface Waters}

Phosphate ions $\left(\mathrm{H}_{2} \mathrm{PO}_{4}^{-}, \mathrm{HPO}_{4}{ }^{2-}, \mathrm{PO}_{4}^{-3-}\right)$ are a directly bioavailable phosphorus $(\mathrm{P})$ source for biota, including algae. Concentrations of phosphate ions in surface water are relatively low compared to other macronutrients and as such, represent the limiting factor for primary production in freshwater lakes ${ }^{186,187}$. Other condensed inorganic phosphate and organic phosphate-containing metabolites (P metabolites) can also be present in surface waters ${ }^{76}$. Species of dissolved inorganic $\mathrm{P}$ in natural waters include condensed linear polyphosphates, metaphosphates (cyclic phosphates) and ultraphosphates (branched cyclic structures) ${ }^{76}$. Phosphate containing species can be produced by biological activity and also introduced into natural waters by anthropogenic activities ${ }^{186}$. Phosphorus from the inorganic condensed P species is not directly bioavailable to algae $\mathrm{e}^{92}$, while the organic phosphate-containing species such as sugar phosphates, glycerophosphates, polynucleotides and phospholipids can be released from decomposed cells and utilized by phytoplankton after phosphatase-catalyzed mineralization ${ }^{14}$. Phosphatase thus promotes the release of directly bioavailable P from metabolites, contributing to the $\mathrm{P}$ recycling dynamics in surface waters ${ }^{78,188}$. Alkaline phosphatases are membrane-bound glycoproteins that catalyze the hydrolysis of $\mathrm{P}$ metabolites into phosphate and the organic moieties at alkaline $\mathrm{pH}^{189}$. Phosphatases are also involved in other metabolic processes such as transport of substances across membranes and synthesis of new organic phosphates (transphosphorylation) ${ }^{190}$. Phosphatases can be essential for phosphate regeneration and 
planktonic nutrition in lakes ${ }^{188}$. Lake water can contain alkaline phosphatases, while acid phosphatases play a role in the internal cell metabolism of algae ${ }^{188}$. Steiner hypothesized in 1938 the release of enzymes in surface waters from plankton after observing the conversion of organic phosphate compounds into inorganic phosphate in solvent-lysed plankton suspensions ${ }^{191}$. Huang et al. studied phosphatase-mediated hydrolysis mechanisms by alkaline and acid phosphatase using nuclear magnetic resonance (NMR) ${ }^{78}$. Organic phosphate esters are involved in biochemical reactions as energy carriers, coenzymes or as intermediates. They are also involved in photosynthesis, carbohydrate metabolism, lipid metabolism, the nitrogen cycle and in other biochemical reactions involving energy transfer ${ }^{192}$. Monitoring the directly bioavailable phosphate and the indirectly bioavailable phosphate species released by phytoplankton can provide important information to the algal bloom research.

\subsubsection{Analysis of Phosphorus Species in Surface Waters}

Phosphate remains a widely measured parameter in environmental samples and the spectrophotometric parameter measured known as soluble reactive phosphate or soluble reactive phosphorus (SRP), with the values being presented either as phosphate or phosphorus ${ }^{100,193,194 .}$ In the classic spectrophotometric or colorimetric approach, phosphate is quantified after forming an antimony-phospho-molybdate complex (peak absorption at $880 \mathrm{~nm}$ ) under acidic conditions (e.g. ascorbic acid) ${ }^{100,193,194}$. The SRP parameter represents the sum of phosphate directly bioavailable to algae ${ }^{92}$ (present in surface water at neutral $\mathrm{pH}$ as $\mathrm{H}_{2} \mathrm{PO}_{4}^{-}$and $\mathrm{HPO}_{4}{ }^{2-}$ at approximately 1:1 ratio) and non-directly bioavailable phosphate (released from condensed phosphates under acidic conditions required for the antimony-phospho-molybdate complex formation) ${ }^{195-198}$. Current environmental standard methods recommend the spectrophotometric method for samples with SRP concentrations higher than $10 \mu \mathrm{g} \mathrm{L}^{-1}$ as $\mathrm{P}^{100,193,194}$. 
In oligotrophic natural waters, phosphate is often present at concentrations below $1 \mu \mathrm{g} \mathrm{L}^{-1}$ as $\mathrm{P}$, requiring more sensitive analysis techniques for accurate quantification. Speciation of phosphorus compounds has been demonstrated by NMR ${ }^{177,179,180}$, inductively-coupled plasma mass spectrometry (ICP-MS) ${ }^{143-145}$ and ion chromatography electrospray ionization mass spectrometry (IC-ESI-MS) ${ }^{123,124}$. However, phosphorus speciation in surface waters remains problematic due to sub-ppb concentration levels of many P-containing compounds. High concentrations of sulfate and other anions such as chloride and nitrate can affect the separation and interfere with the phosphate measurement by $\mathrm{IC}^{199-201}$. In natural waters the sulfate concentration is in general over 1000 times higher than the phosphate concentration ${ }^{202}$, limiting the anion column capacity for the separation of phosphate, as well as causing signal suppression during the ESI process ${ }^{203}$. To increase the analytical signal, some off-line procedures have been described, including the removal of high concentrations of chloride and sulfate with functionalized ion exchange resins (e.g. $\left.\mathrm{Ag}^{+}, \mathrm{Ba}^{2+}\right){ }^{204}$ and phosphate pre-concentration with formation of molybdophosphoric $\operatorname{acid}^{205}$. On-line approaches for elimination of interferences include microdialysis ${ }^{206}$, column-switching systems ${ }^{207}$ and solid-phase microextraction ${ }^{208}$.

\subsubsection{Phosphate Adsorption on Glassware}

Sorption of the phosphate to surfaces of various types of containers and sediment particles has been well documented ${ }^{95,209-214}$. Losses of up to $20 \%$ of phosphate on acid-washed glass were reported by Ryden et $\mathrm{al}^{210}$. Studies with radioactive ${ }^{32} \mathrm{P}$ and colorimetry showed $8 \%$ phosphate adsorption on borosilicate glass from a $7.5 \mu \mathrm{g} \mathrm{L}^{-1}$ as $\mathrm{P}$ solution after 3 days and as much as $31 \%$ on polyethylene containers ${ }^{211}$. Lambert et al..$^{95}$ measured changes in concentration of the phosphorus fractions in water stored at $4{ }^{\circ} \mathrm{C}$ and found within 4 hours of sampling $28-45 \%$ decreases in total dissolved phosphorus, $33-40 \%$ in total reactive phosphorus and $36-58 \%$ in SRP 
concentrations. The adsorption of phosphate on porous glass and silica $\left(\mathrm{SiO}_{2}\right)$ surfaces is mainly driven by electrostatic forces and strongly influenced by the ionic strength in the solution and temperature. At $\mathrm{pH} 2$ the adsorption was five times higher on porous glass than on silica, either due to increased interaction between the potential fields from opposite walls in micropores or the $\mathrm{Al}_{2} \mathrm{O}_{3}$ content ${ }^{212}$. The adsorption is $\mathrm{pH}$, solution composition and species dependent, with phosphate being less adsorbed than condensed phosphates, but stronger than the organic phosphate species $^{215}$.

In this study, an IC-ESI-MS instrument was chosen for the simultaneous analysis of phosphate, pyrophosphate, triphosphate and 11 organic P metabolites in surface water samples collected from Lake St. Clair, Lake Ontario and Georgian Bay (ON, Canada). This is the first report of using an isotope dilution quantitation for phosphate measurement in surface water samples. The field spiking with ${ }^{18} \mathrm{O}$-labeled internal standard (IS) allowed measurement of phosphate existent at collection time, contrasting with existent analytical methods for phosphate analysis that cannot easily compensate for the sample-dependent losses of phosphate by adsorption and biological uptake. Total phosphorus measurements and phosphate reanalysis after phosphatase addition were also used to measure directly bioavailable, indirectly bioavailable (phosphatasehydrolyzed) and non-bioavailable (non-hydrolizable) P fractions. A set of organic P metabolites were monitored and identified for the first time in surface water samples.

\subsection{Experimental Section}

\subsubsection{Standards and chemicals}

Certified phosphate standards were purchased from Inorganic Ventures (Christiansburg, VA, USA) and NSI Lab Solutions (Raleigh, USA). The isotope-labeled phosphate, $\mathrm{H}_{3} \mathrm{P}^{18} \mathrm{O}_{4}$ (IS), the 
P metabolite salts, adenosine 5'-monophosphate (AMP) disodium salt, adenosine 5'-diphosphate (ADP) sodium salt, adenosine 5'- triphosphate (ATP) disodium salt hydrate, D-fructose 6phosphate (Fructose-P) disodium salt hydrate, D-fructose 1,6-biphosphate (Fructose-Bi-P) trisodium salt hydrate, D-glucose 6-phosphate (Glucose-P) sodium salt, $\alpha$-D-glucose 1,6biphosphate (Glucose-Bi-P) potassium salt hydrate, $\alpha$-D-galactose 1-phosphate (Galactose-P) dipotassium salt pentahydrate, D-ribulose 5-phosphate (Ribulose-P) disodium salt, D-ribulose 1,5 - bisphosphate (Ribulose-Bis-P) sodium salt hydrate, D-erythrose 4-phosphate (Erythrose-P) sodium salt, D-(-)-3-phosphoglyceric acid (PGA) disodium salt, uridine 5'- diphosphoglucose (UDP-Glucose) disodium salt hydrate and acid phosphatase (from potato) were purchased from Millipore Sigma (Oakville, ON, Canada). Calibration standards were obtained by mixing these $11 \mathrm{P}$ metabolites, containing each analyte at at $0 \mathrm{nM}$ (Blank), $1 \mathrm{nM}, 10 \mathrm{nM}, 100 \mathrm{nM}$ and 1000 $\mathrm{nM}$ concentrations. A second set of calibration standards was prepared for phosphate at $0 \mu \mathrm{g} \mathrm{L}^{-1}$ (Blank), $1 \mu \mathrm{g} \mathrm{L}^{-1}, 2 \mu \mathrm{g} \mathrm{L}^{-1}, 5 \mu \mathrm{g} \mathrm{L}^{-1}, 10 \mu \mathrm{g} \mathrm{L}^{-1}, 20 \mu \mathrm{g} \mathrm{L}^{-1}$ and $50 \mu \mathrm{g} \mathrm{L}^{-1}$ as $\mathrm{P}$, with each standard containing ${ }^{18} \mathrm{O}-$ labeled phosphate (IS) at $20 \mu \mathrm{g} \mathrm{L}^{-1}$ as P. HPLC grade acetonitrile, sodium pyrophosphate tetrabasic and sodium triphosphate pentabasic were purchased from Millipore Sigma (Oakville, ON, Canada). A third set of calibration standards was prepared containing pyrophosphate and triphosphate, each at $0 \mathrm{nM}$ (Blank), $1 \mathrm{nM}, 10 \mathrm{nM}, 100 \mathrm{nM}$ and $1000 \mathrm{nM}$.

\subsubsection{Field Sampling and Storage Containers}

Surface water samples were collected from coastline of Georgian Bay (including embayments and river mouths, N=51, October 2016), and Lake St. Clair (including river sites, N=1030, May November 2017). A third set was collected from Lake Ontario adjacent to the cities of Toronto and Mississauga and included sites at the mouths of urban rivers, waste water treatment plant outfalls, in close proximity to the shoreline and in the oligotrophic offshore of the lake during the 
late spring and early summer of $2018(\mathrm{~N}=203)$. The water was either pumped by the flowthrough system located on the sampling vessel or collected using a Van Dorn beta sampler. After filtering through a Millex-HV syringe driven $0.45 \mu \mathrm{m}$ Durapore filter (Fisher Scientific Company, Ottawa, ON, Canada) at each sampling station, $10 \mathrm{~mL}$ of each sample was immediately pipetted in a $15 \mathrm{~mL}$ high density polyethylene (HDPE) amber screw-cap bottle (Thermo Scientific, Mississauga, ON, Canada) and spiked with $100 \mu \mathrm{L}$ of IS at $2 \mathrm{mg} \mathrm{L}^{-1}$ as $\mathrm{P}$, achieving the same final IS concentration as in the calibration standards $\left(20 \mu \mathrm{g} \mathrm{L}^{-1}\right.$ as $\left.\mathrm{P}\right)$. Samples were stored at $5 \pm 3{ }^{\circ} \mathrm{C}$ until analysis. Additional types of containers were used for a stability study including $15 \mathrm{~mL}$ Wheaton polypropylene and $60 \mathrm{~mL}$ Nalgene HDPE (Fisher Scientific Company, Ottawa, ON, Canada), $120 \mathrm{~mL}$ borosilicate glass (pre-cleaned with $30 \%$ $\mathrm{H}_{2} \mathrm{SO}_{4}$ ) and $20 \mathrm{~mL}$ borosilicate glass (System Plus, Baden, ON, Canada).

\subsubsection{Instrumental Analysis}

Analysis was performed on an ICS $5000^{+}$ion chromatograph (IC) coupled to a QExactive Mass Spectrometer (Thermo Scientific, Mississauga, ON). The IC has a dual configuration with one autosampler, two pumps, two auxiliary pumps, two eluent generators, two ion suppressors (AERS-500 2mm) and two conductivity detectors. The ESI source has a HESI-II probe housed in the IonMax Source. The MS was operated in negative mode, full scan $(\mathrm{m} / \mathrm{z} 50-700)$ at 70000 resolution with $3 \times 10^{6} \mathrm{AGC}$ target and $200 \mathrm{~ms}$ maximum injection time. The IC eluent was combined with $0.2 \mathrm{~mL} \mathrm{~min}^{-1}$ acetonitrile prior to entering the MS source, using the following ESI settings: $-3.5 \mathrm{kV}$ spray voltage, 12 for sheath gas , 3 for auxiliary gas , $320^{\circ} \mathrm{C}$ capillary temperature, 90 for S-lens RF and $200{ }^{\circ} \mathrm{C}$ auxiliary gas temperature. XCalibur software version 3.0 was used for data acquisition and TraceFinder version 3.2 (Thermo Scientific, Mississauga, ON) for quantitation. 


\subsubsection{Method A (IC-ESI-MS analysis)}

Separation was achieved at a flow rate of $0.3 \mathrm{~mL} \mathrm{~min}^{-1}$ with $100 \mu \mathrm{L}$ injection volume, AG24 Dionex guard column (2 mm I.D. x $50 \mathrm{~mm}$ ) and AS24 Dionex separation column (2 mm I.D. $\mathrm{x}$ $250 \mathrm{~mm}$ ). The 30 min gradient separation was started at $20 \mathrm{mM} \mathrm{OH}^{-}$for the first $6.5 \mathrm{~min}$, increased to $45 \mathrm{mM}$ during the next $3 \mathrm{~min}$, then further increased to $60 \mathrm{mM}$ for the next 6 min, followed by a decrease to $20 \mathrm{mM}$ during the last $5 \mathrm{~min}$ of the run. The highest calibration standard for phosphate was $20 \mu \mathrm{g} \mathrm{L}^{-1}$ as $\mathrm{P}, \mathrm{R}^{2} \geq 0.9995$ and method detection limit (MDL) of $0.15 \mu \mathrm{g} \mathrm{L} \mathrm{L}^{-1}$ as $\mathrm{P}$.

\subsubsection{Method B (2D-IC-ESI-MS analysis)}

The two-dimensional chromatographic separation was used to divert to waste sulfate and prior

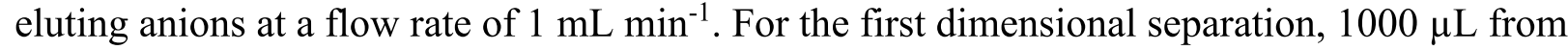
each sample was injected onto an AG18 Dionex guard column (4 mm I.D. x $50 \mathrm{~mm}$ ) and AS18 Dionex analytical separation column (4 mm I.D. x $250 \mathrm{~mm}$ ). The 45 min gradient separation on the first column was obtained by increasing from 30 to $60 \mathrm{mM} \mathrm{OH}^{-}$during the first 8 minutes. The hydroxide concentration remained constant for the following $32 \mathrm{~min}$, then decreased to 30 $\mathrm{mM}$ during the last $5 \mathrm{~min}$ of the run. The second dimensional separation was achieved with AS24 separation column ( $2 \mathrm{~mm}$ I.D. $x 250 \mathrm{~mm}$ ) at a $0.3 \mathrm{~mL} \mathrm{~min}^{-1}$ flow rate. The $45 \mathrm{~min}$ gradient separation on the second dimension started with $60 \mathrm{mM} \mathrm{OH}^{-}$for $15 \mathrm{~min}$, decreased to $30 \mathrm{mM}$ for the following $5 \mathrm{~min}$, then increased to $60 \mathrm{mM}$ for the remaining $25 \mathrm{~min}$ (see Supporting Information (SI)). During the first $7 \mathrm{~min}$ of the run, eluent passing through the first column dimension and subsequent suppressor was diverted to waste in order to remove sulfate and other earlier eluting anions. During the following $13 \mathrm{~min}$, the anions present in the eluent 
were loaded onto an IonPac TAC-ULP1 Anion Concentrator (5 mm I.D. x $23 \mathrm{~mm}$ ). $20 \mathrm{~min}$ after the initial sample injection, the anions were eluted from the concentrator column and separated by the second-dimension column during the last $25 \mathrm{~min}$ of the run. The column switching time window was determined from the retention times by injecting a standard solution containing phosphate and sulfate at $100 \mu \mathrm{g} \mathrm{L}{ }^{-1}$. The highest calibration phosphate standard was $50 \mu \mathrm{g} \mathrm{L}^{-1}$ as $\mathrm{P}, \mathrm{R}^{2} \geq 0.9995$ and MDL of $0.06 \mu \mathrm{g} \mathrm{L} \mathrm{L}^{-1}$ as $\mathrm{P}$.

\subsection{Results and Discussions}

\subsubsection{Field Spiking and Isotope Dilution Measurement of Phosphate}

The phosphate analysis was initially done with Method A by IC-ESI-MS for 51 samples collected from Georgian Bay. A subset of 11 samples were collected as replicates, with the first set spiked immediately with IS, the second set spiked after $24 \mathrm{~h}$ and the third set spiked after 120 h. All samples contained trace-level phosphate between 0.7 and $1.8 \mu \mathrm{g} \mathrm{L}^{-1}$ as $\mathrm{P}$. The set of samples immediately spiked were considered as free of any phosphate loss by adsorption and their concentrations were compared with the phosphate concentrations measured in the delayedspike sets to identify the adsorbed fractions. Samples spiked after $24 \mathrm{~h}$ had phosphate results lower by an average of $30.2 \%$, while the samples spiked after $120 \mathrm{~h}$ had lower results by an average of $52.6 \%$ (Figure 3.1). Similarly, another test on 8 samples identified an average phosphate loss of $33.7 \%$ for the set spiked after $48 \mathrm{~h}$ from collection time (Figure S1, SI). Studies of phosphate adsorption on porous glass and $\mathrm{SiO}_{2}$ showed that adsorption equilibrium was established within 10 minutes, regardless of the initial phosphate concentration in the solution ${ }^{216}$. Increases in ionic strength of the adsorption medium resulted in suppression of the phosphate uptake, suggesting a significant contribution of electrostatic forces in the adsorption process. 


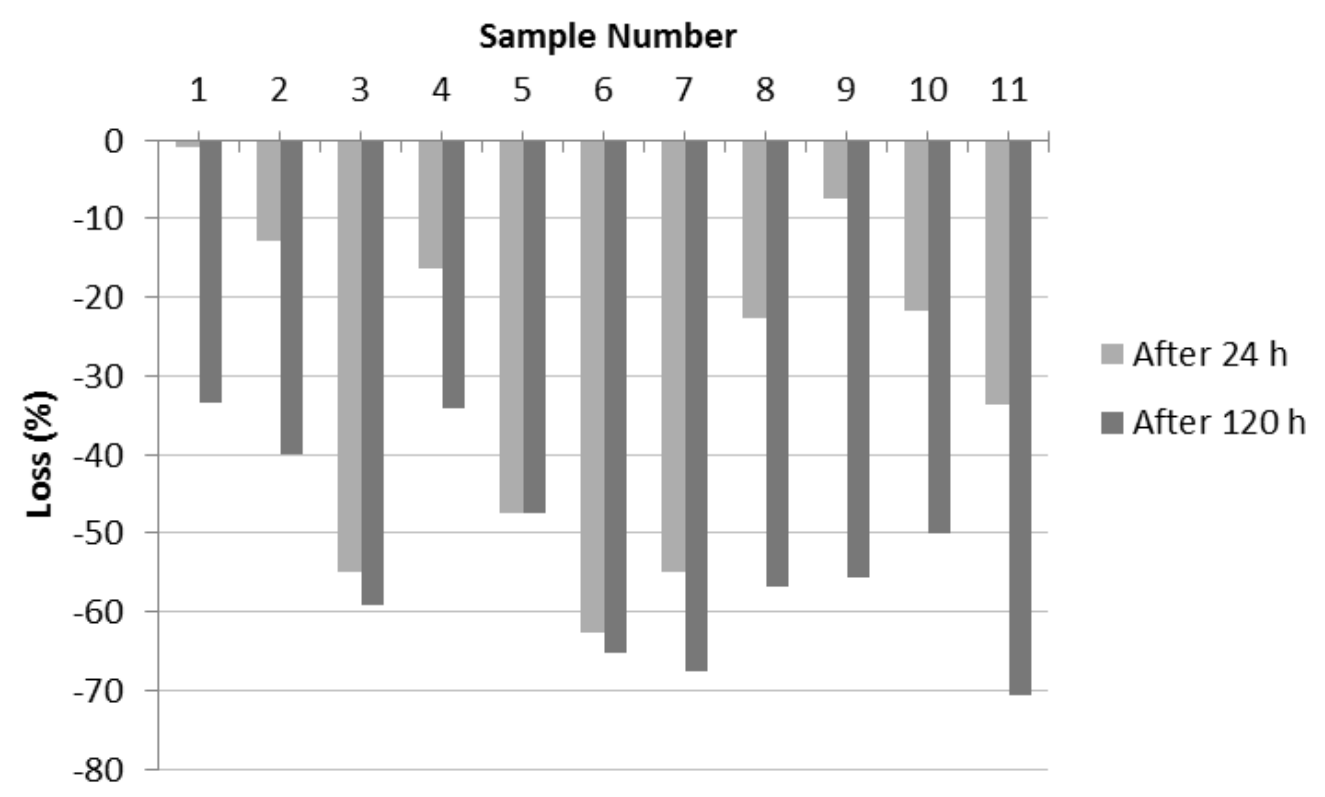

Figure 3.1. Phosphate loss (\%) calculated from single measured concentrations in samples spiked $24 \mathrm{~h}$ and $120 \mathrm{~h}$ after collection. The phosphate content in samples spiked immediately after collection varied between 0.7 and $1.8 \mu \mathrm{g} \mathrm{\textrm {L } ^ { - 1 }}$ as $\mathrm{P}$.

Similarly, Lambert et al. ${ }^{95}$ showed a fast phosphate adsorption with concentration decreases within 4 hours from sampling for total dissolved phosphate (TDP) (28-45\%), total reactive phosphate (TRP) (33-40\%) and soluble reactive phosphate (SRP) (36-58\%). The results from this study confirmed previous findings about adsorption loss and suggest that accurate phosphate results (e.g. phosphate, SRP, TRP) can be obtained only if samples are analyzed immediately onsite. For most studies such an approach would be difficult. US EPA method ${ }^{122}$ for IC analysis allows holding times of up to $48 \mathrm{~h}$ for phosphate, but based on this study a $30 \%$ average phosphate loss was observed within $24 \mathrm{~h}$. The percentage absorption loss of phosphate is a function of the total phosphate concentration in a sample, with appreciably lower absorption losses from high concentration samples (e.g. urban river) than lower concentration samples (e.g. oligotrophic lake). 
The influence of different sample containers on the adsorption of phosphate has been previously studied $^{211}$. To investigate the container influence on phosphate stability during storage, a larger volume $(500 \mathrm{~mL})$ surface water sample was filtered in a PET container, spiked immediately with concentrated IS ( $1 \%$ of the sample volume), then subsamples were transferred in five different plastic and glass containers, then stored at $4{ }^{\circ} \mathrm{C}$ for up to 21 days. The results showed that the phosphate concentrations could be accurately quantified with isotope dilution for up to 21 days of storage. Overall the phosphate concentration measured by isotope dilution in HDPE and glass containers remained stable within $\pm 5 \%$ of the initial values (Figure 3.2a). The variation is within the uncertainty of the phosphate results of $\pm 6.3 \%$ at $20 \mu \mathrm{g} \mathrm{L} \mathrm{L}^{-1}$ as $\mathrm{P}$. Ignoring the internal standard values and quantifying phosphate peaks by external calibration, the phosphate results obtained were $32.5 \%$ lower for a sample containing $20 \mu \mathrm{g} / \mathrm{L}$ phosphate as $\mathrm{P}$, with the results within $\pm 15 \%$ of the initial values. The third set of values (Day 21) is not available for the $15 \mathrm{~mL}$ containers due to insufficient sample volume. The relatively high charge density of the phosphate ions at neutral $\mathrm{pH}$ explains their higher adsorption affinity compared to the other major ions present in natural water. The adsorption rate and mechanism depends on the type of the container material, pre-treatment of sample containers, surface area to volume ratio, matrix composition and concentration of phosphate in the sample ${ }^{211}$. Sample containers such as plastic and glass have positively charged ion-exchange sites, which become neutral after sorption of anions from the aqueous sample ${ }^{217}$. The isotope dilution quantitation with field-spiked IS allowed measurement of the initial phosphate concentration even after 21 days, because the ratio between phosphate and IS $\left({ }^{18} \mathrm{O}\right.$-labeled phosphate) remained the same in the sample even after phosphate adsorption occurred, as both phosphate and IS are adsorbed at the same rate. The phosphate concentration dependence of the IS adsorption was observed also in the calibration standards 
(Figure $3.2 \mathrm{~b}$ ). A $40-50 \%$ loss of the internal standard was observed when spiked at $20 \mu \mathrm{g} \mathrm{L}^{-1}$ in calibration standard solutions containing less than $10 \mu \mathrm{g} \mathrm{L}^{-1}$ phosphate. A much smaller loss $(0-$ $20 \%$ ) was observed in solutions containing $20-50 \mathrm{ug} / \mathrm{L}$ phosphate. The age of the solutions and also instrumental factors can influence the measured peak areas of the phosphate and the internal standard, with the good linearity of the calibration curve achieved by the new isotope dilution (internal standard) method as a proof of compensating for all these factors.

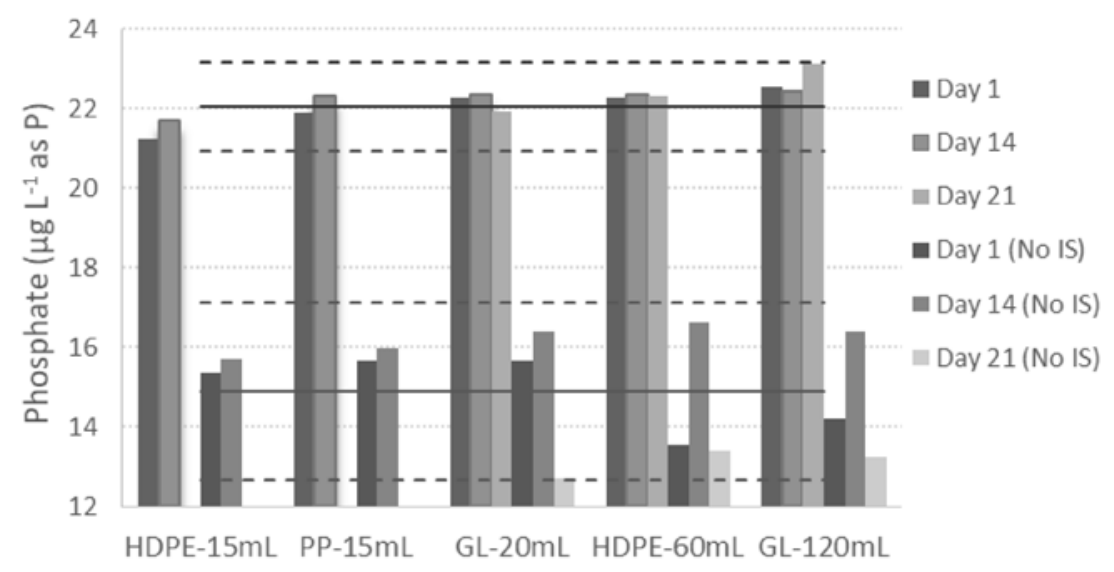

a

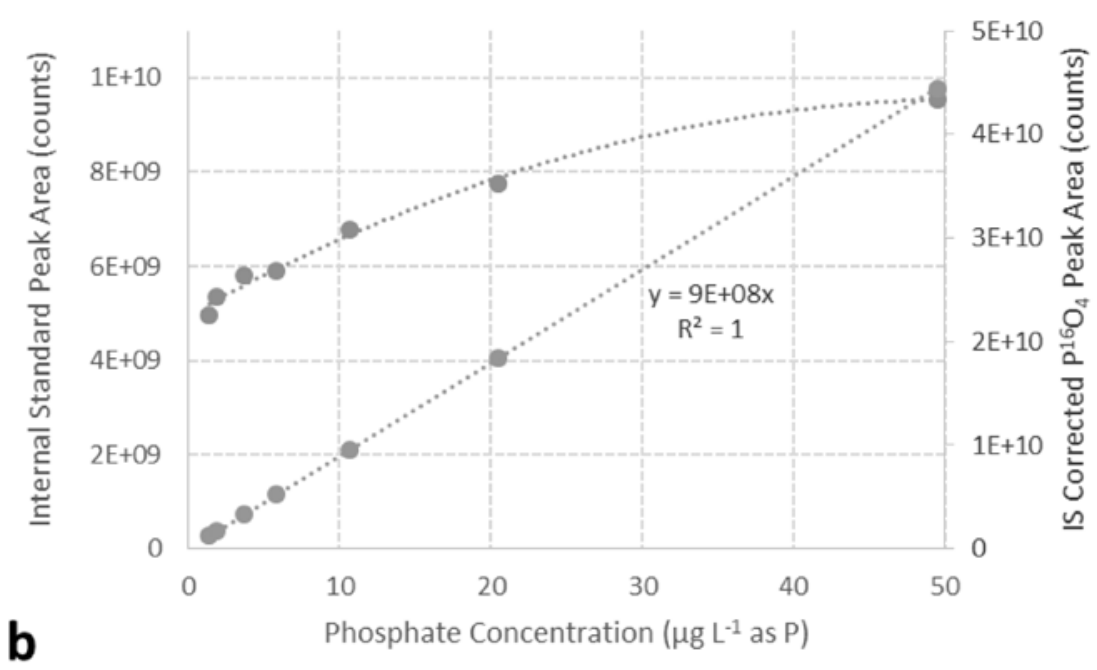


Figure 3.2. a) Phosphate concentration in a surface water sample (initial values mean of $22.05 \pm 1.10 \mu \mathrm{g} \mathrm{L}^{-1}$ ) remained stable (within $\pm 5 \%$ ) when stored for up to 21 days in high density polyethylene (HDPE, 15 and $60 \mathrm{~mL}$ capacity), polypropylene (PP, $15 \mathrm{~mL}$ ) and borosilicate glass (GL, 20 and $120 \mathrm{~mL}$ ). External calibration (set of smaller bars in brown shades) provided 32.5\% lower results from Day 0 (initial values mean of $14.89 \pm 2.23 \mu \mathrm{g} \mathrm{L}{ }^{-1}$ ), with values varying within $\pm 15 \%$. b) Variation of the internal standard peak area with phosphate concentration $\left(\mathrm{H}_{2} \mathrm{P}^{16} \mathrm{O}_{4}{ }^{-}\right)$in the calibration standard set and a linear calibration curve obtained with $\mathrm{H}_{2} \mathrm{P}^{18} \mathrm{O}_{4}{ }^{-}$as internal standard.

\subsubsection{Isotope Dilution, External Calibration and Colorimetric Measurement of Phosphate}

A set of 217 samples collected from Lake St. Clair in 2017 were quantified by isotope dilution with Method B, a 2D-IC-ESI-MS method. The same set of samples was quantified by external calibration and also analyzed by a classical colorimetric method (see SI) to demonstrate the advantage of using the isotope dilution quantification against the traditional phosphate measurements. The external calibration quantitation is similar to a simple IC separation with conductivity detection, although the mass spectrometric detection without internal standard is more prone to be affected by matrix effects. As observed in Figure 3.3a, the phosphate results obtained by both, external calibration and colorimetric analysis (SRP) were lower than the isotope dilution results for the entire concentration range, with the exception of some colorimetric results for samples containing less than $3 \mu \mathrm{g} \mathrm{L}-1$ as P. The two data sets, external calibration by 2D-IC-ESI-MS and colorimetric SRP, present similar bias trends (see Figure 3.3b). A positive bias is present for the SRP results below $3 \mu \mathrm{g} \mathrm{L}-1$ as $\mathrm{P}$, as previously presented by Hudson et al. ${ }^{75}$. This is caused by the adsorption of phosphate from the unpreserved calibration standards used by colorimetry and quantification errors inherent to the low end of the 
calibration curve, resulting in an overestimation of the data at low phosphate levels, even in the presence of the adsorption loss in the samples. The same trend is confirmed when the phosphate results were quantified by external calibration using the 2D-IC-ESI-MS generated data. For phosphate levels above $3 \mu \mathrm{g} \mathrm{L} \mathrm{L}^{-1}$ as $\mathrm{P}$, a negative bias was observed in comparison to the isotope dilution approach for both, external calibration and colorimetry data, most likely caused by phosphate adsorption in the analyzed samples. The relatively lower external calibration results in comparison to the SRP results could be the result of matrix effects during the mass spectrometric analysis, but are more likely the consequence of increased phosphate concentrations by colorimetry caused by acid-driven hydrolysis of condensed inorganic and organic phosphates ${ }^{197,}$ 218,219 as well as release of phosphate from colloids ${ }^{120,220-222}$ during the analysis. These results demonstrate the significant advantage of the isotope dilution quantitation against the classical colorimetric and IC methods, being able to provide the phosphate results at the time of collection instead of the phosphate concentrations present in samples at the analysis time. 

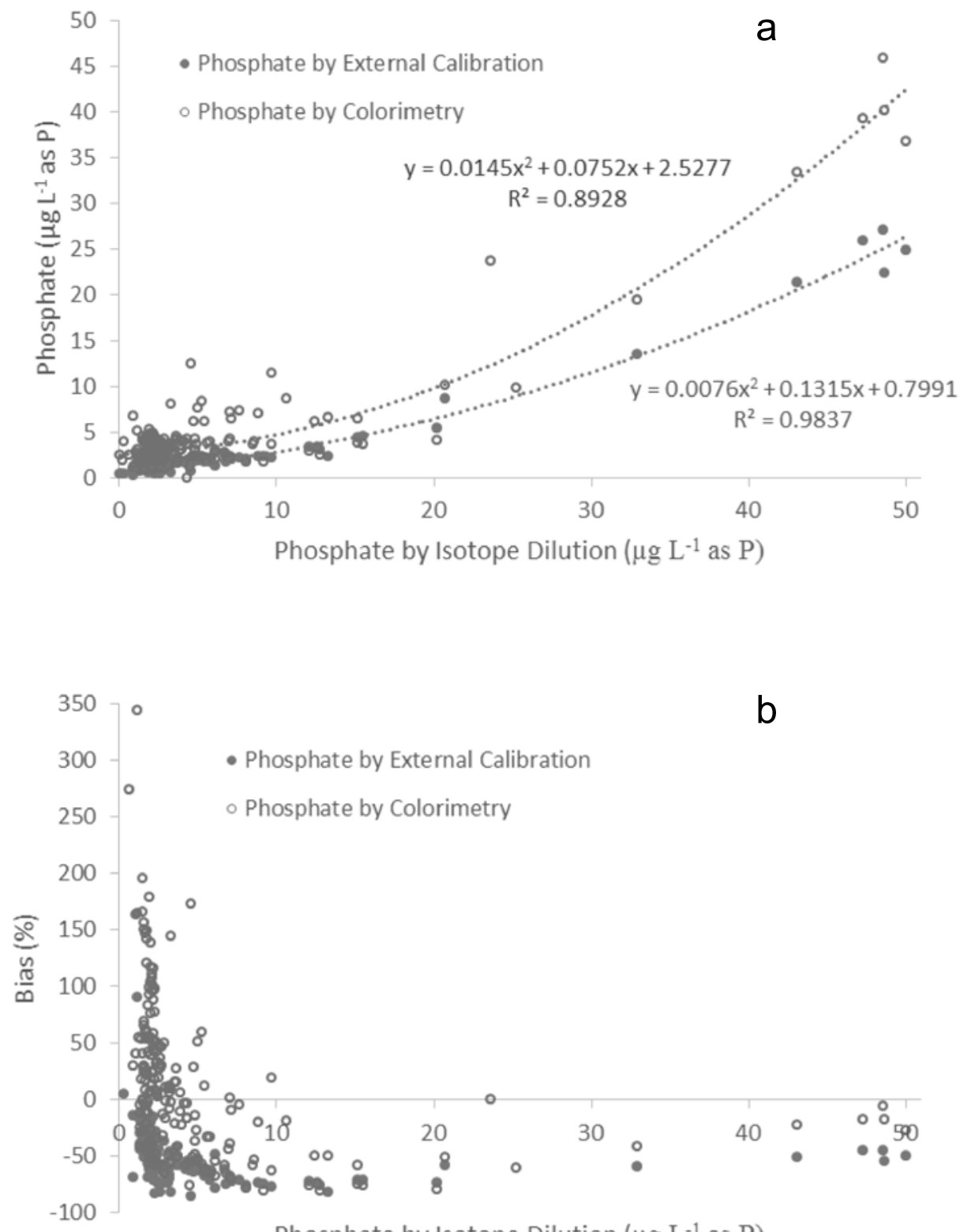

Figure 3.3. Comparison of results (a) and bias (b) for Method B (2D-IC-ESI-MS) phosphate results $(\mathrm{N}=217$, collected from Lake St. Clair in July 2017) obtained by isotope dilution quantification with the results obtained by Method B with external calibration (filled markers) and the colorimetrically measured phosphate, SRP (empty markers). 
The two-dimensional IC configuration allowed removal of sulfate from the sample matrix prior to the chromatographic separation, eliminating signal suppression and column overloading issues. A "heart-cutting" column-switching setup was used to redirect the sulfate and less retained anions to waste and the rest of the anions to the concentrator column. The 2D-IC-ESIMS method allowed lowering the MDL to $0.06 \mu \mathrm{g} \mathrm{L}^{-1}$ as $\mathrm{P}$ from $0.15 \mu \mathrm{g} \mathrm{L}^{-1}$ as $\mathrm{P}$ achieved with Method A (IC-ESI-MS). The procedure did not require sample pre-treatment or sample dilution, minimizing also the risks for phosphate loss and contamination.

Samples collected from Georgian Bay $(2016, \mathrm{~N}=51)$ had lower levels of sulfate and were analyzed by Method A (IC-ESI-MS), while samples collected from Lake St. Clair (2017, $\mathrm{N}=1030$ ) were analyzed by Method B (2D-IC-ESI-MS). All samples were spiked in the field with IS. In Georgian Bay samples, the phosphate concentrations were between 0.20 and $1.87 \mu \mathrm{g}$ $\mathrm{L}^{-1}$ as $\mathrm{P}$ with sulfate present at 5-10 $\mathrm{mg} \mathrm{L}^{-1}$ (see SI for sulfate analysis method). The phosphate concentration in Lake St. Clair samples ranged between 0.06 (MDL) and $50 \mu \mathrm{g} \mathrm{L}^{-1}$ as $\mathrm{P}$, with sulfate present at $15-30 \mathrm{mg} \mathrm{L}^{-1}$. The typical environmental sample concentration ranges can be observed in Figure 3.4, for samples collected from the Georgian Bay, Lake St. Clair and Lake Ontario. The Lake St. Clair data set includes inshore, open-water near-shore and tributaries (Thames River and Detroit River). The Lake Ontario samples were collected adjacent to the cities of Toronto and Mississauga, including sites at the mouths of urban rivers, waste water treatment plant outfalls, in close proximity to the shoreline and in the oligotrophic offshore of the lake. Phosphate from surface water samples provides an indication of the immediately bioavailable $\mathrm{P}$ to algae and can be a predictor of the algal growth ${ }^{223-226}$. The ability of the new isotope dilution method to accurately and reliably measure phosphate across a broad range of concentrations is useful for environmental monitoring programs, particularly those in the Great 
Lakes with a variety of habitats including the oligotrophic offshore waters and the nutrient-rich river mouth areas and tributaries waters.

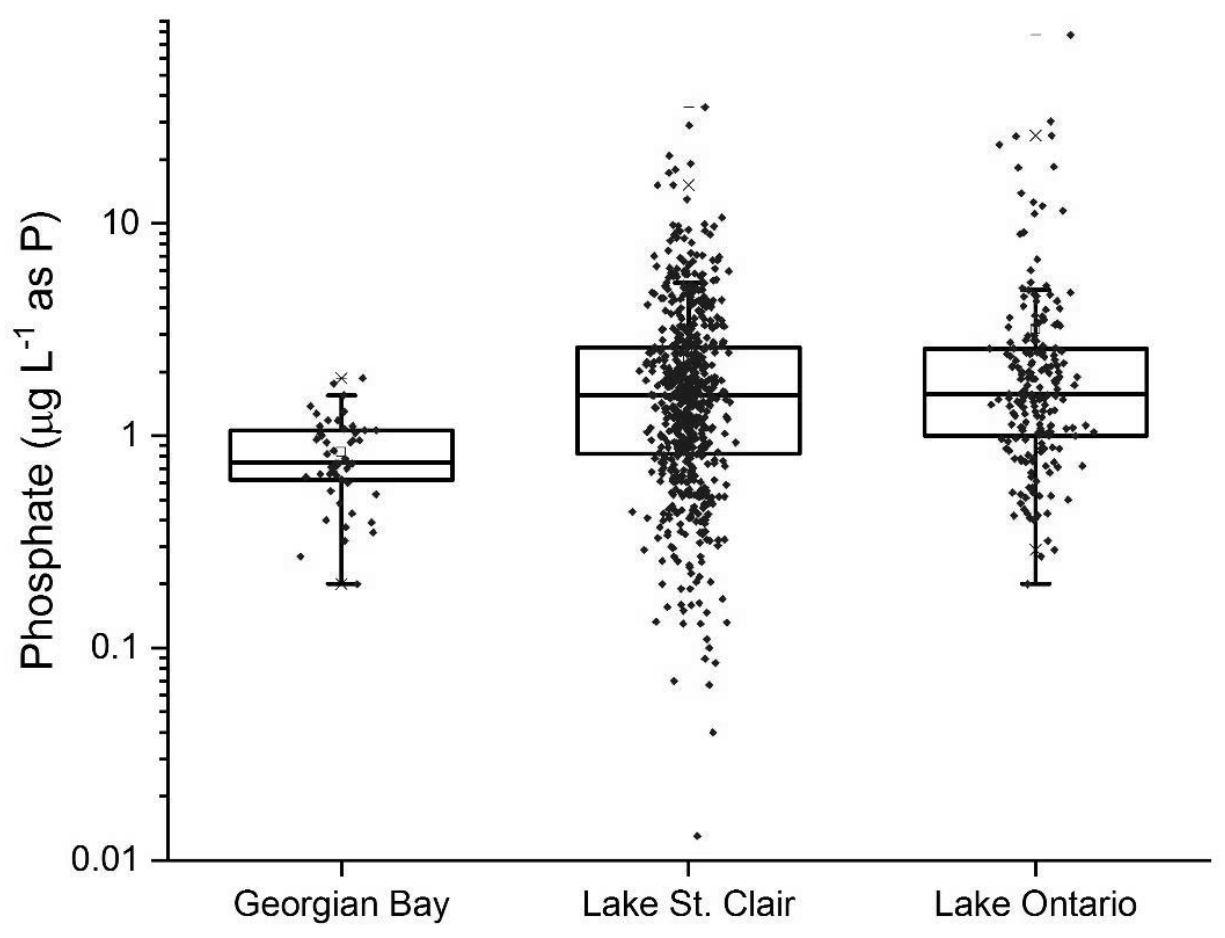

Figure 3.4. Summary of the phosphate concentrations measured in samples collected from: Georgian Bay (N=51), , Lake St. Clair ( $=1030)$ and Lake Ontario $(\mathrm{N}=203)$. Samples from Georgian Bay were analyzed by Method A (IC-ESI-MS), while the rest of the samples were analyzed by Method B (2D-IC-ESI-MS). 


\subsubsection{Comparison of Phosphate and Total Phosphorus Results}

The most common phosphate analysis method in water samples currently used in analytical laboratories is the spectrophotometric approach modified from the original Murphy and Riley method using ascorbic acid as a reducing agent, adapted to colorimetric and continuous flow analyzers ${ }^{101}$. The methods 15681 from the International Organization for Standardization (ISO) ${ }^{193,194}$ that determine the phosphate by flow injection analysis (FIA) and continuous flow analysis (CFA) are suitable for SRP determination and total phosphorus (oxidative-acid digestion prior to analysis) at concentrations between 10 and $1000 \mu \mathrm{g} \mathrm{L}^{-1}$ as P. Colorimetric methods, especially for SRP determination, can be affected by spectrophotometric interferences (e.g. arsenates, silicates, fluoride, nitrite and suspended particles) ${ }^{193}$. A set of 217 samples with SRP concentrations between 0.2 and $45.9 \mu \mathrm{g} \mathrm{L}-1$ as $\mathrm{P}$ and total phosphorus concentrations between 0.3 and 57.6 $\mu \mathrm{g} \mathrm{L}^{-1}$ as P was used to compare isotope dilution measured phosphate (2D-IC-ESI-MS) with colorimetric SRP and total phosphorus results (Figure 3.5). This set of samples was collected in August 2017 from Lake St. Clair (ON, Canada). The advantage of using an IC-ESIMS instrument with isotope dilution instead of a spectrophotometric analyzer is the avoidance of interferences. Graphical representation of the results showed a linear relationship between the 2D-IC-ESI-MS method and the colorimetric total phosphorus results (Pearson correlation coefficient $\mathrm{R}^{2}=0.9049$ ), although such a relationship is not expected because the degree to which biological utilization draws down phosphate or breakdown introduces phosphate in the lake water at the sample collection time is variable and not dependent on TP. Colorimetric SRP and total phosphorus results do not show a linear relationship and no correlation below total phosphorus concentrations of $10 \mu \mathrm{g} \mathrm{L} \mathrm{L}^{-1} \mathrm{P}$. Such non-linear relationship between SRP and TP may be caused also by uncompensated phosphate adsorption losses during storage of samples 
and calibration standards. The field-spiking of the samples with IS and also at calibration standard preparation allowed to compensate for phosphate losses and allowed reliable measurement of the phosphate existent in the samples at the collection time.

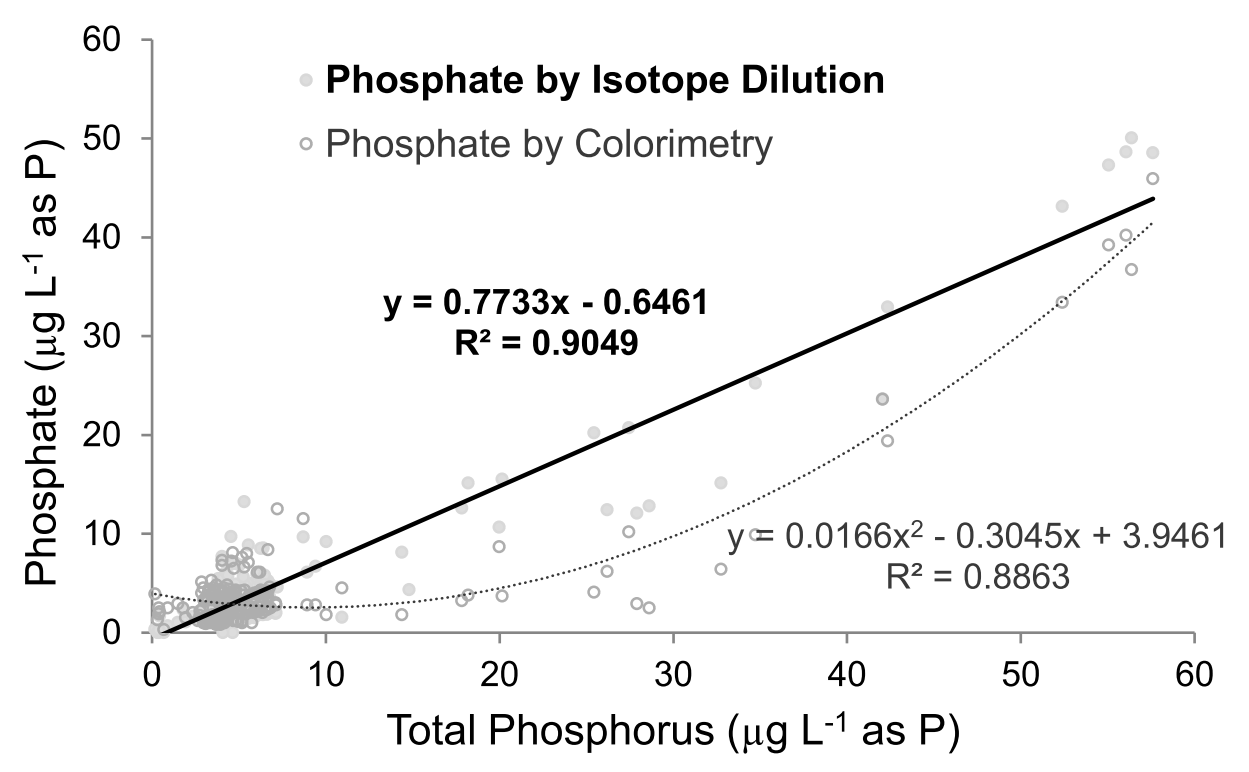

Figure 3.5. Correlations between phosphate concentrations measured by 2D-IC-ESI-MS (Method B) and colorimetry with total phosphorus $(\mathrm{N}=217)$.

\subsubsection{Bioavailable Phosphorus Measured in Surface Waters}

Isotope dilution measurement with Method B (2D-IC-ESI-MS) was used to measure the bioavailable phosphorus, which is the sum of free dissolved phosphate and phosphatasehydrolyzed phosphate expressed as P units. A set of 10 surface water samples with phosphate concentrations between 0.25 and $0.77 \mu \mathrm{g} \mathrm{L}^{-1}$ as $\mathrm{P}$ was selected from the samples collected in late spring from Lake St. Clair. After analyzing for phosphate, the remaining $7 \mathrm{~mL}$ samples were spiked with $100 \mu \mathrm{L}$ of acid phosphatase $\left(0.5\right.$ unit $\mathrm{mL}^{-1}$ enzyme concentration in the sample) and reanalyzed for phosphate after $8 \mathrm{~h}$. The new measured phosphate values, expressed as $\mu \mathrm{g} \mathrm{L}^{-1} \mathrm{P}$, represent the total bioavailable phosphorus. For a complete phosphorus mass balance, the total 
phosphorus was also measured. The total bioavailable $\mathrm{P}$ results are presented in Figure 3.6 as the two bottom bar fractions representing the directly bioavailable $\mathrm{P}$ (phosphate) and indirectly bioavailable P (phosphatase-hydrolyzed phosphate). The top bar fraction represents the difference between the total and total bioavailable phosphorus (non-hydrolyzable P). For the studied samples, the total bioavailable $\mathrm{P}$ averaged at $36 \%(\mathrm{RSD}=12 \%)$, three times higher than the directly bioavailable $\mathrm{P}$ (phosphate, $12 \%, \mathrm{RSD}=4 \%$ ). The selected samples had relatively low P levels with total bioavailable P concentrations between 1.14 and $2.55 \mu \mathrm{g} \mathrm{L}^{-1}$ as $\mathrm{P}$.

Dissolved organic $\mathrm{P}$ species, the precursors of the indirectly bioavailable $\mathrm{P}$ (phosphatase-released P), typically represent $15-30 \%$ of the total phosphorus in lake water, but may increase up to $90 \%$ of the total soluble phosphorus during periods of high biological activity ${ }^{86,87}$. The majority of the samples analyzed in this study had $60-80 \% \mathrm{P}$ as phosphate, with the remaining $20-40 \%$ represented by P from the dissolved organic species and from non-hydrolyzable by phosphatase $\mathrm{P}$ species (non-bioavailable).

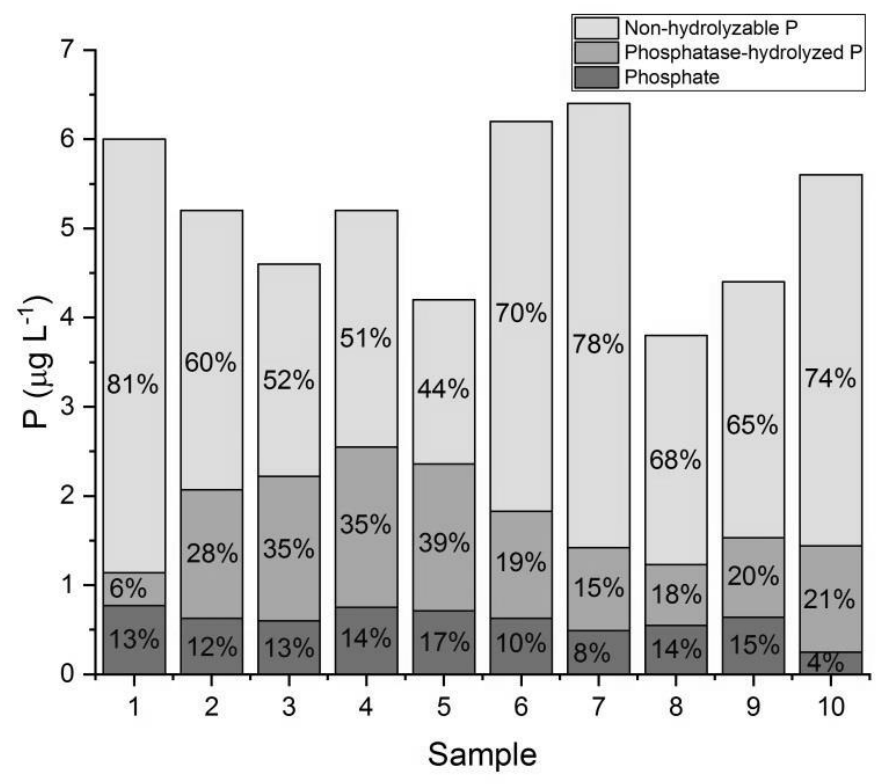


Figure 3.6. Concentrations of phosphate (bottom values), phosphatase-hydrolyzed phosphate (middle values) and non-hydrolyzable phosphorus (top values), all expressed as $\mu \mathrm{g} \mathrm{L}^{-1} \mathrm{P}$ with the percentage values representing the fraction from total $\mathrm{P}$ for each sample. The phosphatasehydrolyzed $\mathrm{P}$ values were calculated as difference between the total bioavailable phosphorus and phosphate concentrations.

The phosphate released from phosphate monoesters in the presence of the alkaline phosphatase incorporates one oxygen atom from water ${ }^{227}$. The result of these enzyme-specific isotopic fractionations at one of the four $\mathrm{O}$ sites in $\mathrm{PO}_{4}$ is an increase in the oxygen isotope ratio of phosphate $\left({ }^{18} \mathrm{O} /{ }^{16} \mathrm{O}\right), \delta^{18} \mathrm{O}_{\mathrm{P}}$, with $82.6 \%$ as the highest $\delta^{18} \mathrm{O}_{\mathrm{P}}$ observed in microbial cell cultures at $25{ }^{\circ} \mathrm{C}^{228}$. Measured $\delta^{18} \mathrm{O}_{\mathrm{P}}$ in Lake Erie ranged from $+10 \%$ to $+17 \%{ }^{229}$. Under these conditions the net calculated effect on the IS $\left(\mathrm{P}^{18} \mathrm{O}_{4}\right)$ is negligible. Stability of the oxygen labeled phosphate in aqueous solution (Figure S4) was also confirmed by Melby et al. ${ }^{230}$ with a slow half-life period of 100 months.

\subsubsection{Analysis of Phosphate-Containing Metabolites and Condensed Phosphate Species}

Various organic phosphorus species (P metabolites) resulting from biological processes may be present in surface waters. P metabolites contain bound phosphate and include species like sugar phosphates, nucleoside phosphates, phytic acid (inositol polyphosphate), phytate and degradation

products. Anthropogenic organophosphorus species such as alkyl substituted phosphonic acids, alkylphosphates, bisphosphonates used as herbicides, pesticides and detergents can also be present in surface waters ${ }^{82}$. Other P metabolites were previously quantified by NMR in surface water as functional group classes, measuring phosphate monoesters, phosphate diesters and polyphosphates, mainly in the particulate fraction and only in one lake water sample in the 
dissolved fraction ${ }^{179}$. Method B (2D-IC-ESI-MS) was used for inorganic and organic phosphate speciation in surface water samples, quantitating eleven anionic P metabolites (AMP, Fructose-P, Fructose-Bi-P, Glucose-P, Glucose-Bi-P, Galactose-P, Ribulose-P, Ribulose-Bis-P, Erythrose-P, PGA and UDP-Glucose) and two inorganic condensed phosphate species (pyrophosphate and triphosphate). A direct comparison between method B (2D-IC-ESI-MS) and NMR is not possible as NMR measures functional group classes of compounds, while new method measures specific metabolites. Separation method B was not optimized to chromatographically separate adenosine diphosphate (ADP) from adenosine triphosphate (ATP) and their in-source fragmentation prevented their separate quantitation. A chromatogram obtained from a $10 \mathrm{nM}$ standard containing the $11 \mathrm{P}$ metabolites is shown in Figure 3.7. Even if the chromatographic separation was not achieved for all species, the high-resolution mass spectrometer used can easily distinguish between these particular species.

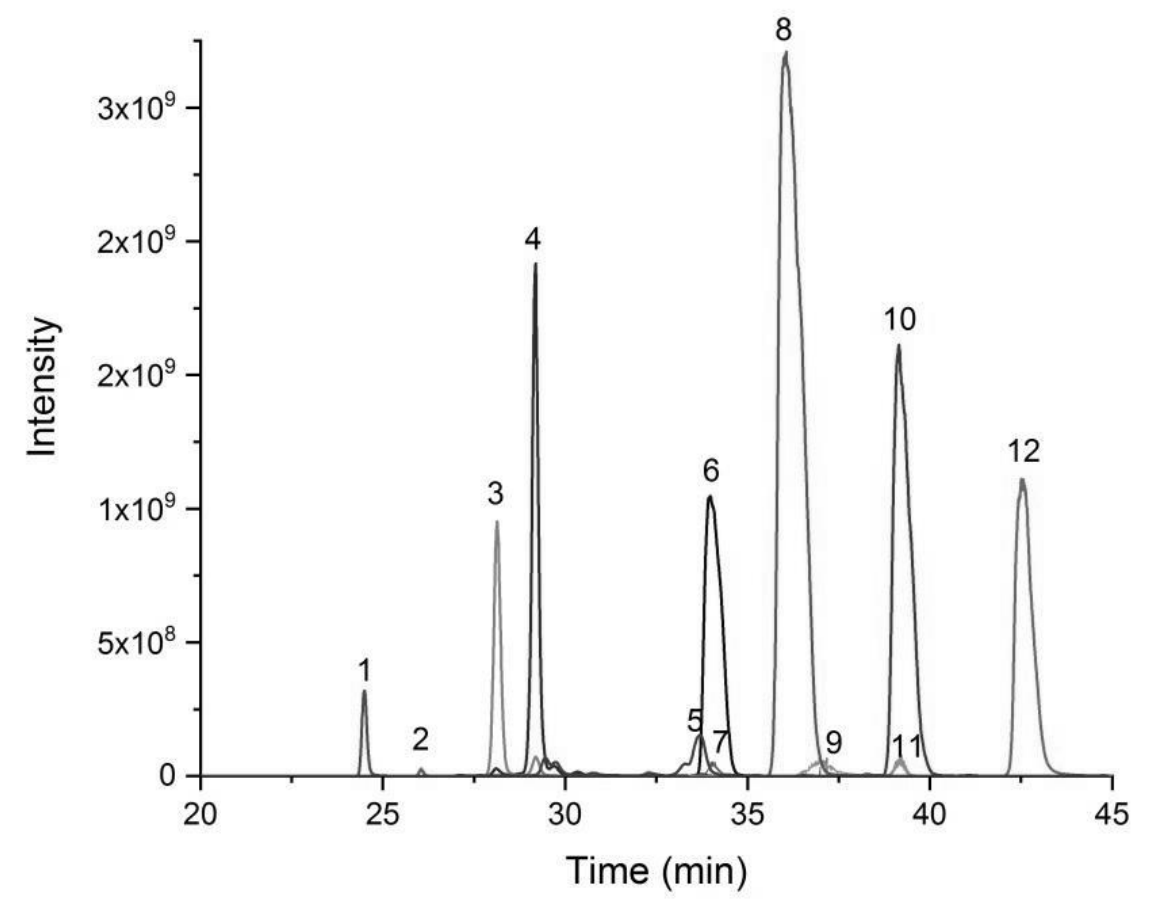


Figure 3.7. Chromatograms of phosphate and phosphate-containing metabolites in a standard mixture analyzed by Method B (2D-IC-ESI-MS) : phosphate (1), Galactose-P (2), Glucose-P (3), Fructose-P (4), Ribulose-P(5), PGA (6), Erythrose-P (7), Glucose-Bi-P (8), AMP (9), FructoseBi-P (10), Ribulose-Bis-P (11) and UDP-Glucose (12).

From the analyzed Lake St. Clair samples, only two P metabolites, AMP and Glucose-P, were present $(\mathrm{N}=70)$ at levels higher than the method detection limit (between $\mathrm{MDL}=0.1 \mathrm{nM}$ and 2 nM) (Figure 3.8), with traces of Glucose-Bi-P below MDL ( $<0.25 \mathrm{nM})$. For easy comparison the corresponding phosphate and TP concentrations were also included with log y axis required to observe the much lower P metabolite concentrations. The $11 \mathrm{P}$ metabolites were not identified in the Georgian Bay samples. While phosphate may be stronger adsorbed on solid surfaces than the organic phosphate species ${ }^{215}$, the current method cannot confirm if any loss of the P metabolites occurred during storage. However, the added IS was present at higher concentrations (20 $\left.\mu \mathrm{g} \mathrm{L}^{-1}\right)$ than the P metabolites and phosphate from the sample and the IS would be predominantly adsorbed during storage, minimizing the loss of P metabolites. 


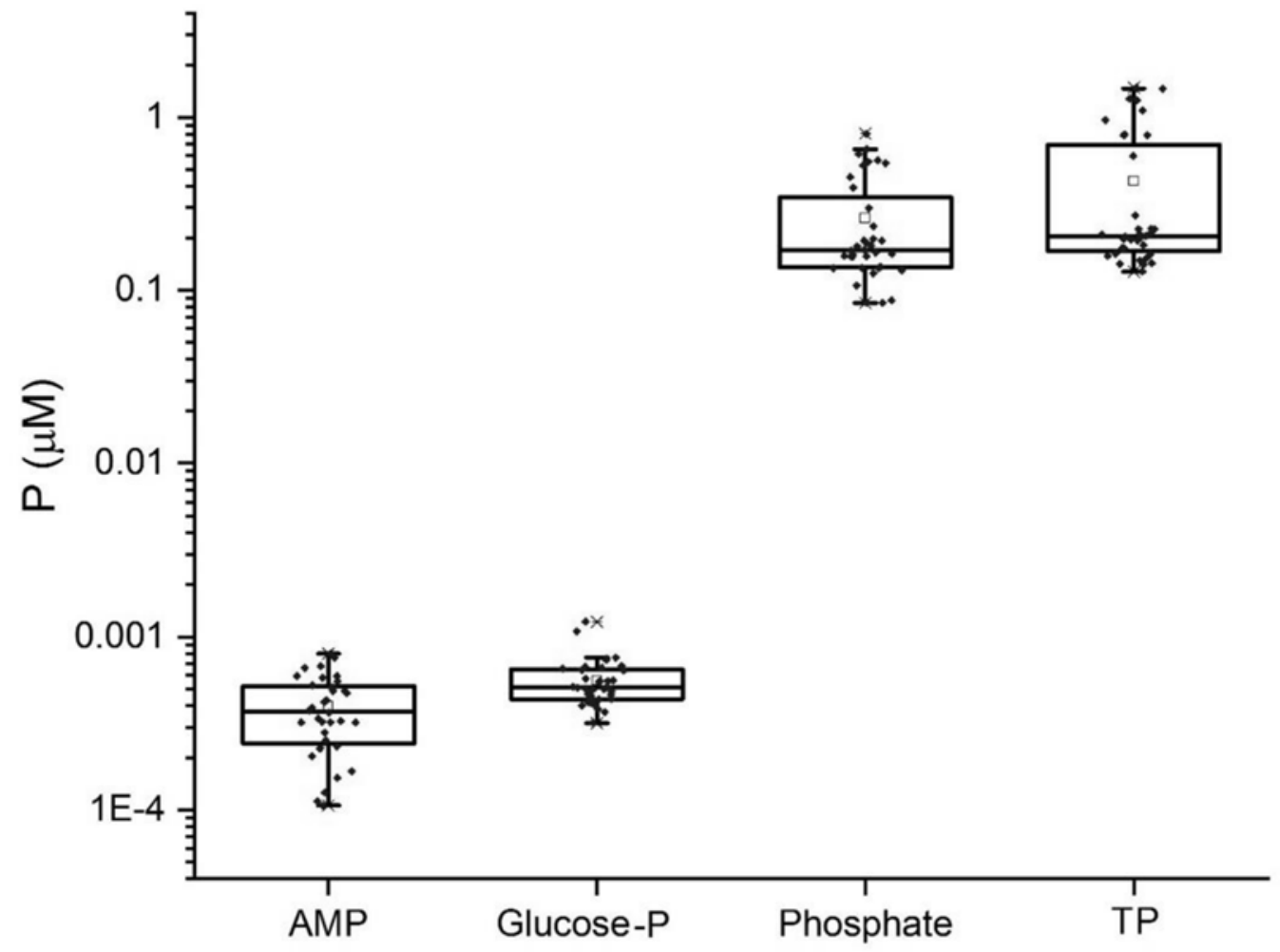

Figure 3.8. Concentration ranges of adenosine 5'-monophosphate (AMP) and D-glucose 6phosphate (Glucose-P) in surface water samples collected in late fall from Lake St. Clair ( $N=70)$ and analyzed by Method B (2D-IC-ESI-MS). Concentrations ranges of the phosphate and total phosphorus (TP) from the same samples.

The field-spiked isotope dilution measurement by IC-ESI-MS demonstrated its advantages for measuring unbiased trace levels of phosphate in surface water samples. Due to immediate field spiking the new proposed IC-ESI-MS method measures the phosphate concentration present at the collection time, instead of the concentration measured at the analysis time by the existent colorimetric and IC methods. Phosphate stability was observed for up to 21 days of storage, a significant increase from the 48 hours holding time, currently recommended by US EPA 300.1 
for phosphate measurement by $\mathrm{IC}^{122}$. In addition, the IC-ESI-MS method allowed quantitation of P species and precise measurement of total bioavailable phosphorus. By implementing a 2D IC separation in the analytical method, lower detection limits were obtained which allowed for reliable quantification of phosphate at trace and ultra-trace levels. The unbiased measurement of phosphate will allow to better estimate P loadings in surface waters. The 2D-IC-ESI-MS method developed on the QExactive MS instrument setup allows simultaneous collection of targeted and non-targeted data and thus the detection of trace polar organic phosphorus metabolites.

\subsubsection{Associated Content}

Additional information about analytical methods for colorimetric measurement of phosphate, total phosphorus, sulfate by IC, MDLs for P-containing metabolites, schematic of the 2D-IC configuration and phosphate loss (\%) in samples spiked $48 \mathrm{~h}$ after collection are included in the Supporting Information file.

\subsubsection{Acknowledgements}

Hany Eskander from the Ontario Ministry of the Environment, Conservation and Parks (OMECP) is thanked for the total phosphorus analysis of the samples. Shelly Chan and Carlos Jurado (OMECP) are thanked for the colorimetric analysis of phosphate. 


\section{CHAPTER 4}

Phosphorus speciation in Toronto Harbour and Rivers 


\subsection{Abstract}

Environmental phosphorus is commonly analyzed as soluble reactive phosphorus and total phosphorus based on colorimetric methods. Quantification and detection of other organic and inorganic phosphorus $(\mathrm{P})$ species in Lake Ontario and some of its tributaries is demonstrated using a two-dimensional ion-chromatography mass spectrometer system. In addition to dissolved phosphate, other P-metabolites such as pyrophosphate, adenosine 5'-monophosphate, glucose 6phosphate, $\alpha$-D-glucose 1,6-biphosphate and D-(-)-3-phosphoglyceric acid were detected and quantified and the results were used to compare the differences between lake and river samples. Multivariate statistical analysis was used to identify potential correlations across analytical data sets and analyze spatial differences in sample matrices.

\subsection{Introduction}

The decline in water quality of Lake Ontario waterfront ranging across nine watersheds can be attributed to the intensive urbanization including shoreline/stream channel alteration and land clearing. These activities have resulted in increased sewage and runoff entering local rivers and subsequently the lake causing increased concentrations of phosphorus and nitrogen-based compounds in Lake Ontario and its tributaries. Eutrophication and nuisance algal bloom due to nutrient enrichment caused by agricultural and urban activities pose a threat to an overall freshwater quality globally.

In surface waters phosphorus is mostly present as phosphate ion (Pi). Pi can precipitate in the presence of $\mathrm{Ca}^{2+}$ or $\mathrm{Fe}^{3+}$ and is upon biological activation involved in metabolic pathways of fish and algae, producing various phosphate containing metabolites (P-metabolites). Pyrophosphate (PPi) presence can result from anthropogenic uses or as a by-product from biota metabolic 
processes. While majority of the analyses are focused on Pi and total phosphorus (TP) measurements, PPi and other species measurements can provide valuable information in better understanding sources of increased phosphorus loadings and algal blooms, particularly the harmful algal blooms (HABs) $)^{17,226,231-234}$. Algae and aquatic macrophytes characterization studies by ${ }^{31}$ NMR showed that organic-P compounds accounted for up to $80 \%$ of TP. Organic P species identified in algal biomass extracts included P monoesters and P diesters ${ }^{235}$. In addition to directly bioavailable inorganic phosphate, pyrophosphate and up to $40 \%$ percent of the organic phosphate from decaying algal biomass can be hydrolyzed to inorganic phosphate and released to water column supporting further growth of aquatic organism and leading to algal blooms ${ }^{236 \text {, }}$ 237.

Adsorption on analytical containers and a subsequent loss of Pi when using colorimetric and other common analytical techniques have been reported. Lambert et al. ${ }^{95}$ confirmed that a fast Pi adsorption caused $28-45 \%$ decrease in total dissolved phosphate (TDP), $33-40 \%$ decrease in total phosphate (TP) and 36-58\% decrease in soluble reactive phosphate (SRP) within first 4 hours of sampling. Two-dimensional electrospray mass spectrometry (2D-ESI-MS) and was recently demonstrated as a reliable methodology for trace and ultra-trace measurements of Pi, mainly because the immediate field spiking with ${ }^{18} \mathrm{O}$-labelled phosphate allowed obtaining results unbiased by the inherent adsorption losses during storage and analysis ${ }^{238}$.

The most common multivariate statistical analysis method, the principal component analysis (PCA), has been widely used to evaluate natural environment and eutrophication ${ }^{239}$ and to classify water sources based on seasonal and spatial criteria. Previous studies showed that performing PCA can identify correlated patterns from a set of multiple analytes and eliminate redundant tracers or the ones with a poor contribution to total variance. Identification and 
assessment of pollution sources as well as seasonal and climatic sources of variations was also successfully achieved by the application of multivariate analysis to analytical datasets ${ }^{240-244}$.

The Toronto and Region Area of Concern (AOC) as identified by the International Joint Commission (IJC) in $1985^{245}$. has been impacted by industrialization and urbanization, being one of the 43 areas in the Great Lakes with badly impaired water quality and ecosystems. The six major watersheds draining into Lake Ontario from Toronto and Region AOC (Etobicoke Creek, Mimico Creek, the Humber River, the Don River, Highland Creek and the Rouge River) cover an area of 2000 square kilometers. They include $42 \mathrm{~km}$ of waterfront, shared by eleven municipal jurisdictions with over 4 million inhabitants ${ }^{245}$.

In this study samples from Lake Ontario (Inner Toronto Harbour area) and from the Lake Ontario tributaries (Humber River, Don River, Rogue River) and Highland Creek were collected during summer and fall months. Concentration of P-containing metabolites, PPi, Pi, TP, major ions, $\mathrm{pH}$, alkalinity and conductivity was analyzed and PCA was applied to test its applicability in source identification and better understanding of the spatial variability in water chemistry and risks associated with development of eutrophic conditions and algal blooms. The study was conducted to identify sources of phosphate and other P species.

\subsection{Study Area}

Water samples for analysis of phosphorus-containing compounds were collected from the nearshore and tributaries of Lake Ontario in the Laurentian Great Lakes within the City of Toronto, Canada (Fig 4.1). The lake samples were collected over six locations within Toronto Harbour, an embayment bordered by the heavily urbanized waterfront of city. This mesotrophic embayment, with a maximum depth of $14 \mathrm{~m}$, exchanges water with oligotrophic Lake Ontario by 
channels at the east and west extents of the harbour, respectively ${ }^{246}$. The harbour receives discharge from numerous storm and combined storm sewers outfalls and runoff from the Don River, one of the four tributaries examined here. In 1987, Toronto and Region was designated as one of 42 locations around the Great Lakes where environmental degradation have been adversely affecting the Great Lakes system. These locations are referred to as Areas of Concern (AOC). AOCs are required to implement a Remedial Action Plan (RAP) that improves the aquatic conditions in their area. Nutrient enrichment and eutrophication were identified as a water quality concern. The decline of water quality in the Toronto Harbour has occurred over 200 years of development in this large urban center bordering, however, there have been improvements in recent years ${ }^{40}$.

The study tributaries vary in size and extent to which urbanized lands makeup the drainage sheds of the rivers. The watershed of Hyland Creek, the smallest of the rivers, is approximately 102 $\mathrm{km}^{2}$ in extent and is fully urbanized falling almost entirely within the City of Toronto. There is a high proportion of paved, impermeable surfaces, such as roads, parking lots and roofs. Approximately $6 \%$ of the Highland Creek watershed is forested, making it the most extensively urbanized watershed in the Toronto region. The larger Don River with a drainage area of approximately $360 \mathrm{~km}^{2}$ stretching its headwaters on the Oak Ridges Moraine to the Keating Channel, where it empties into Toronto Harbour is also highly urbanized. With 1.4 million residents, the watershed is one of the most heavily urbanized in Canada. Despite the challenges associated with this urbanization, the landscape of the Don River is slowly being regenerated and revitalized ${ }^{247}$. The river receives treated wastewater from the Lower Don Wastewater Treatment Plant. 


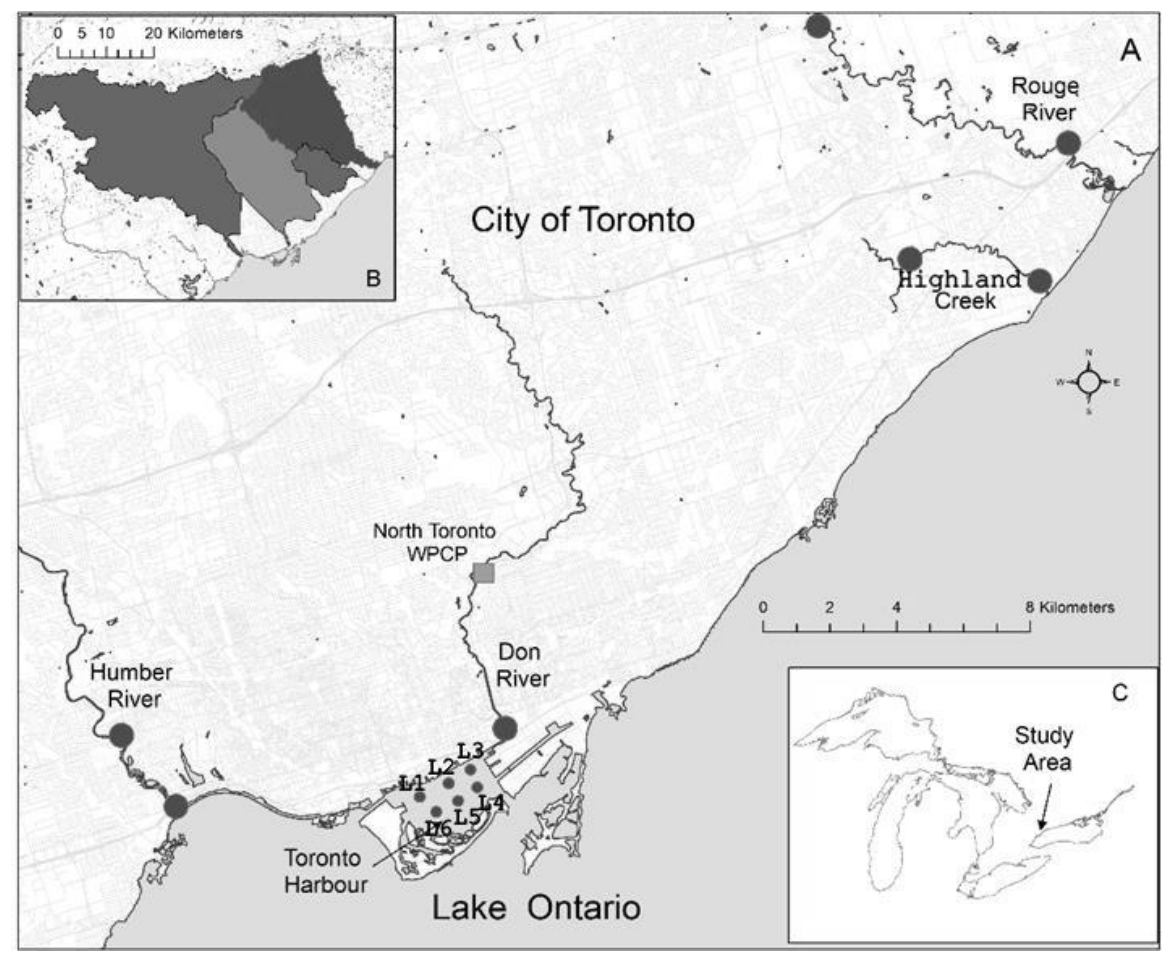

Figure 4.1 Sampling locations in Lake Ontario, Don River, Humber River, Rouge River and Highland Creek.

The Humber River and Rouge River are river systems with appreciable proportions of the drainage area made up of urbanized land, particularly in the reaches where water samples were collected for this study, however, there are also large portions of the drainage area with more mixed character, notably upstream areas with lands used for farming, lower density rural development and parklands. The Humber River, the largest river in study has a watershed of 911 $\mathrm{km}^{2}$ with $>850,000$ residents. The Rouge River watershed with an area $336 \mathrm{~km}^{2}$ is $40 \%$ rural, $35 \%$ urban, $24 \%$ a mix of forest, wetlands and meadows. The southern third of the watershed is protected by Rouge National Urban Park, the middle and western sections of the watershed are urban with sparse natural cover outside of the park. The northeastern areas of the watershed are primarily rural and agricultural with small towns and villages ${ }^{247}$. 


\subsection{Experimental Section}

4.4.1 Standards and chemicals. Certified Pi standards were purchased from Inorganic Ventures (Christiansburg, VA, USA) and NSI Lab Solutions (Raleigh, USA) and the isotope-labeled phosphate, $\mathrm{H}_{3} \mathrm{P}^{18} \mathrm{O}_{4}$ (IS), HPLC grade acetonitrile, alkaline phosphatase, sodium pyrophosphate tetrabasic and sodium triphosphate pentabasic were purchased from Millipore Sigma (Oakville, ON, Canada). Also 11 P-metabolites were purchased from Millipore Sigma as salt species: adenosine 5'-monophosphate (AMP) disodium salt, adenosine 5'-diphosphate (ADP) sodium salt, adenosine 5'- triphosphate (ATP) disodium salt hydrate, D-fructose 6-phosphate (FructoseP) disodium salt hydrate, D-fructose 1,6-biphosphate (Fructose-Bi-P) trisodium salt hydrate, Dglucose 6-phosphate (Glucose-P) sodium salt, $\alpha$-D-glucose 1,6-biphosphate (Glucose-2P) potassium salt hydrate, $\alpha$-D-galactose 1-phosphate (Galactose-P) dipotassium salt pentahydrate, D-ribulose 5-phosphate (Ribulose-P) disodium salt, D-ribulose 1,5 - bisphosphate (RibuloseBis-P) sodium salt hydrate, D-erythrose 4-phosphate (Erythrose-P) sodium salt, D-(-)-3phosphoglyceric acid (PGA) disodium salt, uridine 5'- diphosphoglucose (UDP-Glucose) disodium salt hydrate. A first set of 5 calibration standards contained the $11 \mathrm{P}$-metabolites, each at concentrations between 0 (Blank) and $20 \mathrm{nM}$. A second set of 7 calibration standards was prepared for Pi at concentrations between 0 (Blank) and $50 \mu \mathrm{g} \mathrm{L}^{-1}$ as $\mathrm{P}$, with each standard containing IS at $20 \mu \mathrm{g} \mathrm{L}-1$ as P. A third set of 5 calibration standards contained pyrophosphate and triphosphate, each at concentrations between 0 and $50 \mu \mathrm{g} \mathrm{L}-1$ as $\mathrm{P}$.

4.4.2 Field Sampling and Storage Containers. Surface water samples were collected from 14 sampling sites in Lake Ontario (6 samples from Toronto Harbourfront) and the 4 tributaries Rouge River (upstream, midstream and downstream), Highland Creek (upstream and downstream), Don River (downstream) and Humber River (upstream and downstream). The first 
set of samples were collected in July 2018 and the second set was collected from the same locations in October 2018, with locations presented in Figure 1. Samples were obtained as grab samples (0.5 m depth), except for Lake Ontario samples collected in October 2018, which were collected using a flow-through pumping system located on a sampling vessel. Aliquots collected for the analysis of Pi and P-metabolites were filtered through Fisherbrand $0.45 \mu \mathrm{m}$ Durapore filters (Fisher Scientific Company, Ottawa, ON, Canada), with $10 \mathrm{~mL}$ immediately pipetted in a 15 mL HDPE amber screw-cap bottle (Thermo Scientific, Mississauga, ON, Canada) and spiked with $100 \mu \mathrm{L}$ IS at $2 \mathrm{mg} \mathrm{L}^{-1}$ as P. Additional $500 \mathrm{~mL}$ of unfiltered samples were collected in PET bottles from each sampling site for additional analytical parameters described in the instrumental analysis section. Samples were stored at $5 \pm 3{ }^{\circ} \mathrm{C}$ until analysis.

4.4.3 2D-IC-ESI-MS analysis: The method used for P-metabolite analyses was published ${ }^{238}$ with following P species being analyzed: Pi, P-metabolites (AMP, Fructose-P, Fructose-Bi-P, Glucose-P, Glucose-Bi-P, Galactose-P, Ribulose-P, Ribulose-Bis-P, Erythrose-P, PGA, UDPGlucose), PPi and triphosphate. The system consisted of an ICS $5000^{+}$ion chromatograph (IC) coupled to a QExactive Mass Spectrometer (Thermo Scientific, Mississauga, ON). In brief, the first dimension of the dual system was used to separate sulfate and less retained anions from the sample and divert these analytes to waste. The second dimension was used to separate the $\mathrm{P}$ species.

Three sets of calibration standards for $\mathrm{Pi}$, organic and inorganic $\mathrm{P}$ species, were run to establish calibration curves. The method detection limits (MDLs) and $\mathrm{m} / \mathrm{z}$ ratios of the analytes can be found in the SI. XCalibur software version 3.0 was used for data acquisition and TraceFinder version 3.2 (Thermo Scientific, Mississauga, ON) for quantitation. 
4.4.4 Additional Instrumental Analysis. SRP and TP, chloride, sulfate, bromide, sodium, potassium, magnesium, calcium, nitrate, nitrite and ammonia were measured by capillary IC. Total organic carbon (TOC) was measured by combustion. Also, $\mathrm{pH}$, alkalinity and conductivity were measured for all samples. Additional information regarding these separation methods is included in the SI.

4.4.5 Multivariate Statistical Analysis: PCA and hierarchical cluster analysis (HCA) in this study was applied to 23 analytes in total. The number of meaningful principal components (PC) was determined by eigenvalues $\geq 1$. Calculations and graphical representations of PCA and HCA were performed using Origin Pro 2018. Concentrations of parameters below MDLs were replaced with randomly generated values between 0 and corresponding MDL value for each measured parameter.

\subsection{Results and discussions}

\subsubsection{Inorganic and organic $P$-species in river and lake water}

Samples from 14 locations were collected in July and October of 2018. The Don River watershed, covering the area of 36000 hectares and 1.4 million residents, is one of the most urbanized in Canada. Increase in paved surfaces and combine sewers, carrying both stormwater and sanitary sewage can cause nutrient pollution due to sewer overflow during large storm events $^{247}$. The Don River, connected to Lake Ontario via Keating Channel, has the greatest effect on Inner Harbour (IH) water quality ${ }^{248}$. Samples collected near the mouth of the Don River contained $74 \mu \mathrm{g} \mathrm{L}-1$ of Pi as $\mathrm{P}, 87 \mu \mathrm{g} \mathrm{L}^{-1}$ of SRP as $\mathrm{P}, 166 \mu \mathrm{g} \mathrm{L}^{-1}$ of TP as $\mathrm{P}$ and $23 \mu \mathrm{g} \mathrm{L}^{-1}$ of PPi as $\mathrm{P}$. In comparison, other 3 tributaries contained on average $10 \mu \mathrm{g} \mathrm{L}{ }^{-1}$ of $\mathrm{Pi}$ as $\mathrm{P}, 13 \mu \mathrm{g} \mathrm{L} \mathrm{L}^{-1}$ of SRP as $\mathrm{P}, 41 \mu \mathrm{g} \mathrm{L} \mathrm{L}^{-1}$ of $\mathrm{TP}$ as $\mathrm{P}$ and $2.5 \mu \mathrm{g} \mathrm{L}^{-1}$ of PPi as P. Lake samples collected from six 
Toronto Harbourfront locations contained on average $6 \mu \mathrm{g} \mathrm{L}^{-1}$ of Pi as $\mathrm{P}, 5.9 \mu \mathrm{g} \mathrm{L} \mathrm{L}^{-1}$ of SRP as $\mathrm{P}$, $13 \mu \mathrm{g} \mathrm{L}-1$ of TP as P and $0.35 \mu \mathrm{g} \mathrm{L} \mathrm{L}^{-1}$ of PPi as P. Within harbor analysis of six locations L1-L6 with different proximities to a Don River sampling site confirmed increased concentrations of inorganic and organic P-compounds in locations closer to the Don River sampling site with an average concentration increase of $67 \%$ for inorganic P-compounds and almost the same increase of $69 \%$ in organic P-compounds between the furthest and closest sampling location from the Don River. Concentrations of inorganic and organic P-compounds in Lake Ontario and the tributaries are shown in Figure 4.2. Previously measured TP values showed the highest $P$ concentrations in the northeast corner of Inner Harbor (IH) by the Don River and gradually decreasing through zones to the Outer Harbor $(\mathrm{OH})^{248}$. Howell et al. found nearshore TP values in IH higher than ambient oligotrophic nearshore levels in Lake Ontario ${ }^{249}$, with levels between 8 and $11 \mu \mathrm{g} \mathrm{L}^{-1}$.

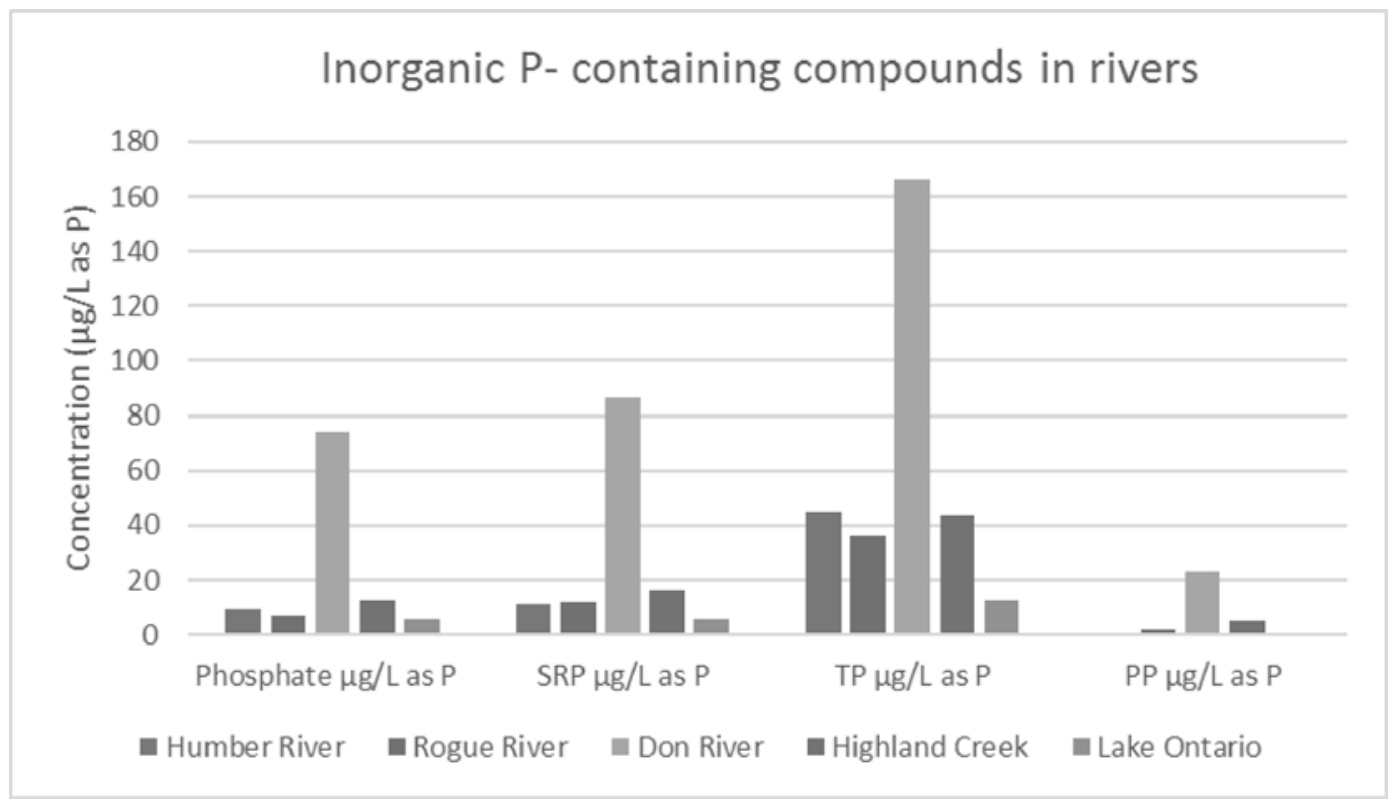




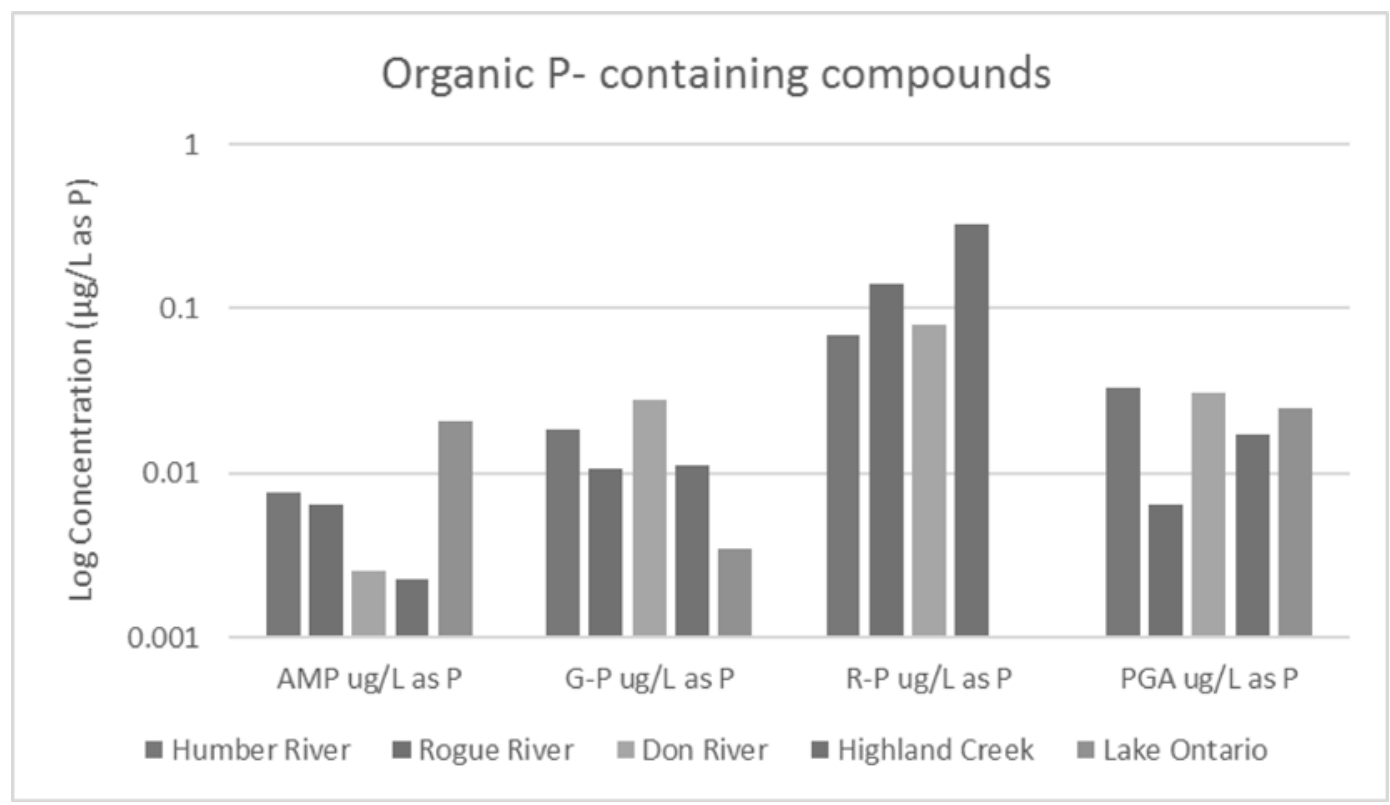

Figure 4.2 Average concentrations of inorganic (above) and organic P-containing compounds (below) in tributaries and Lake Ontario

The shortest chain polyphosphate, PPi, is bioavailable, can function as a phosphate reservoir for aquatic microorganisms as it can be present at higher concentrations than SRP ${ }^{77}$. The main classes of P-species observed by ${ }^{31} \mathrm{P}$ NMR in sewage sludge were Pi, PPi, longer chain polyphosphates, mono and di-esters ${ }^{250}$. Average amount of PPi detected in Lake Ontario tributaries varied between 0.8 and $23 \mu \mathrm{g} \mathrm{L}-1$ as $\mathrm{P}$, with Don River containing the highest PPi levels. The PPi can have an anthropogenic source or be a by-product of biological activity. The most urbanized watersheds, Highland Creek and Don River contained 5 and $23 \mu \mathrm{g} \mathrm{L}^{-1} \mathrm{PPi}$ as P, respectively, while partially urbanized watersheds such as Rouge River and Humber River contained only 1.7 and $0.8 \mu \mathrm{g} \mathrm{L}^{-1} \mathrm{PPi}$ as $\mathrm{P}$, respectively, suggesting an anthropogenic source of PPi in these watersheds. The lake water contained $0.35 \mu \mathrm{g} \mathrm{L} \mathrm{L}^{-1}$ of PPi as $\mathrm{P}$, lower level than in the tributaries, mainly due to lake diluting effect and biological uptake. The concentration ranges of P-containing inorganic and organic compounds quantified in Lake Ontario Harbourfront and 
tributaries are shown in Figure 4.3. The dilution factor of P-containing inorganic compounds and sugar phosphates such as G-P and G-2P in the lake as compared to tributaries ranged from $2.0-$ 10.7, with 10.7 PPi dilution factor (Figure 4.5). The higher concentration of other organic Pcontaining compounds such as PGA and AMP in lake samples than in river samples was probably due to the difference in the biological activity of these two sources.
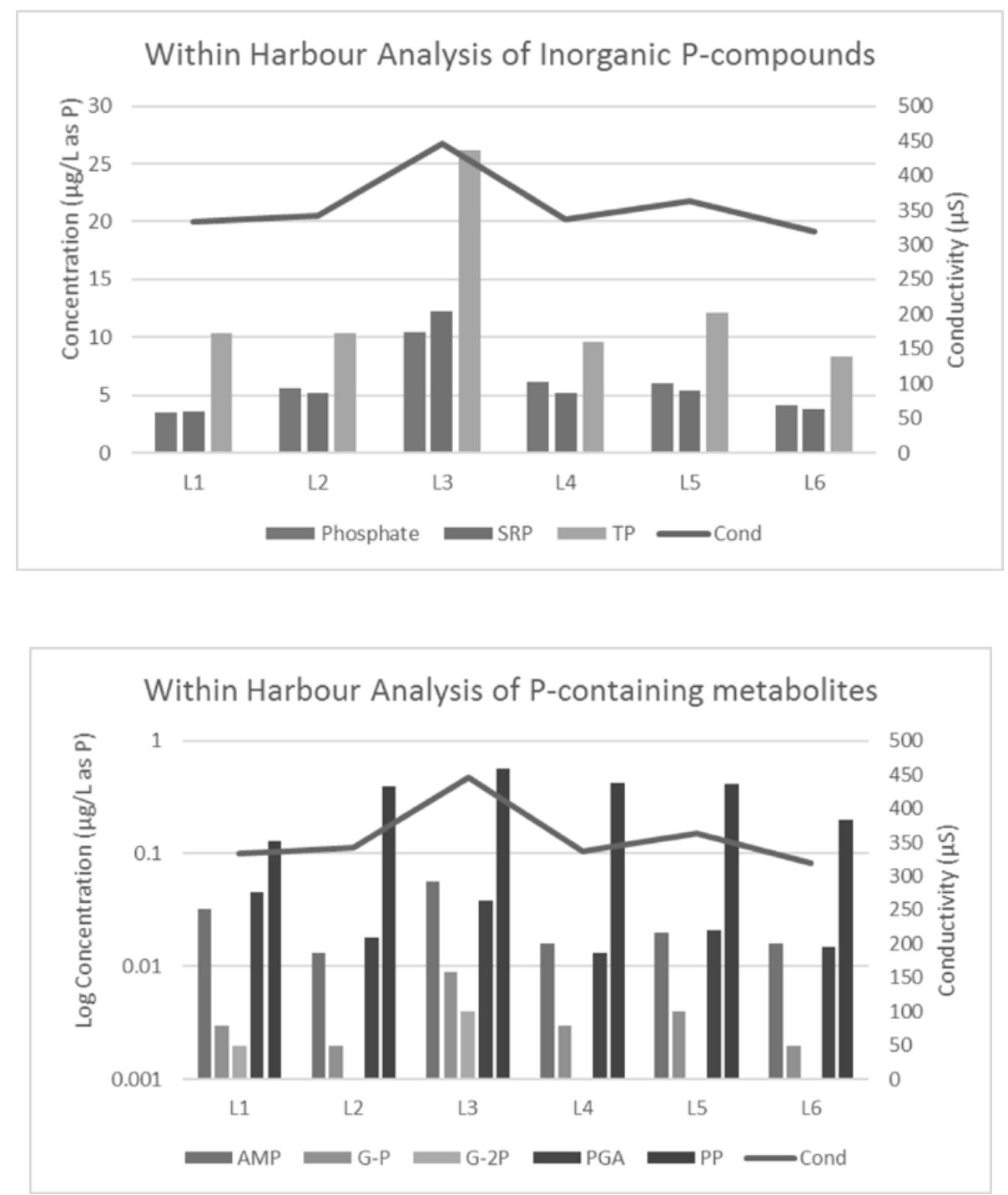

Figure 4.3 Concentrations of inorganic P-compounds (above) and P-containing metabolites (below) per Lake Ontario Inner Harbour location compared with conductivity. 


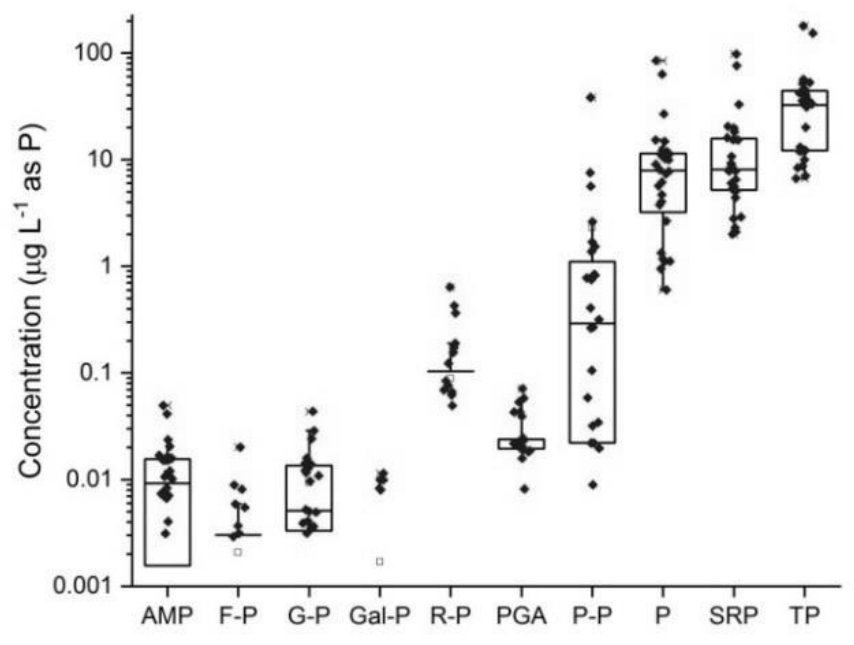

Figure 4.4 Log concentration ranges of P-metabolites and PPi in river and lake samples including SRP and TP.

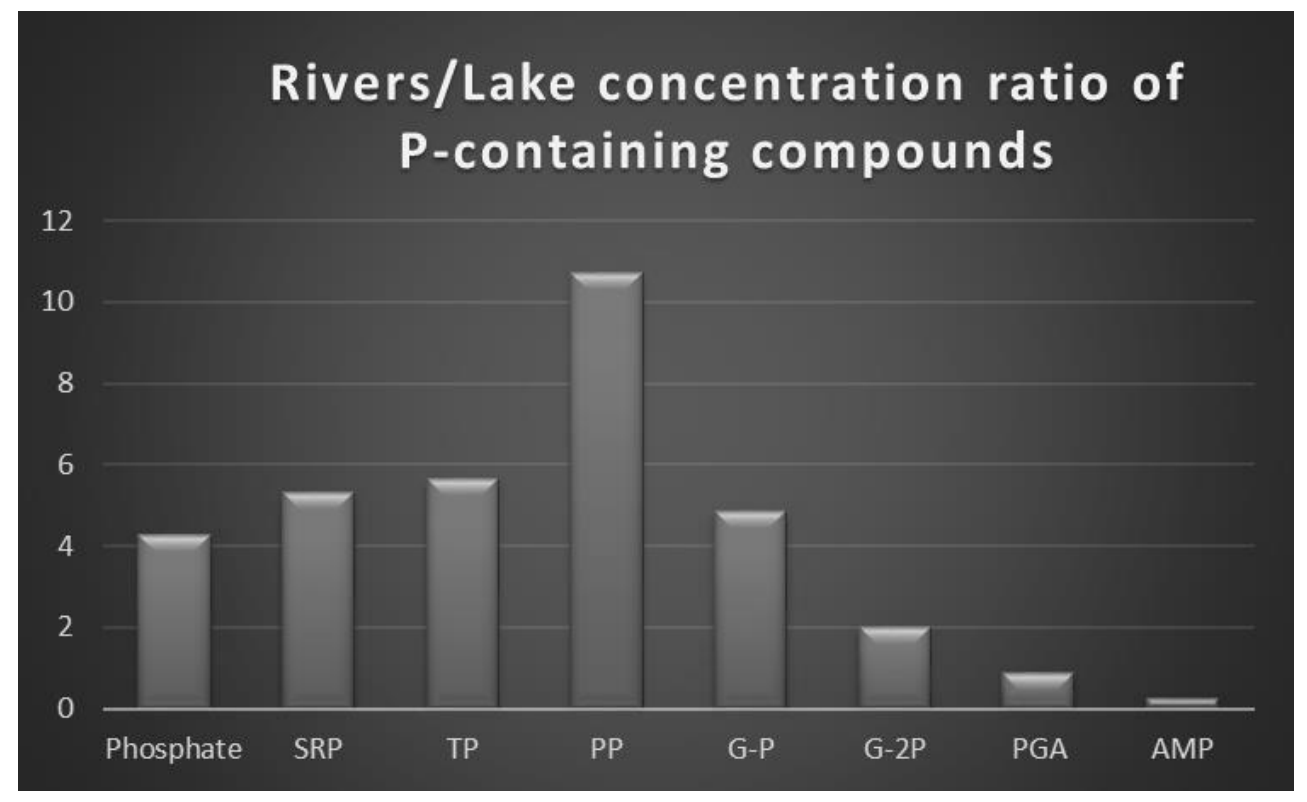

Figure 4.5 Concentration ratio of P-containing compounds between rivers and lake water. 


\subsubsection{PCA and analysis of P-containing metabolites and condensed phosphate species}

Inorganic and organic $\mathrm{P}$ compounds such as phosphonates, $\mathrm{Pi}, \mathrm{P}$ monoesters, $\mathrm{P}$ diesters, $\mathrm{PPi}$ and longer chain polyphosphates in soil, animal manure and algal biomass were previously identified and quantified by ${ }^{31} \mathrm{P} \mathrm{NMR}^{251-254}$. However, its application in surface water environmental samples remained challenging until recently ${ }^{238}$, due to trace concentrations of $\mathrm{P}$ species in rivers and lakes. The same IC-ESI-MS method was used in this study to quantify P-metabolites in surface water. down to nM levels. Previous ${ }^{31} \mathrm{P}$ NMR measurements of surface water samples were based on quantification of functional groups ${ }^{179}$, while IC-ESI-MS measures separate $\mathrm{P}$ species present at much lower concentrations. The analyzed river samples contained AMP up to $8 \mathrm{ng} \mathrm{L}^{-1}$ as $\mathrm{P}$ in July and $12 \mathrm{ng} / \mathrm{L}$ in October, F-P below $\mathrm{MDL}=2.8 \mathrm{ng} \mathrm{L}^{-1}$ as $\mathrm{P}$ in July and up to $20 \mathrm{ng} \mathrm{L}^{-1}$ as $\mathrm{P}$ in October, G-P up to $44 \mathrm{ng} \mathrm{L}^{-1}$ as $\mathrm{P}$ in July and $14 \mathrm{ng} \mathrm{L}^{-1}$ as $\mathrm{P}$ in October, Gal-P below MDL $=5.6 \mathrm{ng} \mathrm{L}^{-1}$ as $\mathrm{P}$ in July and up to $11 \mathrm{ng} \mathrm{L}^{-1}$ as $\mathrm{P}$ in October, R-P up to $360 \mathrm{ng} \mathrm{L}^{-1}$ as $\mathrm{P}$ in July and $640 \mathrm{ng} \mathrm{L^{-1 }}$ as $\mathrm{P}$ in October, PGA up to $53 \mathrm{ng} \mathrm{L}^{-1}$ as $\mathrm{P}$ in July and $43 \mathrm{ng} \mathrm{L}^{-1}$ as $\mathrm{P}$ in October and PP up to $7.5 \mu \mathrm{g} \mathrm{L}^{-1}$ as $\mathrm{P}$ in July and $38 \mu \mathrm{g} \mathrm{L}^{-1}$ as $\mathrm{P}$ in October. Concentrations of 16 most commonly analyzed inorganic parameters, isotope dilution Pi and 11 P-metabolites were used for PCA. Figure 4.6 shows corresponding loading graphs, scree diagrams and PCA of the 28 parameters. More information on the analytical procedures used in this study can be found in the SI file. From the 616 parameters used for PCA 65 (10.5\%) were below MDL. The values below MDL were replaced with randomly generated values between 0 and corresponding MDLs for each measured parameter. Separate PCA was done using only P species (Figure 4.7), with 252 parameters with the same 65 values below MDL replaced by randomly generated values between 0 and corresponding MDLs Concentration units were normalized from data distribution using standardization (z-score) based on mean and standard deviation prior to PCA. 


\subsubsection{Statistical analysis based on all measured analytical parameters}

For July samples, two PCs (1 and 2) accounted for $85 \%$ of the total variance and three PCs $(1,2$ and 3) accounted for $92 \%$ of the total variance. The most significant PC1 components were TP, TOC, Pi, SRP, G-P and PPi (0.28 to 0.31), AMP (-0.14) and $\mathrm{pH}(-0.19)$ and the most significant components of $\mathrm{PC} 2$ were sulfate, $\mathrm{Mg}, \mathrm{Ca}, \mathrm{Cond}, \mathrm{Na}, \mathrm{Cl}$ (0.29 to 0.31), PGA, AMP and nitrate (0.20 to -0.24). The number of significant PCs for all PCA calculations was selected based on eigenvalues $>1$ (Figure 4.6). For October samples, $\mathrm{PC} 1$ and $\mathrm{PC} 2$ accounted for $84 \%$ of the total variance, three PCs (1, 2 and 3) accounted for $92 \%$ and four PCs (1, 2, 3 and 4) accounted for $96 \%$ of the total variance. The most significant components of PC1were K, F-P, Na, Cl (all 0.25) and AMP (-0.24). The most significant components of PC2 were nitrite, ammonia, PPi, Pi ( 0.3 to $0.34)$ and G-P, SO4, R-P and $\mathrm{pH}(-0.20$ to -0.25$)$. PC1 / PC2 relationship is shown in Figure 4.7. The figure shows a spatial evaluation and clear distinction between lake samples (L1-L6) and river samples (R1-R8), with each group being correlated to the particular analytes. Lake samples collected in July were correlated with AMP and the river samples (except R3) were correlated with major ions, $\mathrm{pH}$, alkalinity, conductivity, sulfate, chloride and R-P. River sample R3 contained higher concentration of nutrients than the other river samples and was correlated with inorganic nitrogen and P species. Similar PC1/PC2 distribution and spatial separation of lake and river samples was observed in October samples (Fig.4.7). 

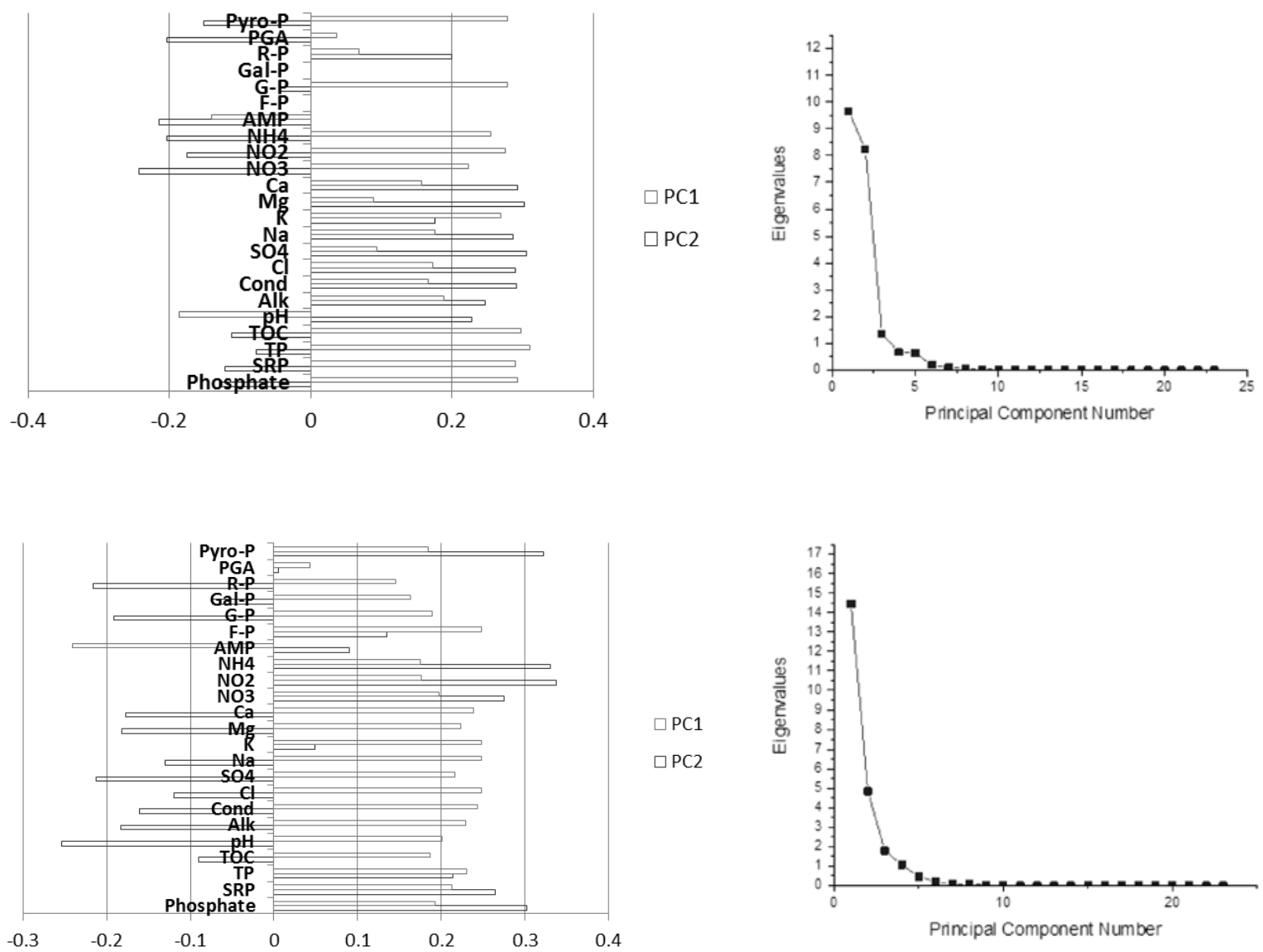

Figure 4.6 Loading graphs and Scree diagrams based on all analyzed variables in July (top) and October (bottom). 

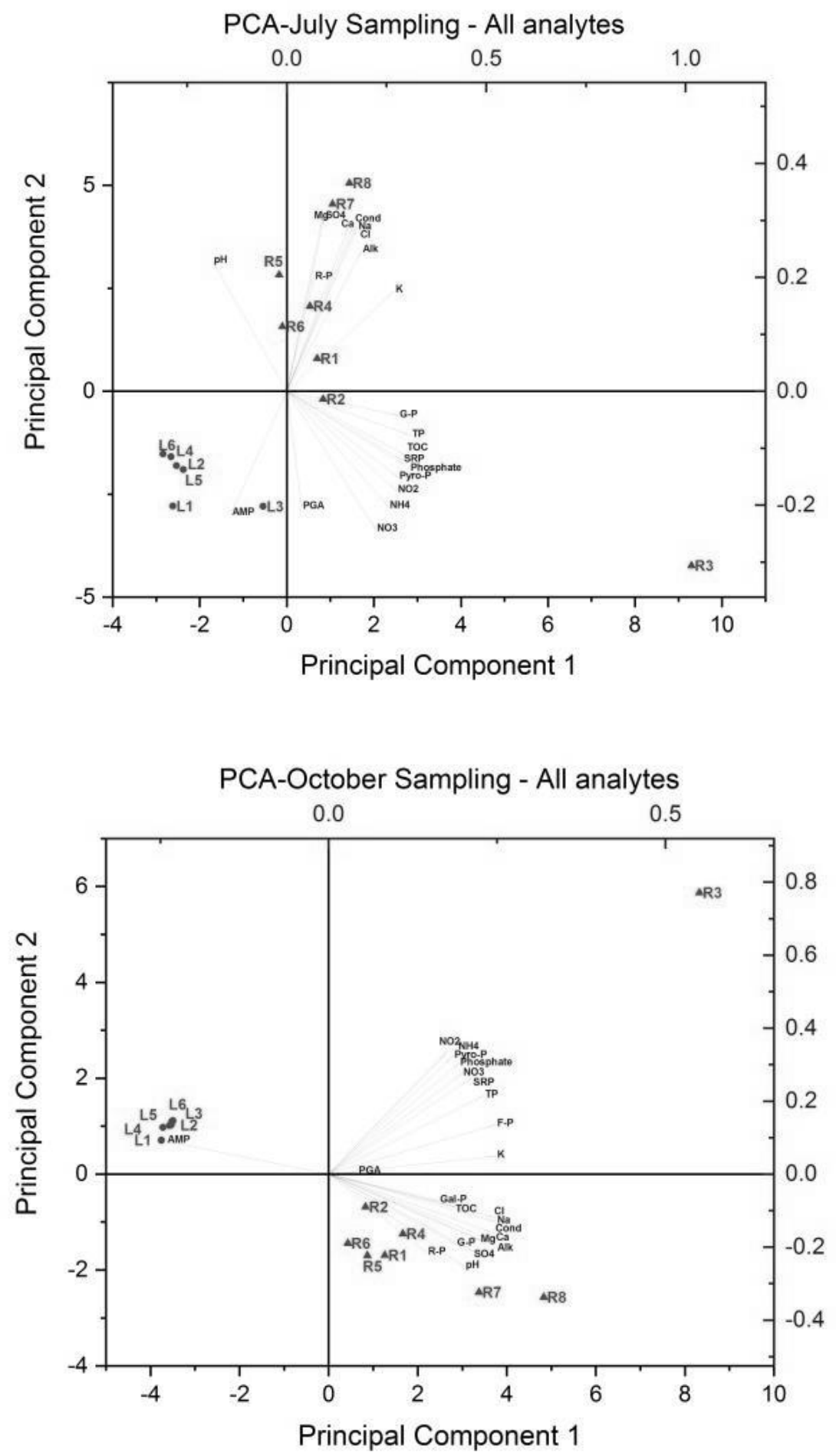

Figure 4.7 PCA based on all analyzed variables in July (top) and October (bottom). 


\subsubsection{Statistical analysis based on measured P-species.}

Two PCs (1 and 2) accounted for $85 \%$ of the total variance in July sampling, the same as when all the analytes were used. Three PCs (1, 2 and 3$)$ accounted for $92 \%$ of the total variance (Figure 4.8). The most significant PC1 components were TP, Pi, SRP, PPi and G-P (0.40 to 0.46) and the most significant components of PC2 were AMP, PGA (both 0.60) and R-P (-0.53). In October sampling PC1 and PC2 accounted for 77\% and three PCs (1, 2 and 3) accounted for $89 \%$ of the total variance (Figure 4.8). The most significant components of PC1 were TP, Pi, SRP, PPi and F-P (0.37 to 0.41) and the most significant components of PC were G-P (0.5), R-P (0.53) and Pi, AMP and pyro-P (-0.30 to -0.34). Spatial distribution of river and lake samples based on PCA of P species in July and October are showed in Figure 4.9. In July, lake and river samples are grouped vertically along the PC2 axis with AMP, PGA and R-P being the most significant components. In October, lake samples and river samples are separated along PC2 with lake samples correlated with AMP and river samples correlated with G-P, R-P, Gal-P and PGA. Successful PCA separation of the river and lake matrix based only on P species reduced number of analytes needed for PCA by 13 (from 23 to 10) or 56\%. Sample source hierarchical cluster analysis (HCA) dendrograms are shown in Figure 4.10 (using 23 analytes) and Figure 4.11 (P species only). HCA yielded two statistically significant clusters separating river and lake samples when all analytes were used for calculation. When using HCA based on P-species, the dendrogram selected 3 statistically significant clusters separating river and lake samples and separating highly polluted R3 sample from other two clusters. July dendrogram failed to assign L3 and R5 to the proper clusters. 

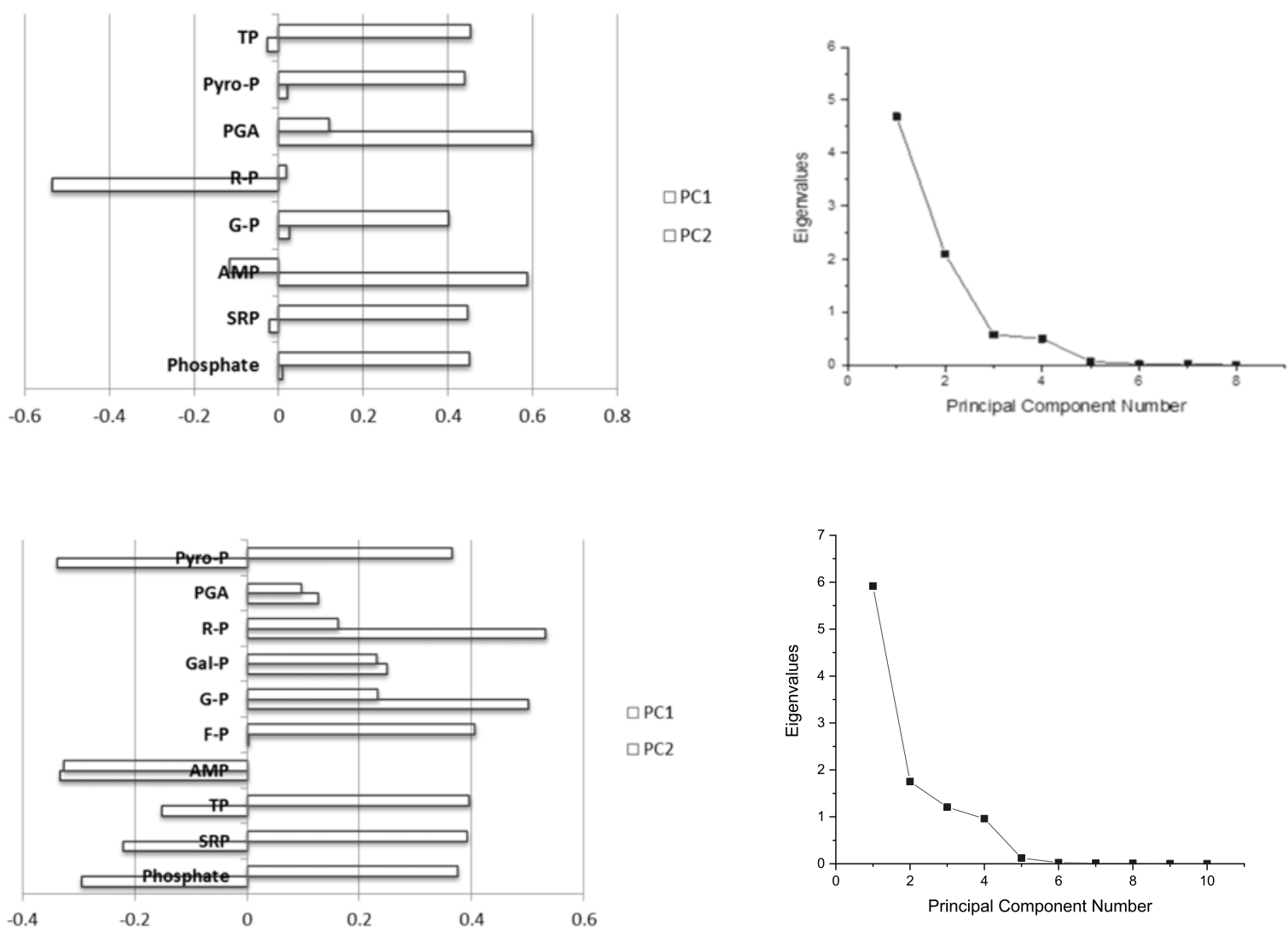

Figure 4.8 Loading and Scree diagrams using P species sampled in July (top) and October (bottom). 

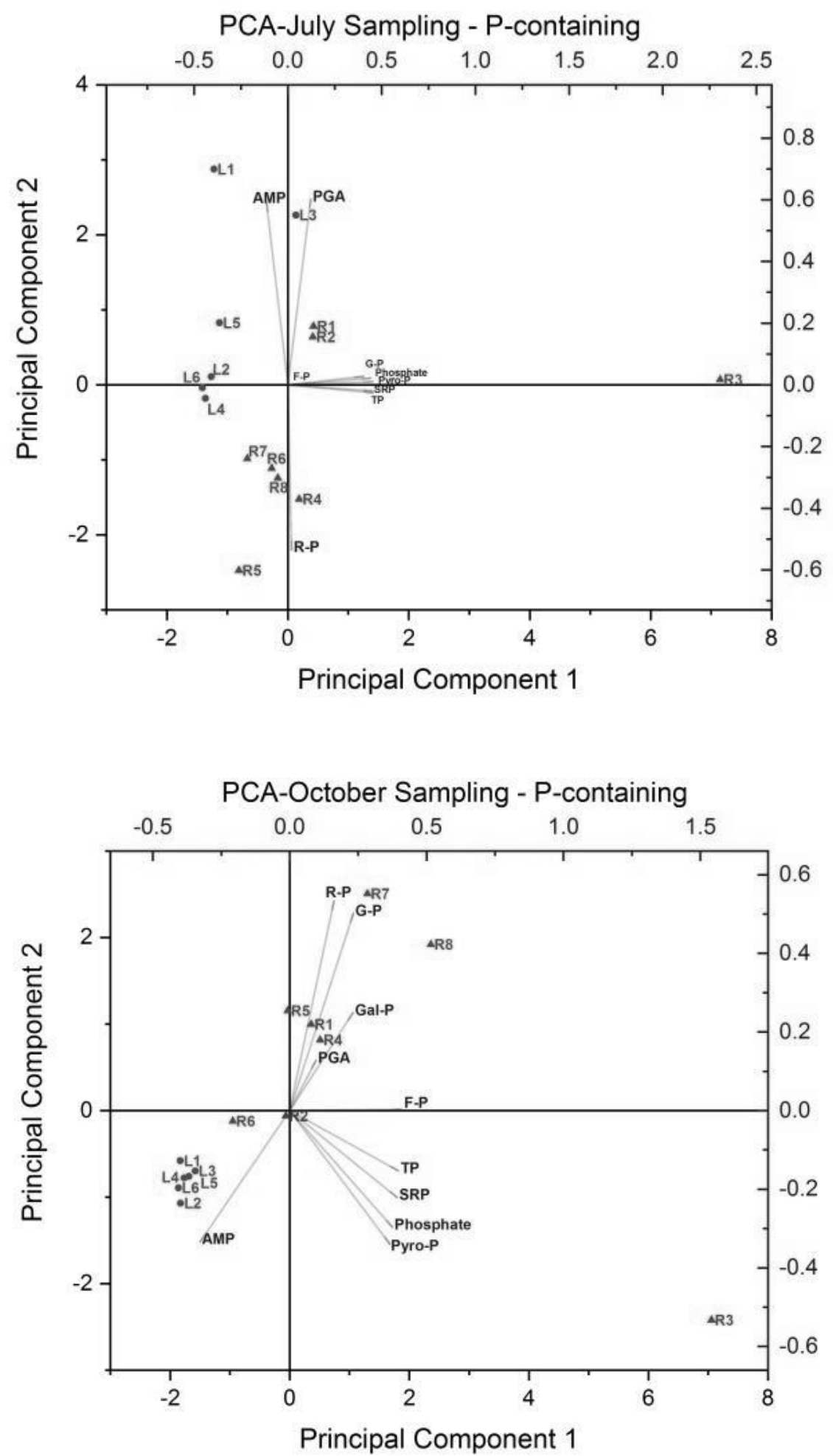

Figure 4.9 PCA based on P-containing compounds in July (top) and October (bottom). 


\subsubsection{Correlation between inorganic and organic P-species}

Inorganic P parameters such as $\mathrm{Pi}, \mathrm{SRP}, \mathrm{TP}$ and PPi were highly correlated in both sampling sets (early summer and fall samples) with correlation coefficients over 0.90 . Organic P-species were not well correlated between each other or with other parameters, most correlation coefficients being below 0.5 . Due to low correlation of these species with other analytical parameters it is therefore useful to analyze organic $\mathrm{P}$-species as separate entities in addition to total organic $\mathrm{P}$ to better understand their dynamics in the aquatic environment.

\subsection{Conclusions}

Soluble reactive phosphorus and total phosphorus analysis and data provide useful information of phosphorus interaction with aquatic environment. The data has been widely used for decades for monitoring and prevention of an excessive nutrient loadings into the Great Lakes. With the contribution of many other environmental variables the eutrophication of freshwater is still a major threat to the aquatic ecology. Nuisance algal blooms is still a widespread phenomenon causing a vast economic and environmental damage. A large variety of P-containing organic metabolite species can be released into the aquatic environment during periods of a high biological activity. The identification and quantification of these species continue to be problematic and their functions and interactions in the water column remains not fully understood. Quantification of biologically available phosphate species which can greatly contribute to algal growth provide an additional valuable information for better understanding of phosphorus dynamics and its biological utilization. However, the analysis requires highly sensitive and selective analytical methods. Two-dimensional ion chromatography with tandem mass spectrometry confirmed its suitability for low-level phosphate quantification and ultra-trace 
analysis of P-containing organic and inorganic compounds present in freshwater samples. The large injection volume and the concentrator used in the second dimension of the analytical separation eliminated the need for off-line pre-concentration or other sample pre-treatment methods. Various P-containing metabolites including pyrophosphate, adenosine 5'monophosphate, glucose 6-phosphate, $\alpha$-D-glucose 1,6-biphosphate, D-ribulose 5-phosphate and D-(-)-3-phosphoglyceric acid were identified and quantified for the first time in Lake Ontario and its tributaries. Multivariate statistical analysis of lake and river samples separated matrices into distinct groups even when using only P-containing analytical variables as inputs for a PCA analysis suggesting that P-containing compounds could be used for an identification of pollution sources. 

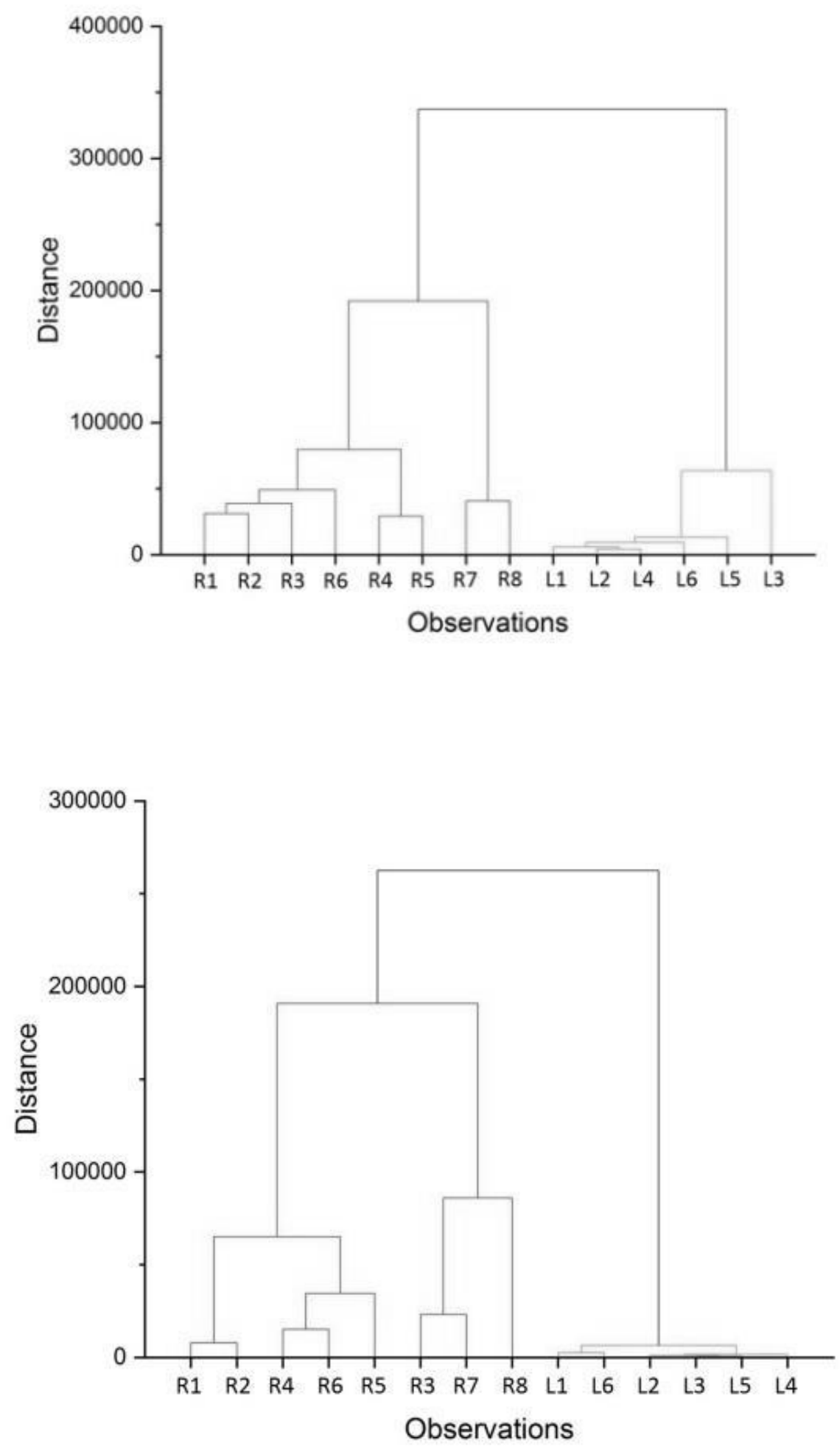

Figure 4.10 Dendrograms using all analytes (top) July sampling (bottom) October sampling 

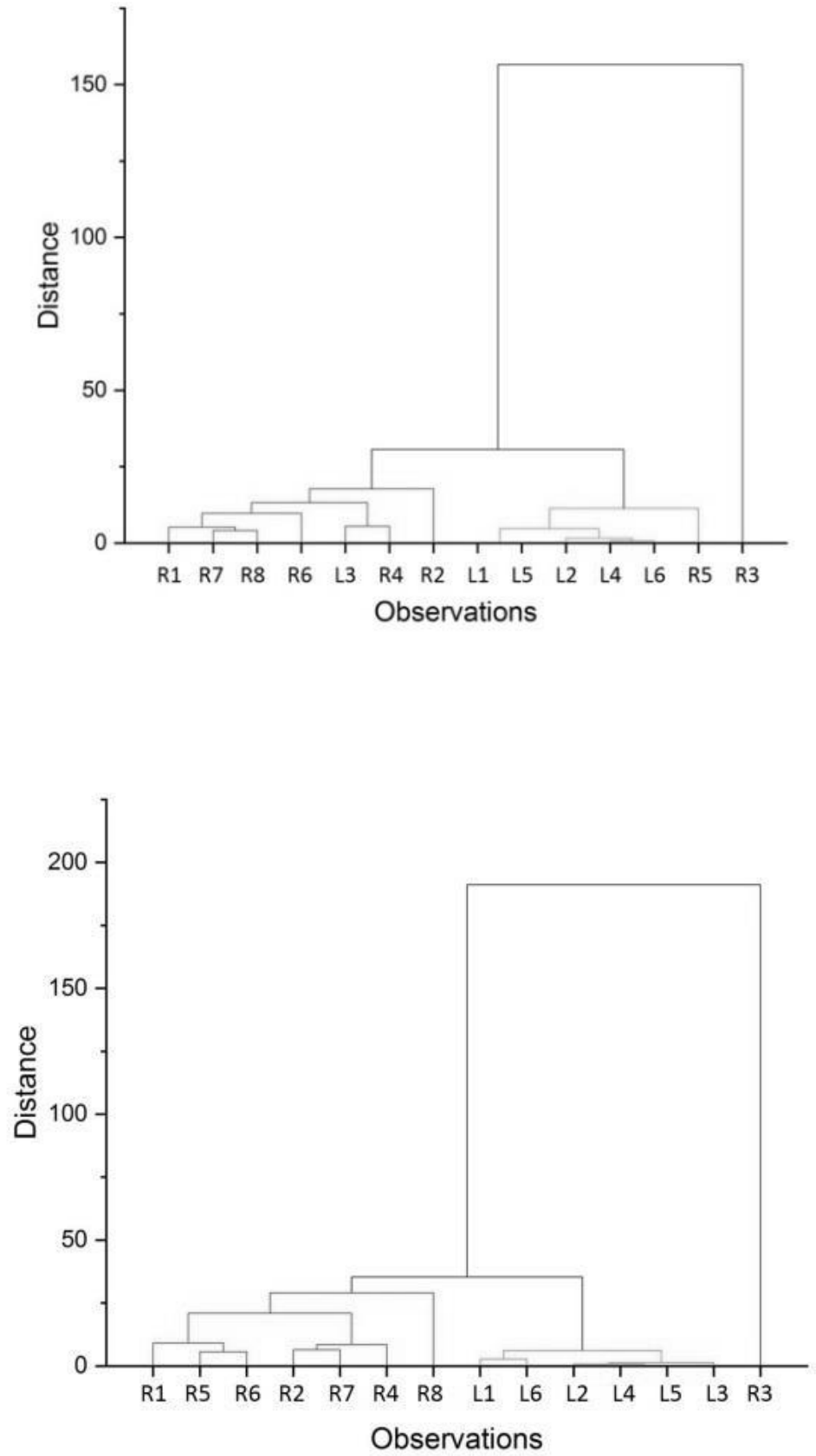

Figure 4.11 Dendrograms using P-metabolites only (top) July sampling (bottom) October sampling 


\subsection{Associated Content}

Additional information about analytical methods for colorimetric measurement of Pi, TP, sulfate by IC, MDLs for species, schematic of the 2D-IC configuration and Pi loss (\%) in samples spiked 48h after collection are included in the Supporting Information file.

\subsection{Summary and Future Work}

Incorporating P-speciation data in the environmental monitoring programs can contribute to better understanding of phosphorus dynamics in aquatic environment and prevent potential largescale ecological and economic losses to the society. The Ontario Ministry of the Environment, Conservation and Parks has been using this new method to evaluate the advantages in measuring phosphate in surface water samples. There was a limited number of inorganic and organic Pspecies present in natural waters covered in our experimental work. Other species may be identified by unknown identification software. Utilization of such software including analysis of MS-MS data can give us information on presence of up to hundreds of P-containing metabolites in the samples. The newly identified species can be quantified once their standards become available. 


\title{
APPENDIX A \\ SUPPORTING INFORMATION
}

Unbiased Measurement of Phosphate and Phosphorus Speciation in Surface Waters

Vlastimil Packa $^{+}, \neq$, Stefanie Maedler ${ }^{+}$, Todd Howell $^{+}$, Vadim Bostan $^{\ddagger}$, Ngan Diep $^{+}$, Robert Tooley $^{+}$and Vasile I. Furdui ${ }^{+, \neq}$

${ }^{\dagger}$ Ontario Ministry of the Environment, Conservation and Parks, 125 Resources Road, Toronto, ON, M9P 3V6, Canada

${ }^{\ddagger}$ Ryerson University, 350 Victoria Street, Toronto, Ontario M5B 2K3, Canada

\section{SUPPORTING INFORMATION}

\begin{abstract}
Page
Phosphate measurement by colorimetry.................................................................... SI-2

Total phosphorus (TP) measurement ......................................................................... SI-2

Sulfate measurement by ion chromatography (IC) …............................................... SI-3

Anion separation by capillary IC (Figure S1) ............................................................. SI-4

MDLs for analyzed P-containing metabolites (Table S4) …............................................. SI-4

Schematic of the 2D-IC configuration (Figure S2) .......................................................... SI-5

Phosphate loss (\%) in samples spiked 48h after collection (Figure S3) ........................... SI-5

Distribution of the ${ }^{18} \mathrm{O}$ labeled $\mathrm{H}_{2} \mathrm{PO}_{4}{ }^{-}$species during storage (Figure $\mathrm{S} 4$ ) ..................... SI-6
\end{abstract}




\section{Phosphate measurement by colorimetry}

Soluble reactive phosphorus (SRP) was measured using a Skalar continuous flow analyzer (Breda, Netherlands). SRP was measured after formation of a phospho-antimonyl-molybdate complex in the presence of the ascorbic acid as a reducing agent. The absorbance was measured at $880 \mathrm{~nm}$ with quantitation based on external calibration. The method detection limit (MDL) was $3 \mu \mathrm{g} \mathrm{L}^{-1}$ as $P$. This method is slightly modified (see Table S1) from the reference method 4500-P G from the Standard Methods for the Examination of Water and Wastewater ${ }^{100}$.

Table S1. Differences between Standard Method 4500-P G and SRP method

\begin{tabular}{|l|l|l|}
\hline Analysis Modification & Standard Method 4500-P G & SRP Method \\
\hline $\begin{array}{l}\text { Antimony potassium } \\
\text { tartrate solution }\end{array}$ & $1.37 \mathrm{~g}$ to $500 \mathrm{~mL}$ water & $5 \mathrm{~g}$ to $4000 \mathrm{~mL}$ water \\
\hline $\begin{array}{l}\text { Ammonium molybdate } \\
\text { solution }\end{array}$ & $20 \mathrm{~g}$ to $500 \mathrm{~mL}$ water & $240 \mathrm{~g}$ to $4000 \mathrm{~mL}$ water \\
\hline Ascorbic acid solution & $1.76 \mathrm{~g}$ to $100 \mathrm{~mL}$ & $10 \mathrm{~g}$ to $500 \mathrm{~mL}$ water \\
\hline Wetting agent & Not used/needed & FDD6 soap \\
\hline
\end{tabular}

\section{Total phosphorus (TP) measurement}

Samples were preserved with sulfuric acid and $10 \mathrm{~mL}$ aliquots were digested at $121^{\circ} \mathrm{C}$ for $30 \mathrm{~min}$ after adding potassium persulfate using a Tuttnauer 2540 EK-B/L autoclave (Heidolph Brinkmann, Hauppauge, NY, USA). After digestion TP was measured as phosphate using a Skalar continuous flow analyzer (Breda, Netherlands) with $\mathrm{MDL}=0.1 \mu \mathrm{g} \mathrm{\textrm {L } ^ { - 1 }}$ as $\mathrm{P}$. This method is slightly modified (see Table S2) from the reference method 4500-P (section B5 for digestion and section $\mathrm{F}$ for

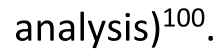


Table S2. Differences between Standard Method 4500-P B5 and TP method

\begin{tabular}{|l|l|l|}
\hline Digestion Modification & Standard Method 4500- P B5 & TP Method \\
\hline Indicator solution & Phenolphthalein & Not used \\
\hline Persulfate & $\begin{array}{l}\text { Add } 0.5 \text { g solid } \mathrm{K}_{2} \mathrm{~S}_{2} \mathrm{O}_{8} \\
\text { to each sample }\end{array}$ & $\begin{array}{l}\text { Add } 150 \mu \mathrm{L} \text { of saturated } \mathrm{K}_{2} \mathrm{~S}_{2} \mathrm{O}_{8} \\
\text { solution to } 10 \mathrm{~mL} \text { of sample }\end{array}$ \\
\hline Analysis Modification & Standard Method 4500-P F & TP Method \\
\hline Flow cell & 15 or $50 \mathrm{~mm}$ & $500 \mathrm{~mm}$ \\
\hline $\begin{array}{l}\text { Antimony potassium } \\
\text { tartrate solution }\end{array}$ & $0.3 \mathrm{~g}$ to $100 \mathrm{~mL}$ water & $2.3 \mathrm{~g}$ to $100 \mathrm{~mL}$ water \\
\hline $\begin{array}{l}\text { Ammonium molybdate } \\
\text { solution }\end{array}$ & $4 \mathrm{~g}$ to $100 \mathrm{~mL}$ water & $3 \mathrm{~g}$ to $1000 \mathrm{~mL}$ water \\
\hline Ascorbic acid solution & $1.76 \mathrm{~g}$ to $100 \mathrm{~mL}$ water & $0.2 \mathrm{~g}$ to $100 \mathrm{~mL}$ water \\
\hline Wetting agent & Not used/needed & FDD6 soap \\
\hline
\end{tabular}

\section{Sulfate measurement by ion chromatography (IC)}

Sulfate was analyzed using capillary ion chromatography (ICS-5000', Thermo Fisher Scientific, Mississauga, ON, Canada) containing AS-AP, DP, EG and DC modules. Separation of all major anions, including sulfate was obtained in 25 minutes using an AS18 column and conductivity detector (see Figure S1). The method is similar to US EPA Method 300.1 (Determination of Inorganic Anions in Drinking Water by lon Chromatography PART A. Common Anions in EPA $300.1)^{255}$, with differences summarized in Table S3. The phosphate was simultaneously measured, but it was below MDL for the majority of the analyzed surface water samples.

Table S3. Differences between Standard Method EPA 300.1 and IC method used

\begin{tabular}{|l|l|l|}
\hline Analysis Modification & EPA Method $\mathbf{3 0 0 . 1}$ & IC Method \\
\hline IC Column & AS9-HC & AS18 \\
\hline Eluent & $9 \mathrm{mM}$ carbonate & $10-34 \mathrm{mM}$ hydroxide \\
\hline Injection Volume & $40 \mu \mathrm{L}$ & $0.4 \mu \mathrm{L}$ \\
\hline Analysis Time & $15 \mathrm{~min}$ & $25 \mathrm{~min}$ \\
\hline Column type & $4 \mathrm{~mm}$ & capillary \\
\hline
\end{tabular}


1. Standard methods for the examination of water and waste water, 23rd ed. American Public Health Association, American Water Works Association, Water Environment Federation, Washington, DC: 2017.

2. Hautman, D. P.; Munch, D. J., Method 300.1: Determination of inorganic anions in drinking water by ion chromatography. EPA: Ohio 1997.

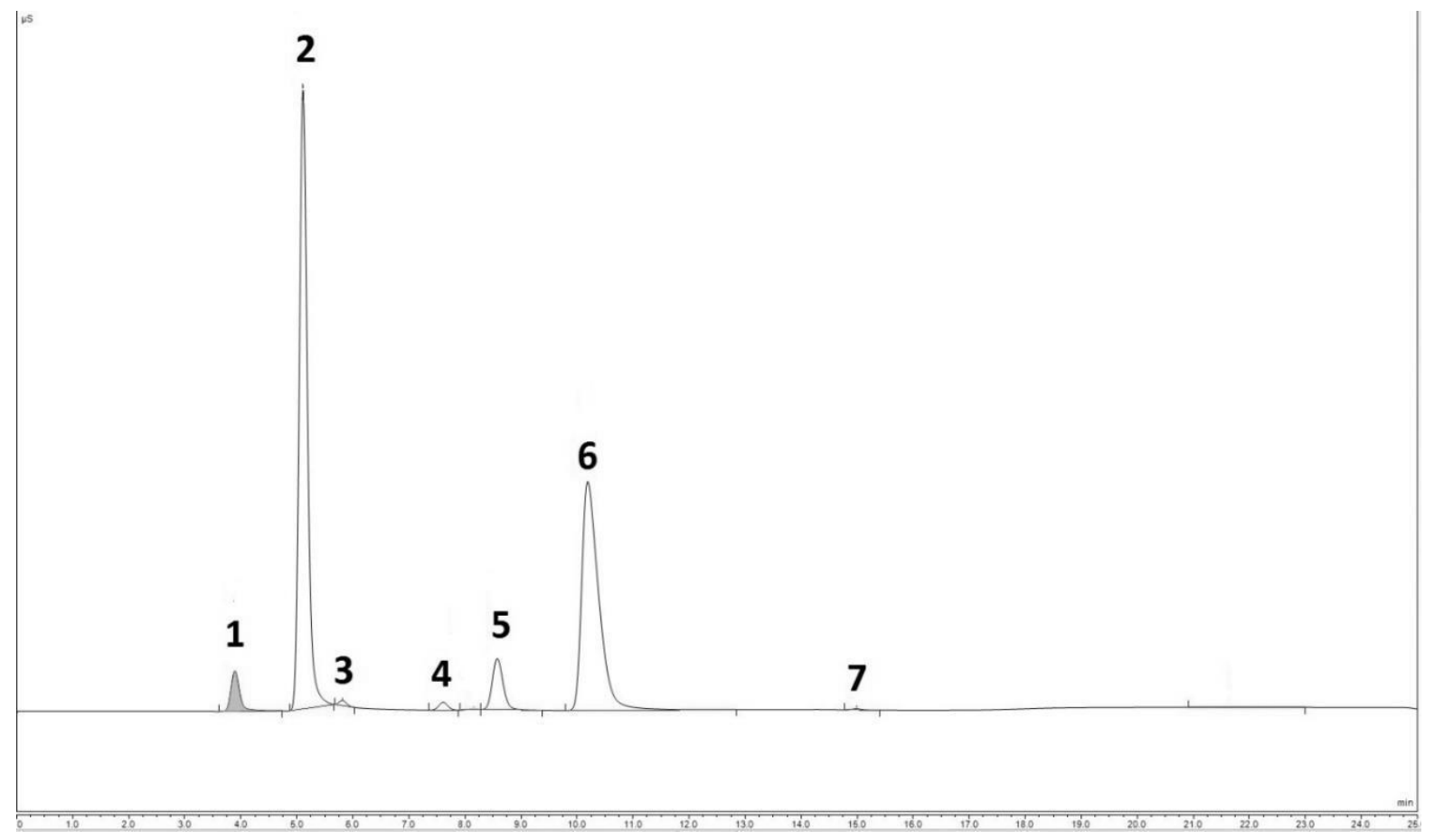

Figure S1. Anion separation by capillary IC from a standard mixture containing: (1) fluoride, (2) chloride, (3) nitrite, (4) bromide, (5) nitrate, (6) sulfate, (7) phosphate.

Table S4. List of phosphate and P-containing metabolites with their MDLs by IC-Q Exactive MS (Method B):

\begin{tabular}{|c|l|l|c|c|}
\hline $\begin{array}{c}\text { Peak } \\
\text { No. }\end{array}$ & \multicolumn{1}{|c|}{ Name } & \multicolumn{1}{|c|}{ Formula } & [M-H] & MDL \\
\hline 1 & Phosphoric Acid & $\mathrm{H}_{3} \mathrm{PO}_{4}$ & 96.969 & $0.06 \mu \mathrm{g} \mathrm{L}^{-1}$ as P \\
\hline 2 & Galactose-P & $\mathrm{C}_{6} \mathrm{H}_{13} \mathrm{O}_{9} \mathrm{P}$ & 259.022 & $0.18 \mathrm{nM}$ \\
\hline 3 & Glucose-P & $\mathrm{C}_{6} \mathrm{H}_{13} \mathrm{O}_{9} \mathrm{P}$ & 259.022 & $0.10 \mathrm{nM}$ \\
\hline 4 & Fructose-P & $\mathrm{C}_{6} \mathrm{H}_{13} \mathrm{O}_{9} \mathrm{P}$ & 259.022 & $0.09 \mathrm{nM}$ \\
\hline 5 & Ribulose-P & $\mathrm{C}_{5} \mathrm{H}_{11} \mathrm{O}_{8} \mathrm{P}$ & 229.012 & $0.27 \mathrm{nM}$ \\
\hline 6 & PGA & $\mathrm{C}_{3} \mathrm{H}_{7} \mathrm{O}_{7} \mathrm{P}$ & 184.986 & $0.36 \mathrm{nM}$ \\
\hline 7 & Erythrose-P & $\mathrm{C}_{4} \mathrm{H}_{9} \mathrm{O}_{7} \mathrm{P}$ & 199.001 & $0.09 \mathrm{nM}$ \\
\hline 8 & Glucose-Bi-P & $\mathrm{C}_{6} \mathrm{H}_{14} \mathrm{O}_{12} \mathrm{P}_{2}$ & 338.989 & $0.25 \mathrm{nM}$ \\
\hline 9 & AMP & $\mathrm{C}_{10} \mathrm{H}_{14} \mathrm{~N}_{5} \mathrm{O}_{7} \mathrm{P}$ & 346.056 & $0.10 \mathrm{nM}$ \\
\hline 10 & Fructose-Bi-P & $\mathrm{C}_{6} \mathrm{H}_{14} \mathrm{O}_{12} \mathrm{P}_{2}$ & 338.989 & $0.14 \mathrm{nM}$ \\
\hline 11 & Ribulose-Bis-P & $\mathrm{C}_{5} \mathrm{H}_{12} \mathrm{O}_{11} \mathrm{P}_{2}$ & 308.978 & $0.31 \mathrm{nM}$ \\
\hline 12 & UDP-Glucose & $\mathrm{C}_{15} \mathrm{H}_{24} \mathrm{~N}_{2} \mathrm{O}_{17} \mathrm{P}_{2}$ & 565.048 & $0.23 \mathrm{nM}$ \\
\hline
\end{tabular}




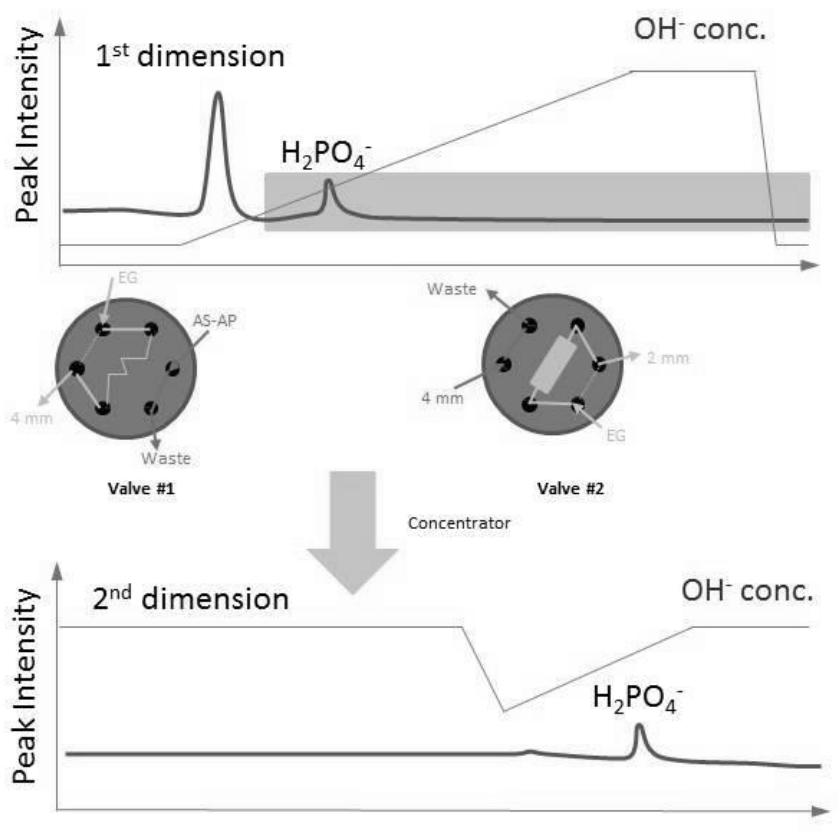

Figure S2. Schematic of the 2D-IC configuration

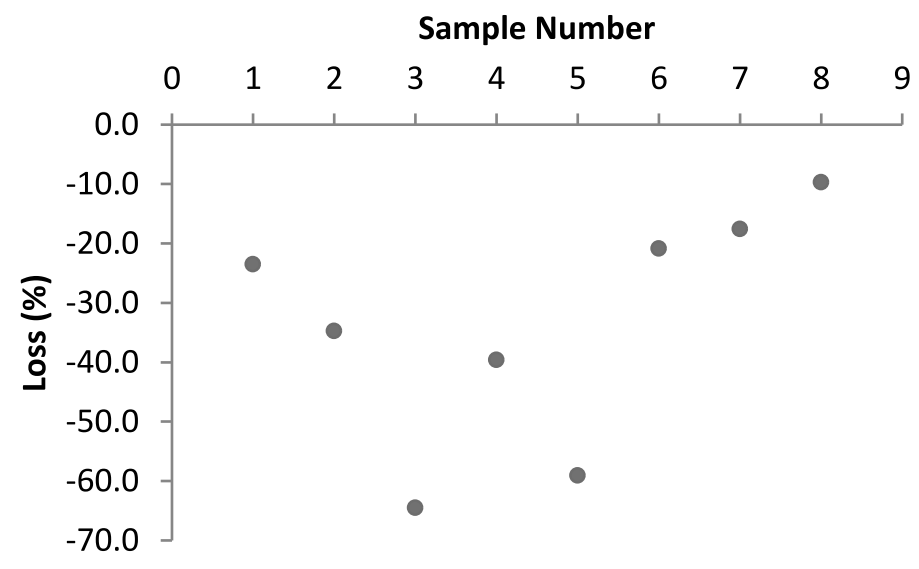

Figure S3: Phosphate loss (\%) in samples spiked $48 \mathrm{~h}$ after collection calculated by comparing with the phosphate in corresponding replicates spiked immediately when collected. 


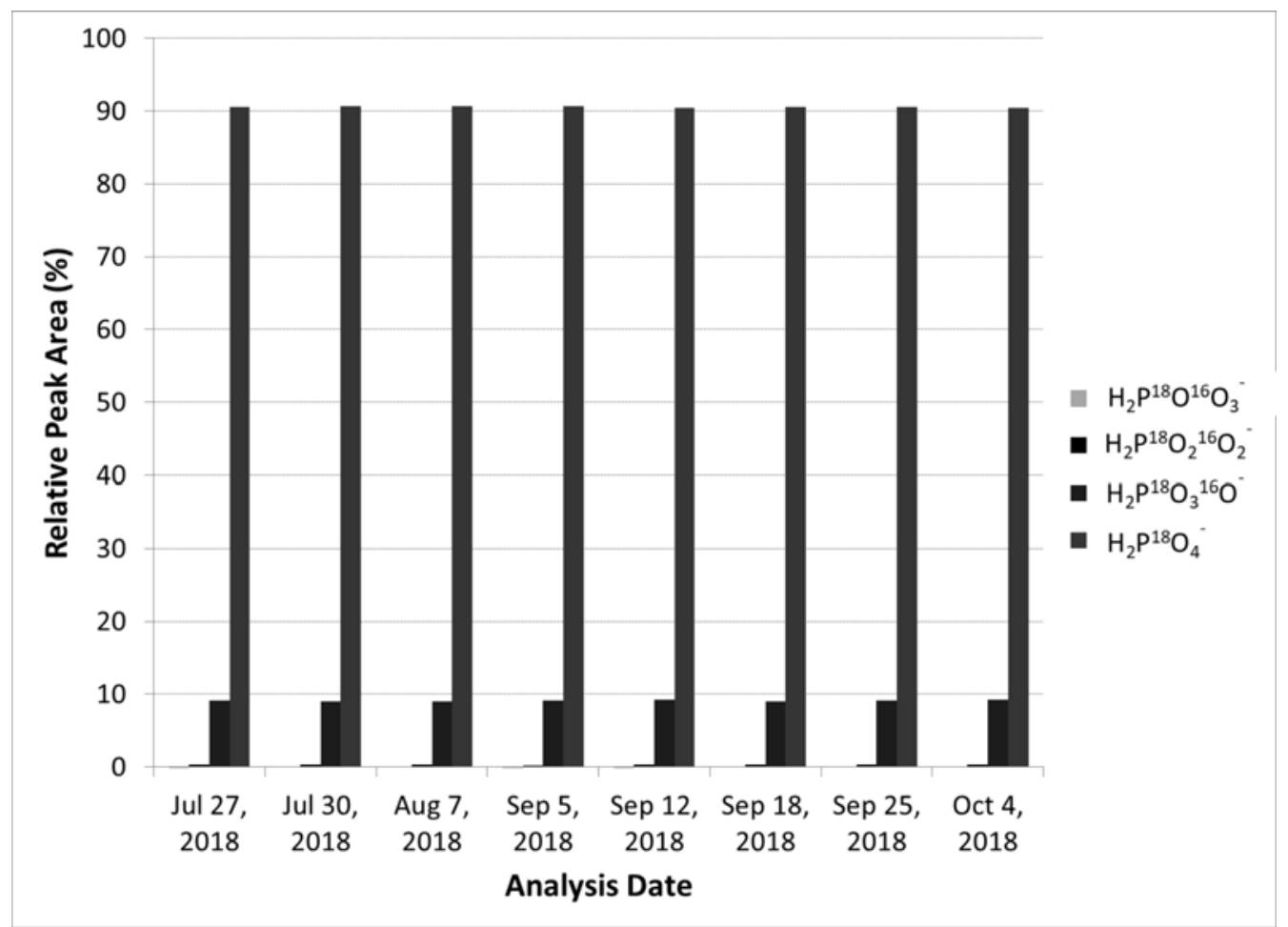

Figure S4: Distribution of the ${ }^{18} \mathrm{O}$ labeled $\mathrm{H}_{2} \mathrm{PO}_{4}{ }^{-}$species remained unchanged over a two months storage (pure water sample spiked with ${ }^{18} \mathrm{O}-\mathrm{H}_{2} \mathrm{PO}_{4}^{-}$at same level as all samples at $20 \mu \mathrm{g}$ $\mathrm{L}^{-1}$ as $\left.\mathrm{P}\right)$. 


\title{
APPENDIX B
}

\section{Supporting Information}

\section{Phosphorus Speciation in Toronto Harbour and Rivers}

Vlastimil Packa ${ }^{+} \neq$, Stefanie Maedler ${ }^{+}$, Todd Howell $^{+}$, Vadim Bostan $^{\ddagger}$, Ngan Diep $^{+}$, Robert Tooley $^{+}$and Vasile I. Furdui ${ }^{+,} \neq$

${ }^{\dagger}$ Ontario Ministry of the Environment, Conservation and Parks, 125 Resources Road, Toronto, ON, M9P 3V6, Canada

${ }^{\ddagger}$ Ryerson University, 350 Victoria Street, Toronto, Ontario M5B 2K3, Canada

\section{SUPPORTING INFORMATION}

\begin{abstract}
Page
Phosphate measurement by colorimetry .................................................................. SI-2

Total phosphorus (TP) measurement ........................................................................ SI-2

Sulfate measurement by ion chromatography (IC) …................................................... SI-3

Anion separation by capillary IC (Figure S1) ................................................................. SI-4

MDLs for analyzed P-containing metabolites (Table S4) ................................................ SI-4

Schematic of the 2D-IC configuration (Figure S2) .......................................................... SI-5
\end{abstract}




\section{The determination of ammonia, nitrite, nitrate and phosphate by colorimetry}

Ammonia, Nitrite, Nitrate plus Nitrite and Phosphorus are determined simultaneously using automated colourimetry on the same aliquot of sample. The ammonia analysis is based on formation of blue complex in buffered alkaline media. Ammonia is converted to a blue complex using sodium nitroprusside as catalyst. The concentration is determined by an absorbance at $630 \mathrm{~nm}$ against the set of standards (calibration range: $0-2 \mathrm{mg} / \mathrm{L}$ as $\mathrm{N}$ ). ). The method detection limit (MDL) was $15 \mu \mathrm{g} \mathrm{L}^{-1}$ as $\mathrm{N}$. Nitrite analysis is based on nitrite reaction with sulphanilamide and afterwards coupling with $\mathrm{N}$ (1-naphthyl) ethylenediamine dihydrochloride at $\mathrm{pH} 1$ to produce a light red color solution. The absorbance of the solution is measured at $520 \mathrm{~nm}$ and concentration is determined by comparison against the set of calibration standards (calibration range: $0-0.2 \mathrm{mg} / \mathrm{L}$ as $\mathrm{N})$. ). $\mathrm{MDL}$ of the method was $3 \mu \mathrm{g} \mathrm{\textrm {L } ^ { - 1 }}$ as $\mathrm{N}$.Nitrate is determined as a difference between the nitrite + nitrate and nitrite analysis. Nitrate and nitrite are determined simultaneously on the same aliquot sample. Nitrate is reduced to nitrite by heating the aliquote of the sample to $37^{\circ} \mathrm{C}$ with hydrazine in alkaline media with the addition of cupric ion as a catalyst. Subsequently, an azo dye is formed in acid media by diazotizing sulphanilamide with nitrite and coupling the product with $\mathrm{N}$ (I-naphthyl) ethylenediamine dihydrochloride. The absorbance of light red azo dye was measured at $520 \mathrm{~nm}$ and quantified against a set of known mixed calibration standards (calibration range nitrite+nitrate: $0-12.2 \mathrm{mg} / \mathrm{L}$ as $\mathrm{N}$ ). ). MDL was $60 \mu \mathrm{g} \mathrm{L} \mathrm{L}^{-1}$ as $\mathrm{N}$.Soluble reactive phosphorus (SRP) was measured using a Skalar continuous flow analyzer (Breda, Netherlands). SRP was measured after formation of a phospho-antimonyl-molybdate complex in the presence of the ascorbic acid as a reducing agent. The absorbance was measured at $880 \mathrm{~nm}$ with quantitation based on external calibration (calibration range $0-0.3 \mathrm{mg} / \mathrm{L}$ as $\mathrm{P}$ ). MDL was 
$3 \mu \mathrm{g} \mathrm{L}^{-1}$ as P. Quality control of the method was assured by running in-run quality control standards, duplicates, method blanks and reference samples. The phosphate method for was modified (see Table S1) from the reference method 4500-P G from the Standard Methods for the Examination of Water and Wastewater ${ }^{100}$.

Table S1. Differences between Standard Method 4500-P G and SRP method

\begin{tabular}{|l|l|l|}
\hline Analysis Modification & Standard Method 4500-P G & SRP Method \\
\hline $\begin{array}{l}\text { Antimony potassium } \\
\text { tartrate solution }\end{array}$ & $1.3715 \mathrm{~g}$ to $500 \mathrm{~mL}$ of water & $5 \mathrm{~g}$ to $4000 \mathrm{~mL}$ of water \\
\hline $\begin{array}{l}\text { Ammonium molybdate } \\
\text { solution }\end{array}$ & $20 \mathrm{~g}$ to $500 \mathrm{~mL}$ of water & $240 \mathrm{~g}$ to $4000 \mathrm{~mL}$ water of water \\
\hline Ascorbic solution & $1.76 \mathrm{~g}$ to $100 \mathrm{~mL}$ & $10 \mathrm{~g}$ to $500 \mathrm{~mL}$ of water \\
\hline Wetting agent & Not used/needed & FDD6 soap \\
\hline
\end{tabular}

Total phosphorus (TP) measurement

Samples were preserved with sulfuric acid and $10 \mathrm{~mL}$ aliquots were digested at $121^{\circ} \mathrm{C}$ for $30 \mathrm{~min}$ after adding potassium persulfate using a Tuttnauer 2540 EK-B/L autoclave (Heidolph Brinkmann, Hauppauge, NY, USA). After digestion TP was measured as phosphate using a Skalar continuous flow analyzer (Breda, Netherlands) where phosphate reacted in an acidic medium with ammonium molybdate and potassium antimony tartrate forming antimony-phosphomolybdate acid. The complex is reduced by ascorbic acid and forms a molybdenum blue complex. The absorbance is measured at $880 \mathrm{~nm}$ and compared with calibration standards (calibration range: $0-40 \mu \mathrm{g} \mathrm{L}-1$ as P). MDL of the method was $0.2 \mu \mathrm{g} \mathrm{L^{-1 }}$ as P. Quality control of the method was monitored by running quality control standards, duplicates, blanks and reference material. This method is slightly modified (see Table S2) from the reference method 4500-P (section B5 for digestion and section $\mathrm{F}$ for analysis ${ }^{100}$. 
Table S2. Differences between Standard Method 4500-P B5 and TP method

\begin{tabular}{|l|l|l|}
\hline Digestion Modification & Standard Method 4500- P B5 & TP Method \\
\hline Indicator solution & Phenolphthalein & Not used \\
\hline Persulfate & $\begin{array}{l}\text { Add } 0.5 \mathrm{~g} \text { solid } \mathrm{K}_{2} \mathrm{~S}_{2} \mathrm{O}_{8} \\
\text { to each sample }\end{array}$ & $\begin{array}{l}\text { Add } 150 \mu \mathrm{L} \text { of saturated } \mathrm{K}_{2} \mathrm{~S}_{2} \mathrm{O}_{8} \\
\text { solution to } 10 \mathrm{~mL} \text { of sample }\end{array}$ \\
\hline Analysis Modification & Standard Method 4500-P F & TP Method \\
\hline Flow cell & 15 or $50 \mathrm{~mm}$ & $500 \mathrm{~mm}$ \\
\hline $\begin{array}{l}\text { Antimony potassium } \\
\text { tartrate solution }\end{array}$ & $0.3 \mathrm{~g}$ to $100 \mathrm{~mL}$ of water & $2.3 \mathrm{~g}$ to $100 \mathrm{~mL}$ of water \\
\hline $\begin{array}{l}\text { Ammonium molybdate } \\
\text { Solution }\end{array}$ & $4 \mathrm{~g}$ to $100 \mathrm{~mL}$ of water & $3 \mathrm{~g}$ to $1000 \mathrm{~mL}$ water of water \\
\hline Ascorbic solution & $1.76 \mathrm{~g}$ to $100 \mathrm{~mL}$ & $0.2 \mathrm{~g}$ to $100 \mathrm{~mL}$ of water \\
\hline Wetting agent & Not used/needed & FDD6 soap \\
\hline
\end{tabular}

Analysis of sulfate, chloride, sodium, calcium, potassium and magnesium by capillary ion chromatography (Cap-IC).

Sulfate, chloride, bromide, sodium, calcium, potassium and magnesium were analyzed using capillary ion chromatography (ICS-5000+, Thermo Fisher Scientific, Mississauga, ON, Canada) containing AS-AP, DP, EG and DC modules. Separation of major anions was obtained in 25 minutes by using an AS18 column and conductivity detector (see Figure S1). The method is similar to US EPA Method 300.1 (Determination of Inorganic Anions in Drinking Water by lon Chromatography PART A. Common Anions in EPA 300.1) ${ }^{255}$, with differences summarized in Table S3. The phosphate was simultaneously measured, but it was below method MDL for the majority of the analyzed surface water samples. 
Table S3. Differences between Standard Method EPA 300.1 and IC method used

\begin{tabular}{|l|l|l|}
\hline Analysis Modification & EPA Method 300.1 & IC Method \\
\hline IC Column & AS9-HC & AS18 \\
\hline Eluent & $9 \mathrm{mM}$ carbonate & $10-34 \mathrm{mM}$ hydroxide \\
\hline Injection Volume & $40 \mu \mathrm{L}$ & $0.4 \mu \mathrm{L}$ \\
\hline Analysis Time & $15 \mathrm{~min}$ & $24 \mathrm{~min}$ \\
\hline Column type & $4 \mathrm{~mm}$ & capillary \\
\hline
\end{tabular}

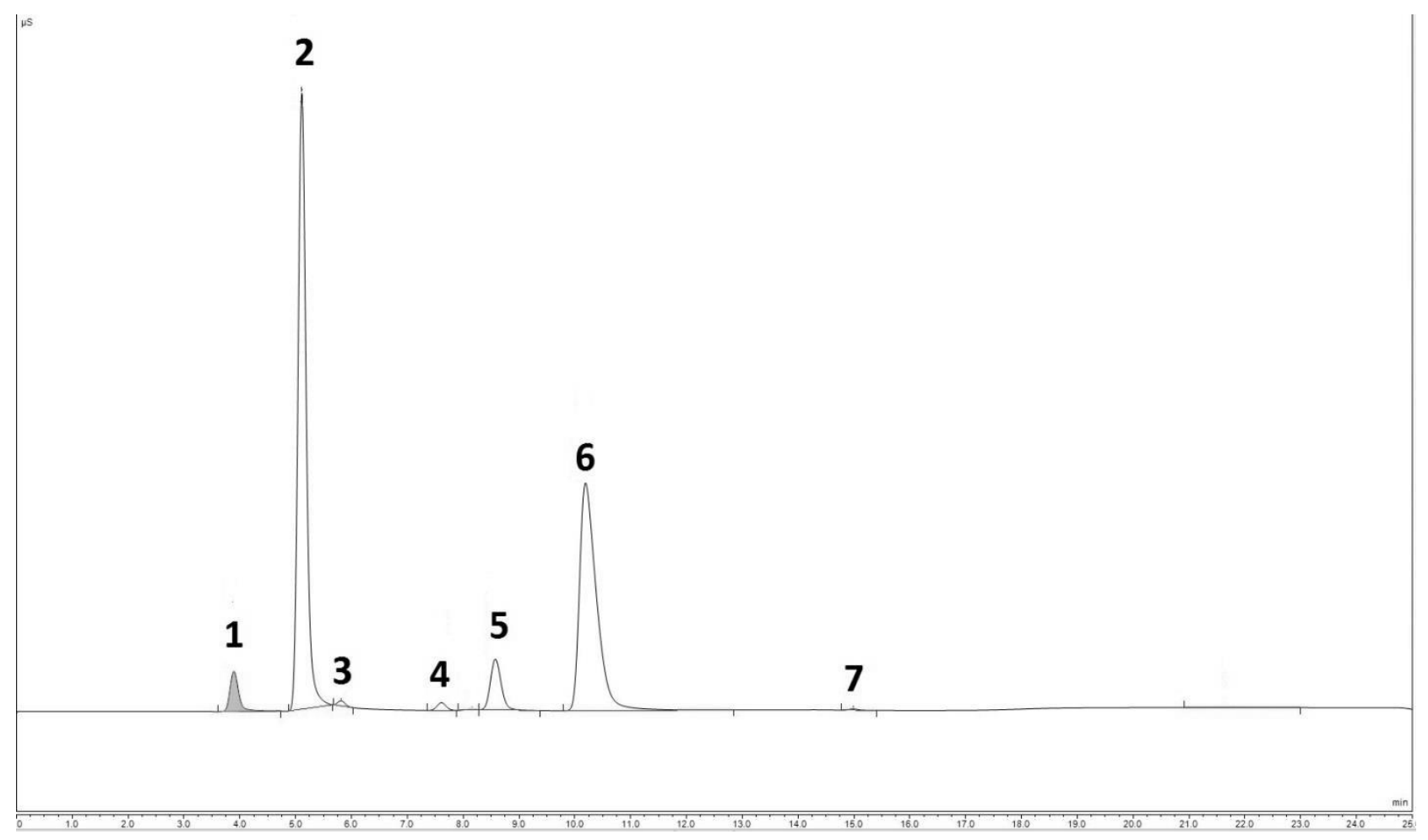

Figure S1. Anion separation by capillary IC from a standard mixture containing: (1) fluoride, (2) chloride, (3) nitrite, (4) bromide, (5) nitrate, (6) sulfate, (7) phosphate. 
Table S4. MDLs of P-containing metabolites

\begin{tabular}{|c|c|}
\hline Compound & MDL (nM) \\
\hline AMP & 0.10 \\
\hline Erythrose-P & 0.09 \\
\hline Fructose-P & 0.09 \\
\hline Fructose-Bi-P & 0.14 \\
\hline Galactose-P & 0.18 \\
\hline Glucose-P & 0.10 \\
\hline Glucose-Bi-P & 0.25 \\
\hline PGA & 0.36 \\
\hline Ribulose-P & 0.27 \\
\hline Ribulose-Bis-P & 0.31 \\
\hline UDP-Glucose & 0.23 \\
\hline
\end{tabular}

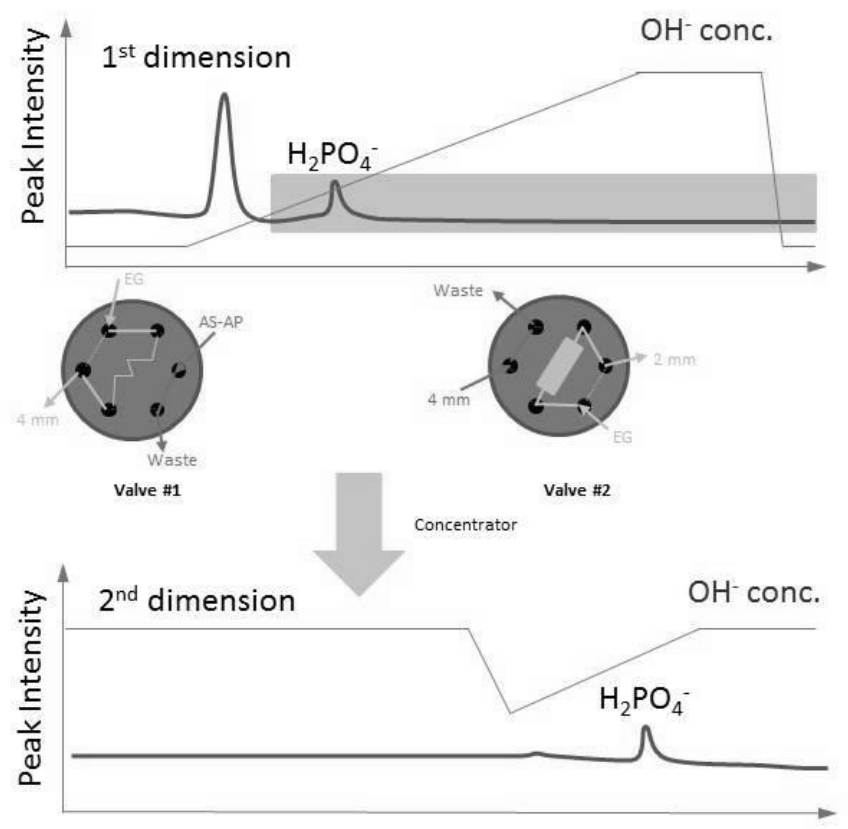

Figure S2. Schematic of the 2D-IC configuration 


\section{BIBLIOGRAPHY}

1. Hecky, R. E.; Kilham, P., Nutrient limitation of phytoplankton in freshwater and marine environments: A review of recent evidence on the effects of enrichment1: Nutrient enrichment. Limnology and Oceanography 1988, 33, (4part2), 796-822.

2. Ashraf P, M.; Edwin, L.; Meenakumari, B., Studies on the seasonal changes of phosphorus in the marine environments off Cochin. Environment International 2006, 32, (2), 159-164.

3. Voutsa, D.; Manoli, E.; Samara, C.; Sofoniou, M.; Stratis, I., A Study of Surface Water Quality in Macedonia, Greece: Speciation of Nitrogen and Phosphorus. Water, Air, and Soil Pollution 2001, 129, (1), 13-32.

4. Schindler, D. W., Evolution of Phosphorus Limitation in Lakes. Science 1977, 195, (4275), 260-262.

5. $\quad$ Sekiguchi, Y.; Mitsuhashi, N.; Kokaji, T.; Miyakoda, H.; Mimura, T., Development of a comprehensive analytical method for phosphate metabolites in plants by ion chromatography coupled with tandem mass spectrometry. Journal of Chromatography A 2005, 1085, (1), 131136.

6. Jürgens, U. J.; Drews, G.; Weckesser, J., Primary structure of the peptidoglycan from the unicellular cyanobacterium Synechocystis sp. strain PCC 6714. Journal of Bacteriology 1983, 154, (1), 471-478.

7. Hoiczyk, E.; Hansel, A., Cyanobacterial cell walls: news from an unusual prokaryotic envelope. Journal of bacteriology 2000, 182, (5), 1191-1199.

8. Huisman, J.; Matthijs, H. C. P.; Visser, P. M., Harmful cyanobacteria. Springer: 2005; Vol. 3.

9. Aubriot, L.; Bonilla, S.; Falkner, G., Adaptive phosphate uptake behaviour of phytoplankton to environmental phosphate fluctuations. FEMS microbiology ecology 2011, 77, (1), 1 .

10. Kornberg, A., Inorganic polyphosphate: toward making a forgotten polymer unforgettable. Journal of Bacteriology 1995, 177, (3), 491-496.

11. Ducobu, H.; Jonker, R. R.; Mur, L. R., Competition between a prochlorophyte and a cyanobacterium under various phosphorus regimes: Comparison with the Droop model. Journal of Phycology 1998, 34, (3), 467-476.

12. Dufresne, A.; Allen, E. E.; Larimer, F. W.; Waterbury, J.; Partensky, F.; Hauser, L.; McCarren, J.; Palenik, B.; Land, M.; Paulsen, I.; Regala, W.; Lamerdin, J.; Webb, E. A.; Chain, P.; Brahamsha, B., The genome of a motile marine Synechococcus. Nature 2003, 424, (6952), 1037-1042.

13. Bentzen, E.; Taylor, W. D.; Millard, E. S., The Importance of Dissolved Organic Phosphorus to Phosphorus Uptake by Limnetic Plankton. Limnology and Oceanography 1992, 37, (2), 217-231.

14. Pant, H. K.; Reddy, K. R., Hydrologic influence on stability of organic phosphorus in wetland detritus. Journal of environmental quality 2001, 30, (2), 668.

15. Hayes, F. R.; Phillips, J. E., Lake Water and Sediment IV. Radiophosphorus Equilibrium with Mud, Plants, and Bacteria Under Oxidized and Reduced Conditions. Limnology and Oceanography 1958, 3, (4), 459-475.

16. Spivakov, B. Y.; Maryutina, T. A.; Muntau, H., Phosphorus Speciation in Water and Sediments. Pure and Applied Chemistry 1999, 71, (11), 2161-2176. 
17. Baldwin, D. S., Organic phosphorus in the aquatic environment. Environmental Chemistry 2013, 10, (6), 439-454.

18. Worsfold, P. J.; Monbet, P.; Tappin, A. D.; Fitzsimons, M. F.; Stiles, D. A.; McKelvie, I. D., Characterisation and quantification of organic phosphorus and organic nitrogen components in aquatic systems: A Review. Analytica Chimica Acta 2008, 624, (1), 37-58.

19. Elser, J. J., Phosphorus: a limiting nutrient for humanity? Current Opinion in Biotechnology 2012, 23, (6), 833-838.

20. Elser, J.; Bennett, E., Phosphorus cycle: A broken biogeochemical cycle. Nature U6 ctx_ver $=Z 39.88-2004 \&$ ctx_enc $=$ info $\% 3 \mathrm{Aofi} \% 2 \mathrm{Fenc} \% 3 \mathrm{AUTF}$ -

$8 \& r f r \_i d=i n f o \% 3 \mathrm{Asid} \% 2 \mathrm{Fsummon}$. serialssolutions.com\& $r f$ f val_fmt $=$ info $\% 3 \mathrm{Aofi} \% 2 \mathrm{Ffmt} \% 3 \mathrm{Ak}$ ev\%3Amtx\%3Ajournal\&rft.genre $=$ article\&rft.atitle $=$ Phosphorus + cycle $\% 3 A+A+$ broken + biogeo chemical + cycle\&rft.jtitle $=$ Nature\&rft.au $=$ Elser $\% 2 C+$ James\&rft.au $=$ Bennett $\% 2 C+$ Elena\&rft.d ate $=2011-10-05 \&$ rft.eissn $=1476-$

$4687 \& r f t$.volume $=478 \& r f t . i s s u e=7367 \& r f t . s p a g e=29 \& r f t$ id $=i n f o \% 3 \mathrm{Apmid} \% 2 F 21979027 \& r f t$. externalDocID=21979027\&paramdict=en-US U7 - Journal Article 2011, 478, (7367), 29.

21. Smith, V. H., Eutrophication of freshwater and coastal marine ecosystems a global problem. Environmental Science and Pollution Research 2003, 10, (2), 126-139.

22. Le, C.; Zha, Y.; Li, Y.; Sun, D.; Lu, H.; Yin, B., Eutrophication of Lake Waters in China: Cost, Causes, and Control. Environmental Management 2010, 45, (4), 662-668.

23. Organisation for Economic, C.-o.; Development, Eutrophication of waters: monitoring, assessment and control. Organisation for Economic Co-operation and Development: 1982.

24. Le Moal, M.; Gascuel-Odoux, C.; Ménesguen, A.; Souchon, Y.; Étrillard, C.; Levain, A.; Moatar, F.; Pannard, A.; Souchu, P.; Lefebvre, A.; Pinay, G., Eutrophication: A new wine in an old bottle? Science of the Total Environment 2019, 651, (Pt 1), 1-11.

25. He, X.; Liu, Y.-L.; Conklin, A.; Westrick, J.; Weavers, L. K.; Dionysiou, D. D.; Lenhart, J. J.; Mouser, P. J.; Szlag, D.; Walker, H. W., Toxic cyanobacteria and drinking water: Impacts, detection, and treatment. Harmful Algae 2016, 54, 174-193.

26. Paerl, H. W.; Hall, N. S.; Calandrino, E. S., Controlling harmful cyanobacterial blooms in a world experiencing anthropogenic and climatic-induced change. Science of the Total Environment 2011, 409, (10), 1739-1745.

27. Daniel, T. C.; Sharpley, A. N.; Edwards, D. R.; Wedepohl, R.; Lemunyon, J. L., Minimizing surface water eutrophication from agriculture by phosphorus management. Journal of Soil and Water Conservation 1994, 49, (2), S30.

28. Peter, J. A. K.; Sharpley, A. N.; McDowell, R. W.; Flaten, D. N.; Buda, A. R.; Tao, L.; Bergstrom, L.; Zhu, Q.; Sveriges, 1., Managing agricultural phosphorus for water quality protection: principles for progress. Plant and Soil 2011, 349, (1/2), 169-182.

29. Bowes, M. J.; Smith, J. T.; Neal, C.; Leach, D. V.; Scarlett, P. M.; Wickham, H. D.; Harman, S. A.; Armstrong, L. K.; Davy-Bowker, J.; Haft, M.; Davies, C. E., Changes in water quality of the River Frome (UK) from 1965 to 2009: Is phosphorus mitigation finally working? Science of the Total Environment 2011, 409, (18), 3418-3430.

30. Kelly, M. G.; Wilson, S., Effect of phosphorus stripping on water chemistry and diatom ecology in an eastern lowland river. Water Research 2004, 38, (6), 1559-1567.

31. Meals, D. W.; Dressing, S. A.; Davenport, T. E., Lag time in water quality response to best management practices: a review. Journal of environmental quality 2010, 39, (1), 85.

32. Bowes, M. J.; Ings, N. L.; McCall, S. J.; Warwick, A.; Barrett, C.; Wickham, H. D.; Harman, S. A.; Armstrong, L. K.; Scarlett, P. M.; Roberts, C.; Lehmann, K.; Singer, A. C., 
Nutrient and light limitation of periphyton in the River Thames: Implications for catchment management. Science of the Total Environment 2012, 434, 201-212.

33. Jarvie, H. P.; Neal, C.; Williams, R. J., Assessing Changes in Phosphorus Concentrations in Relation to In-Stream Plant Ecology in Lowland Permeable Catchments: Bringing Ecosystem Functioning Into Water Quality Monitoring. Water, Air and Soil Pollution: Focus 2004, 4, (2), 641-655.

34. Neal, C.; Jarvie, H. P.; Williams, R.; Love, A.; Neal, M.; Wickham, H.; Harman, S.; Armstrong, L., Declines in phosphorus concentration in the upper River Thames (UK): links to sewage effluent cleanup and extended end-member mixing analysis. The Science of the total environment 2010, 408, (6), 1315-1330.

35. Jarvie, H. P.; Sharpley, A. N.; Withers, P. J. A.; Scott, J. T.; Haggard, B. E.; Neal, C., Phosphorus mitigation to control river eutrophication: murky waters, inconvenient truths, and "postnormal" science. Journal of environmental quality 2013, 42, (2), 295.

36. McDowell, R.; Sharpley, A., Availability of residual phosphorus in high phosphorus soils. Communications in Soil Science and Plant Analysis 2002, 33, (7-8), 1235-1246.

37. Sharpley, A.; Jarvie, H. P.; Buda, A.; May, L.; Spears, B.; Kleinman, P., Phosphorus legacy: overcoming the effects of past management practices to mitigate future water quality impairment. Journal of environmental quality 2013, 42, (5), 1308.

38. Jarvie, H. P.; Sharpley, A. N.; Spears, B.; Buda, A. R.; May, L.; Kleinman, P. J. A., Water Quality Remediation Faces Unprecedented Challenges from "Legacy Phosphorus".

Environmental Science \& Technology 2013, 47, (16), 8997-8998.

39. www.livescience.com/29312-great-lakes.html.

40. Environmental Commissioner of Ontario Annual Report 2014/2015, p.69-75.

41. Environment and Climate Change Canada, 2012 Great Lakes Water Quality Agreement www.ec.gc.ca/grandslacs-greatlakes/default.asp?lang $=$ En\&n=647DC488-1.

42. Small, H., Landmarks in the evolution of ion chromatography. LC-GC North America 2013, 31, (4), S8.

43. Michalski, R., Application of IC-MS and IC-ICP-MS in environmental research. $L C$ - $G C$ North America 2012, 30, (10), S32.

44. Small, H.; Stevens, T. S.; Bauman, W. C., Novel ion exchange chromatographic method using conductimetric detection. Analytical Chemistry 1975, 47, (11), 1801-1809.

45. T.Lebedev, A., Comprehensive Environmental Mass Spectrometry. ILM Publications: 2012.

46. Crotti, S.; Seraglia, R.; Traldi, P., Some Thoughts on Electrospray Ionization Mechanisms. In SAGE Publications: London, England, 2011; Vol. 17, pp 85-99.

47. Hu, Q.; Noll, R. J.; Li, H.; Makarov, A.; Hardman, M.; Graham Cooks, R., The Orbitrap: a new mass spectrometer. Journal of Mass Spectrometry 2005, 40, (4), 430-443.

48. https://www.thermofisher.com/us/en/home/industrial/mass-spectrometry/liquid-

chromatography-mass-spectrometry-lc-ms/lc-ms-systems/orbitrap-lc-ms.html.

49. Ngan Diep, A. D., Todd Howell, Sean Backus Lake St. Clair-Thames River Water

Quality and Harmful Algal Bloom Assessment; MOECP: 2017.

50. www.thermofisher.com www.thermofisher.com

51. ThermoScientific, IOnMax Source Hardware Manual.

52. ThermoScientific, QExactive Series Operations Manual. Thermo Scientific: 2014.

53. The Merck Index. Fourteenth ed.; Merck and Co., Inc.: Whitehouse Station, NJ, USA, 2006. 
54. Mellor, J. W., A comprehensive treatise on inorganic and theoretical chemistry. Wiley: 1962.

55. Toy, A. D. F., Elemental Phosphorus. The Chemistry of Phosphorus 1973, 3, 389-406.

56. Stwertka, A., A Guide to the Elements. Third ed.; Oxford University Press, Inc: New York, NY, USA, 2012.

57. Bingham, E.; Cohrssen, B.; H Powell, C., Patty's Toxicology, 5th edition in 9 volumes. 2001; Vol. 8, p 45-46.

58. Jacobs, M. B., The analytical toxicology of industrial inorganic poisons. Interscience Publishers: 1967.

59. Siekierski, S.; Burgess, J., 11 - Group 15. In Concise Chemistry of the Elements, Woodhead Publishing: 2002; pp 107-114.

60. Greenwood, A. E. a. N., 12 - Phosphorus. In Chemistry of the Elements (Second Edition), Butterworth-Heinemann: Oxford, 1997; pp 473-546.

61. Theocharis, C. R., Industrial inorganic chemistry By W. Büchner, R. Schliébs, G. Winter and K. H. Bücjel, VCH Verlagsgesellschaft, Weinheim, 1989. pp. $1+614$, price DM145.00, $£ 51.00$. ISBN 3-527-26629-1. Journal of Chemical Technology \& Biotechnology 1990, 47, (2), 182-182.

62. Waggaman, W. H., Phosphoric Acid, Phosphates, and Phosphatic Fertilizers. LWW: 1952; Vol. 74.

63. Albaigés, J., Stanley E. Manahan,Environmental chemistry: 9th edition, Boca Raton, FL, USA, CRC Press, 2010, 783 pp., 96.70 USD (hardback), ISBN 978-1-4200-5920-5.

International Journal of Environmental Analytical Chemistry 2013, 93, (14), 1559-1560.

64. Fernandez-García, C.; Coggins, A. J.; Powner, M. W., A Chemist's Perspective on the Role of Phosphorus at the Origins of Life. Life 2017, 7, (3), 31.

65. Westheimer, F. H., Why Nature Chose Phosphates. Science 1987, 235, (4793), 11731178.

66. Davis, B. D., On the importance of being ionized. Archives of Biochemistry and Biophysics 1958, 78, (2), 497-509.

67. Voet, D.; Voet, J. G., Biochemistry. J. Wiley \& Sons: 1990.

68. Condron, L.; Turner, B.; Cade-Menun, B., Phosphorus: Agriculture and the

Environment. ASA, CSSA, and SSSA: 2005.

69. Corbridge, D. E. C., Phosphorus : an outline of its chemistry, biochemistry, and uses.

Fifth edition. Amsterdam ; New York : Elsevier, 1995.: 1995.

70. Wood, H. G.; Clark, J. E., Biological Aspects of Inorganic Polyphosphates. Annual

Review of Biochemistry 1988, 57, (1), 235-260.

71. Kulakovskaya, T. V.; Lichko, L. P.; Ryazanova, L. P., Diversity of phosphorus reserves in microorganisms. Biochemistry (Moscow) 2014, 79, (13), 1602-1614.

72. Lahti, R., Microbial inorganic pyrophosphatases. Microbiological Reviews 1983, 47, (2), 169-179.

73. Pick, U.; Weiss, M., Polyphosphate Hydrolysis within Acidic Vacuoles in Response to Amine-Induced Alkaline Stress in the Halotolerant Alga Dunaliella salina. Plant Physiology 1991, 97, (3), 1234-1240.

74. Walter Dodds, M., Freshwater Ecology. Academic Press: 2010.

75. Hudson, J. J.; Schindler, D. W.; Taylor, W. D., Phosphate concentrations in lakes. Nature 2000, 406, (6791), 54-56. 
76. Broberg, O.; Persson, G., Particulate and dissolved phosphorus forms in freshwater: composition and analysis. Hydrobiologia 1988, 170, (1), 61-90.

77. Sundareshwar, P. V.; Morris, J. T.; Pellechia, P. J.; Cohen, H. J.; Porter, D. E.; Jones, B. C., Occurrence and Ecological Implications of Pyrophosphate in Estuaries. Limnology and Oceanography 2001, 46, (6), 1570-1577.

78. Huang, R.; Wan, B.; Hultz, M.; Diaz, J. M.; Tang, Y., Phosphatase-Mediated Hydrolysis of Linear Polyphosphates. Environmental Science \& Technology 2018, 52, (3), 1183-1190.

79. Rosset, R.; Hui, F.; Xie, J.; Kolodziejczyk, H.; Bayri, B., Les méthodes chromatographiques et électrophorétiques récentes d'analyse des phosphates inorganiques. Analusis 1998, 26, (2), 53-60.

80. Francko, D. A.; Heath, R. T., Functionally distinct classes of complex phosphorus compounds in lake water1: Complex phosphorus compounds. Limnology and Oceanography 1979, 24, (3), 463-473.

81. McKnight, D. M.; Duren, S. M., Biogeochemical processes controlling midday ferrous iron maxima in stream waters affected by acid rock drainage. Applied Geochemistry 2004, 19, (7), 1075-1084.

82. Ruiz-Calero, V.; Galceran, M. T., Ion chromatographic separations of phosphorus species: a review. Talanta 2005, 66, (2), 376-410.

83. Cade-Menun, B. J.; Navaratnam, J. A.; Walbridge, M. R., Characterizing dissolved and particulate phosphorus in water with 31P nuclear magnetic resonance spectroscopy.

Environmental science \& technology 2006, 40, (24), 7874.

84. Nanny, M. A.; Minear, R. A., Characterization of soluble unreactive phosphorus using 31P nuclear magnetic resonance spectroscopy. Marine Geology 1997, 139, (1), 77-94.

85. Read, E. K.; Ivancic, M.; Hanson, P.; Cade-Menun, B. J.; McMahon, K. D., Phosphorus speciation in a eutrophic lake by.sup.31P NMR spectroscopy. Water Research 2014, 62, 229.

86. Minear, R. A., Characterization of naturally occurring dissolved organophosphorus compounds. Environmental Science \& Technology 1972, 6, (5), 431-437.

87. Rigler, F. H., The Phosphorus Fractions and the Turnover Time of Inorganic Phosphorus in Different Types of Lakes. Limnology and Oceanography 1964, 9, (4), 511-518.

88. Maher, W.; Woo, L., Procedures for the storage and digestion of natural waters for the determination of filterable reactive phosphorus, total filterable phosphorus and total phosphorus. Analytica Chimica Acta 1998, 375, (1-2), 5-47.

89. Schindler, D. W.; Hecky, R. E.; Findlay, D. L.; Stainton, M. P.; Parker, B. R.; Paterson, M. J.; Beaty, K. G.; Lyng, M.; Kasian, S. E. M., Eutrophication of lakes cannot be controlled by reducing nitrogen input: Results of a 37-year whole-ecosystem experiment. Proceedings of the National Academy of Sciences 2008, 105, (32), 11254-11258.

90. Elser, J. J.; Marzolf, E. R.; Goldman, C. R., Phosphorus and Nitrogen Limitation of Phytoplankton Growth in the Freshwaters of North America: A Review and Critique of Experimental Enrichments. Canadian Journal of Fisheries and Aquatic Sciences 1990, 47, (7), 1468-1477.

91. Xu, H.; Paerl, H. W.; Qin, B.; Zhu, G.; Gaoa, G., Nitrogen and phosphorus inputs control phytoplankton growth in eutrophic Lake Taihu, China. Limnology and Oceanography 2010, 55, (1), 420-432.

92. Boström, B.; Persson, G.; Broberg, B., Bioavailability of different phosphorus forms in freshwater systems. Hydrobiologia 1988, 170, (1), 133-155. 
93. Worsfold, P. J.; Gimbert, L. J.; Mankasingh, U.; Omaka, O. N.; Hanrahan, G.; Gardolinski, P. C. F. C.; Haygarth, P. M.; Turner, B. L.; Keith-Roach, M. J.; McKelvie, I. D., Sampling, sample treatment and quality assurance issues for the determination of phosphorus species in natural waters and soils. Talanta 2005, 66, (2), 273-293.

94. Dodds, W. K.; Whiles, M. R., Chapter 14 - Nitrogen, Sulfur, Phosphorus, and Other Nutrients. In Freshwater Ecology (Second Edition), Academic Press: London, 2010; pp 345-373. 95. Lambert, D.; Maher, W.; Hogg, I., Changes in phosphorus fractions during storage of lake water. Water Research 1992, 26, (5), 645-648.

96. US Environmental Protection Agency, Method 365.1: Determination of Phosphorus by Semi-Automated Colorimetry. https:/www.epa.gov/sites/production/files/201508/documents/method 365-1 1993.pdf

97. Hall, G. E. M.; Bonham-Carter, G. F.; Horowitz, A. J.; Lum, K.; Lemieux, C.; Quemerais, B.; Garbarino, J. R., The effect of using different $0.45 \mu \mathrm{m}$ filter membranes on 'dissolved' element concentrations in natural waters. Applied Geochemistry 1996, 11, (1), 243249.

98. Horowitz, A. J.; Elrick, K. A.; Colberg, M. R., The effect of membrane filtration artifacts on dissolved trace element concentrations. Water Research 1992, 26, (6), 753-763.

99. Wang, Y.; Hammes, F.; Boon, N.; Egli, T., Quantification of the Filterability of Freshwater Bacteria through 0.45, 0.22, and 0.1 $\mu \mathrm{m}$ Pore Size Filters and Shape-Dependent Enrichment of Filterable Bacterial Communities. Environmental Science \& Technology 2007, 41, (20), 7080.

100. Standard methods for the examination of water and waste water, 23rd ed. American Public Health Association, American Water Works Association, Water Environment Federation, Washington, DC: 2017.

101. Murphy, J.; Riley, J. P., A modified single solution method for the determination of phosphate in natural waters. Analytica Chimica Acta 1962, 27, 31-36.

102. International Organization for Standardization, ISO 15681-1:2003. https://www.iso.org/standard/35050.html

103. International Organization for Standardization, ISO 15681-2:2003. https://www.iso.org/standard/35051.html

104. Eberlein, K.; Kattner, G., Automatic method for the determination of ortho-phosphate and total dissolved phosphorus in the marine environment. Fresenius Zeitschrift für Analytische Chemie 1987, 326, (4), 354-357.

105. Kitson, R.; Mellon, M., Colorimetric Determination of Phosphorus as

Molybdivanadophosphoric Acid. Industrial \& Engineering Chemistry Analytical Edition 1944, $16,(6), 379-383$.

106. Edwards, G. P.; Molof, A. H.; Schneeman, R. W., Determination of Orthophosphate in Fresh and Saline Waters. Journal - American Water Works Association 1965, 57, (7), 917-925. 107. Menzel, D. W.; Corwin, N., THE MEASUREMENT OF TOTAL PHOSPHORUS IN SEAWATER BASED ON THE LIBERATION OF ORGANICALLY BOUND FRACTIONS BY PERSULFATE OXIDATION. Limnology and Oceanography 1965, 10, (2), 280-282. 108. US Environmental Protection Agency, Method 365.4: Phosphorus, Total (Colorimetric, Automated, Block Digester AA II). https://www.epa.gov/sites/production/files/201508/documents/method 365-4 1974.pdf

109. Minamata Convention on Mercury, United Nations Environment Programme (UNEP). http://www.mercuryconvention.org/Convention/tabid/3426/language/en-US/Default.aspx 
110. Valderrama, J. C., The simultaneous analysis of total nitrogen and total phosphorus in natural waters. Marine Chemistry 1981, 10, (2), 109-122.

111. Patton, C. J.; Kryskalla, J. R., Methods of Analysis by the US Geological Survey National Water Quality Laboratory: Evaluation of Alkaline Persulfate Digestion as an Alternative to Kjeldahl Digestion for Determination of Total and Dissolved Nitrogen and Phosphorus in Water. In accessed on October 21, 2017.

112. Hosomi, M.; Sudo, R., Simultaneous determination of total nitrogen and total phosphorus in freshwater samples using persulfate digestion. International Journal of Environmental Studies 1986, 27, (3-4), 267-275.

113. Ebina, J.; Tsutsui, T.; Shirai, T., Simultaneous determination of total nitrogen and total phosphorus in water using peroxodisulfate oxidation. Water Research 1983, 17, (12), 1721-1726. 114. Ormaza-González, F. I.; Statham, P. J., A comparison of methods for the determination of dissolved and particulate phosphorus in natural waters. Water Research 1996, 30, (11), 27392747.

115. Lambert, D.; Maher, W., An evaluation of the efficiency of the alkaline persulphate digestion method for the determination of total phosphorus in turbid waters. Water Research 1995, 29, (1), 7-9.

116. Dayton, E. A.; Whitacre, S.; Holloman, C., Comparison of three persulfate digestion methods for total phosphorus analysis and estimation of suspended sediments. Applied Geochemistry 2017, 78, (Supplement C), 357-362.

117. O'Connor, P. W.; Syers, J. K., Comparison of methods for the determination of total phosphrous in waters containing particulate material. Journal of Environmental Quality 1975, 4, (3), 347-350.

118. Logan, T. J.; Oloya, T. O.; Yaksich, S. M., Phosphate Characteristics and Bioavailability of Suspended Sediments from Streams Draining into Lake Erie. Journal of Great Lakes Research 1979, 5, (2), 112-123.

119. Zhou, M.; Struve, D. M., The effects of post-persulfate-digestion procedures on total phosphorus analysis in water. Water Research 2004, 38, (18), 3893-3898.

120. Xie, C.; Xu, J.; Tang, J.; Baig, S. A.; Xu, X., Comparison of Phosphorus Determination Methods by Ion Chromatography and Molybdenum Blue Methods. Communications in Soil Science and Plant Analysis 2013, 44, (17), 2535-2545.

121. Gjerde, D. T.; Fritz, J. S.; Schmuckler, G., Anion chromatography with low-conductivity eluents. Journal of Chromatography A 1979, 186, 509-519.

122. US Environmental Protection Agency, Method 300.1: Determination of Inorganic Anions in Drinking Water by Ion Chromatography. https:/www.epa.gov/sites/production/files/201508/documents/method 300-1 1997.pdf

123. McDowell, M. M.; Ivey, M. M.; Lee, M. E.; Firpo, V. V. V. D.; Salmassi, T. M.; Khachikian, C. S.; Foster, K. L., Detection of hypophosphite, phosphite, and orthophosphate in natural geothermal water by ion chromatography. Journal of Chromatography A 2004, 1039, (12), 105-111.

124. Ivey, M. M.; Foster, K. L., Detection of phosphorus oxyanions in synthetic geothermal water using ion chromatography-mass spectrometry techniques. Journal of Chromatography $A$ 2005, 1098, (1-2), 95-103.

125. Han, C.; Geng, J.; Xie, X.; Wang, X.; Ren, H.; Gao, S., Determination of phosphite in a eutrophic freshwater lake by suppressed conductivity ion chromatography. Environmental Science and Technology 2012, 46, (19), 10667-10674. 
126. Kojima, H.; Kurihara, S.; Watanabe, Y.; Iwamaru, K.; Sato, K.; Tsunoda, K. I.; Hotta, H., A novel method for determination of inorganic oxyanions by electrospray ionization mass spectrometry using dehydration reactions. Journal of Mass Spectrometry 2016, 51, (2), 123-131. 127. Wang, R.; Wang, N.; Ye, M.; Zhu, Y., Determination of low-level anions in seawater by ion chromatography with cycling-column-switching. Journal of Chromatography A 2012, 1265, 186-190.

128. Altria, K. D., Capillary electrophoresis guidebook: principles, operation, and applications. Humana Press: 1996; Vol. 52.;52;.

129. Arce, L.; Ríos, A.; Valcárcel, M., Flow injection-capillary electrophoresis coupling to automate on-line sample treatment for the determination of inorganic ions in waters. Journal of Chromatography A 1997, 791, (1), 279-287.

130. Hjertén, S., Free zone electrophoresis. Chromatographic Reviews 1967, 9, (2), 122-219.

131. Jandik, P.; Jones, W. R., Optimization of detection sensitivity in the capillary electrophoresis of inorganic anions. Journal of Chromatography A 1991, 546, (C), 431-443. 132. Mayrhofer, K.; Zemann, A. J.; Schnell, E.; Bonn, G. K., Capillary electrophoresis and contactless conductivity detection of ions in narrow inner diameter capillaries. Analytical Chemistry 1999, 71, (17), 3828-3833.

133. Kubáň, P.; Reinhardt, M.; Müller, B.; Hauser, P. C., On-site simultaneous determination of anions and cations in drainage water using a flow injection-capillary electrophoresis system with contactless conductivity detection. Journal of Environmental Monitoring 2004, 6, (3), 169174.

134. Gaudry, A. J.; Guijt, R. M.; Macka, M.; Hutchinson, J. P.; Johns, C.; Hilder, E. F.; Dicinoski, G. W.; Nesterenko, P. N.; Haddad, P. R.; Breadmore, M. C., On-line simultaneous and rapid separation of anions and cations from a single sample using dual-capillary sequential injection-capillary electrophoresis. Analytica Chimica Acta 2013, 781, 80-87.

135. Johns, C.; Breadmore, M. C.; Macka, M.; Ryvolová, M.; Haddad, P. R., Recent significant developments in detection and method development for the determination of inorganic ions by CE. Electrophoresis 2009, 30, (SUPPL. 1), S53-S67.

136. Sugimae, A., Determination of phosphorus in river water, sewer water and domestic waste water by inductively coupled plasma-optical emission spectrometry. BUNSEKI KAGAKU 1980, 29, (8), 502-508.

137. Fujino, O.; Koga, Y.; Hiraki, K., Determination of phosphate ions in natural water by solvent extraction/1CP-AES. BUNSEKI KAGAKU 1991, 40, (1), 19-24.

138. Wennrich, R.; Mroczek, A.; Dittrich, K.; Werner, G., Determination of nonmetals using ICP-AES-techniques. Fresenius' Journal of Analytical Chemistry 1995, 352, (5), 461-469.

139. de Boer, J. L. M.; Kohlmeyer, U.; Breugem, P. M.; van der Velde-Koerts, T., Determination of total dissolved phosphorus in water samples by axial inductively coupled plasma atomic emission spectrometry. Fresenius' Journal of Analytical Chemistry 1998, 360, (1), 132-136.

140. Fan, Z. F.; Du, L. M., Determination of Phosphorus by Inductively Coupled Plasma Atomic Emission Spectroscopy after Hydride Generation. Chinese Chemical Letters 2000, 11, (5), 425-426.

141. Okamoto, Y.; Kanda, K.; Kishiwada, S.; Fujiwara, T., Determination of Phosphorous and Sulfur in Environmental Samples by Electrothermal Vaporization Inductively Coupled Plasma Atomic Emission Spectrometry. Applied Spectroscopy 2004, 58, (1), 105-110. 
142. Cantarero, A.; López, M. B.; Mahía, J.; Maestro, M. A.; Paz, A., Determination of total and dissolved phosphorus in agricultural runoff samples by inductively coupled plasma mass spectrometry. Communications in Soil Science and Plant Analysis 2002, 33, (15-18), 3431-3436. 143. Caruso, J. A.; Montes-Bayon, M., Elemental speciation studies - New directions for trace metal analysis. Ecotoxicology and Environmental Safety 2003, 56, (1), 148-163.

144. Shah, M.; Caruso, J. A., Inductively coupled plasma mass spectrometry in separation techniques: Recent trends in phosphorus speciation. Journal of Separation Science 2005, 28, (15), 1969-1984.

145. Olesik, J. W., Elemental analysis using ICP-OES and ICP/MS. Analytical Chemistry 1991, 63, (1), 12-21A.

146. Kovačevič, M.; Leber, R.; Kohlwein, S. D.; Goessler, W., Application of inductively coupled plasma mass spectrometry to phospholipid analysis. Journal of Analytical Atomic Spectrometry 2004, 19, (1), 80-84.

147. Lovdahl, M. J.; Pietrzyk, D. J., Anion-exchange separation and determination of bisphosphonates and related analytes by post-column indirect fluorescence detection. Journal of Chromatography A 1999, 850, (1), 143-152.

148. Allgrove, J., Biphosphonates. Archives of Disease in Childhood 1997, 76, (1), 73-75.

149. Daley-Yates, P. T.; Gifford, L. A.; Hoggarth, C. R., Assay of 1-hydroxy-3-

aminopropylidene-1,1-bisphosphonate and related bisphosphonates in human urine and plasma by high-performance ion chromatography. Journal of Chromatography B: Biomedical Sciences and Applications 1989, 490, (C), 329-338.

150. Kovačevič, M.; Gartner, A.; Novič, M., Determination of bisphosphonates by ion chromatography-inductively coupled plasma mass spectrometry. Journal of Chromatography $A$ 2004, 1039, (1-2), 77-82.

151. Kline, W. F.; Matuszewski, B. K.; Bayne, W. F., Determination of 4-amino-1hydroxybutane-1,1-bisphosphonic acid in urine by automated pre-column derivatization with 2,3-naphthalene dicarboxyaldehyde and high-performance liquid chromatography with fluorescence detection. Journal of Chromatography B: Biomedical Sciences and Applications 1990, 534, (C), 139-149.

152. Kline, W. F.; Matuszewski, B. K., Improved determination of the bisphosphonate alendronate in human plasma and urine by automated precolumn derivatization and highperformance liquid chromatography with fluorescence and electrochemical detection. Journal of Chromatography B: Biomedical Sciences and Applications 1992, 583, (2), 183-193.

153. Fidalgo-Used, N.; Montes-Bayón, M.; Blanco-González, E.; Sanz-Medel, A., Determination of organophosphorus pesticides in spiked river water samples using solid phase microextraction coupled to gas chromatography with EI-MS and ICP-MS detection. Journal of Analytical Atomic Spectrometry 2005, 20, (9), 876-882.

154. Guo, Z. X.; Cai, Q.; Yang, Z., Determination of glyphosate and phosphate in water by ion chromatography - Inductively coupled plasma mass spectrometry detection. Journal of

Chromatography A 2005, 1100, (2), 160-167.

155. Wigfield, Y. Y.; Lanouette, M., Simplified liquid chromatographic determination of glyphosate and metabolite residues in environmental water using post-column fluorogenic labelling. Analytica Chimica Acta 1990, 233, 311-314.

156. Berchmans, S.; Issa, T. B.; Singh, P., Determination of inorganic phosphate by electroanalytical methods: a review. Analytica chimica acta 2012, 729, 7-20. 
157. Flatt, R.; Brunisholz, G., Sur le dosage argentométrique de l'anion phosphorique. Analytica Chimica Acta 1947, 1, (C), 124-134.

158. Novozamsky, I.; van Riemsdijk, W. H., The behaviour of silver phosphate as the electroactive sensor in a phosphate-sensitive electrode. Analytica Chimica Acta 1976, 85, (1), 4146.

159. Alexander, P. W.; Haddad, P. R.; Trojanowicz, M., Potentiometric flow-injection determination of copper-complexing inorganic anions with a copper-wire indicator electrode. Analytical Chemistry 1984, 56, (13), 2417-2422.

160. Coetzee, J. F.; Gardner, C. W., Determination of Sulfate, Orthophosphate, and Triphosphate Ions by Flow Injection Analysis with the Lead Ion Selective Electrode as Detector. Analytical Chemistry 1986, 58, (3), 608-611.

161. Davey, D. E.; Mulcahy, D. E.; O'Connell, G. R., Flow-injection determination of phosphate with a cadmium ion-selective electrode. Talanta 1990, 37, (7), 683-687.

162. Glazier, S. A.; Arnold, M. A., Selectivity of Membrane Electrodes Based on Derivatives of Dibenzyitin Dichloride. Analytical Chemistry 1991, 63, (8), 754-759.

163. Chen, Z.; Marco, R. D.; Alexander, P. W., Flow-injection Potentiometric Detection of Phosphates Using a Metallic Cobalt Wire Ion-selective Electrode. Analytical Communications 1997, 34, (3), 93-95.

164. Marco, R. D.; Pejcic, B.; Chen, Z., Flow injection potentiometric determination of phosphate in waste waters and fertilisers using a cobalt wire ion-selective electrode. The Analyst 1998, 123, (7), 1635-1640.

165. Zhu, L.; Zhou, X.; Shi, H., A potentiometric cobalt-based phosphate sensor based on screen-printing technology. Frontiers of Environmental Science \& Engineering 2014, 8, (6), 945-951.

166. Li, L.; Shang, G.; Qin, W., Potentiometric sensing of aqueous phosphate by competition assays using ion-exchanger doped-polymeric membrane electrodes as transducers. Analyst 2016, 141, (15), 4573-4577.

167. Warwick, C.; Guerreiro, A.; Soares, A., Sensing and analysis of soluble phosphates in environmental samples: A review. Biosensors and Bioelectronics 2013, 41, (1), 1-11.

168. Fogg, A. G.; Bsebsu, N. K., Differential-pulse voltammetric determination of phosphate as molybdovanadophosphate at a glassy carbon electrode and assessment of eluents for the flow injection voltammetric determination of phosphate, silicate, arsenate and germanate. Analyst 1981, 106, (1269), 1288-1295.

169. Fogg, A. G.; Bsebsu, N. K., Flow injection voltammetric determination of phosphate: direct injection of phosphate into molybdate reagent. Analyst 1982, 107, (1274), 566-570.

170. Fogg, A. G.; Bsebsu, N. K.; Birch, B. J., Differential-pulse anodic voltammetric determination of phosphate, silicate, arsenate and germanate as $\beta$-heteropolymolybdates at a stationary glassy-carbon electrode. Talanta 1981, 28, (7, Supplement 1), 473-476.

171. Barus, C.; Romanytsia, I.; Striebig, N.; Garçon, V., Toward an in situ phosphate sensor in seawater using Square Wave Voltammetry. Talanta 2016, 160, 417-424.

172. Yao, T.; Wasa, T., Simultaneous determination of phosphate and pyrophosphate by an amperometric flow-injection system with immobilized enzyme reactors. Electroanalysis 1993, 5, (9-10), 887-890.

173. Yao, T.; Takashima, K.; Nanjyo, Y., Simultaneous determination of orthophosphate and total phosphates (inorganic phosphates plus purine nucleotides) using a bioamperometric flowinjection system made up by a 16-way switching valve. Talanta 2003, 60, (4), 845-51. 
174. Cheng, W.-L.; Sue, J.-W.; Chen, W.-C.; Chang, J.-L.; Zen, J.-M., Activated nickel platform for electrochemical sensing of phosphate. Analytical chemistry 2010, 82, (3), 1157. 175. Honda, A.; Morimitsu, M., A Novel Sensing Method for HPO42- and HCO3- by Electrochemical Oxidation with Amorphous Mixed Oxide Catalyst. Procedia Engineering 2016, 168, (Supplement C), 501-505.

176. Nanny, M. A.; Minear, R. A.; Leenheer, J. A., Nuclear Magnetic Resonance Spectroscopy in Environmental Chemistry. Oxford University Press: 1997.

177. Cade-Menun, B. J., Characterizing phosphorus in environmental and agricultural samples by 31P nuclear magnetic resonance spectroscopy. Talanta 2005, 66, (2 SPEC. ISS.), 359-371.

178. Cade-Menun, B. J.; Navaratnam, J. A.; Walbridge, M. R., Characterizing dissolved and particulate phosphorus in water with 31P nuclear magnetic resonance spectroscopy.

Environmental Science and Technology 2006, 40, (24), 7874-7880.

179. Read, E. K.; Ivancic, M.; Hanson, P.; Cade-Menun, B. J.; McMahon, K. D., Phosphorus speciation in a eutrophic lake by 31P NMR spectroscopy. Water Research 2014, 62, 229-240. 180. Bai, X. L.; Zhou, Y. K.; Sun, J. H.; Ma, J. H.; Zhao, H. Y.; Liu, X. F., Classes of dissolved and particulate phosphorus compounds and their spatial distributions in the water of a eutrophic lake: a 31P NMR study. Biogeochemistry 2015, 126, (1-2), 227-240.

181. Cade-Menun, B. J., Improved peak identification in 31P-NMR spectra of environmental samples with a standardized method and peak library. Geoderma 2015, 257-258, 102-114.

182. Feng, W.; Zhu, Y.; Wu, F.; He, Z.; Zhang, C.; Giesy, J. P., Forms and Lability of Phosphorus in Algae and Aquatic Macrophytes Characterized by Solution 31 P NMR Coupled with Enzymatic Hydrolysis. Scientific Reports 2016, 6.

183. Maccoux, M. J.; Dove, A.; Backus, S. M.; Dolan, D. M., Total and soluble reactive phosphorus loadings to Lake Erie. Journal of Great Lakes Research 2016, 42, (6), 1151-1165. 184. Huser, B. J.; Futter, M. N.; Wang, R.; Fölster, J., Persistent and widespread long-term phosphorus declines in Boreal lakes in Sweden. Science of The Total Environment 2018, 613614, (Supplement C), 240-249.

185. Heisler, J.; Glibert, P. M.; Burkholder, J. M.; Anderson, D. M.; Cochlan, W.; Dennison, W. C.; Dortch, Q.; Gobler, C. J.; Heil, C. A.; Humphries, E.; Lewitus, A.; Magnien, R.; Marshall, H. G.; Sellner, K.; Stockwell, D. A.; Stoecker, D. K.; Suddleson, M., Eutrophication and harmful algal blooms: A scientific consensus. Harmful Algae 2008, 8, (1), 3-13.

186. Correll, D. L., The role of phosphorus in the eutrophication of receiving waters: A review. Journal of Environmental Quality 1998, 27, (2), 261-266.

187. Correll, D. L., Phosphorus: A rate limiting nutrient in surface waters. Poultry Science 1999, 78, (5), 674-682.

188. Jansson, M.; Olsson, H.; Pettersson, K., Phosphatases; origin, characteristics and function in lakes. Hydrobiologia 1988, 170, (1), 157-175.

189. Sharma, U.; Pal, D.; Prasad, R., Alkaline Phosphatase: An Overview. Indian Journal of Clinical Biochemistry 2014, 29, (3), 269-278.

190. Herries, D., Alkaline phosphataseby R B McComb, G N Bowers, Jr and S Posen. pp 986. Plenum Press, New York and London. 1979. \$75 ISBN 0-306-40214-9. Biochemical Education 1981, 9, (2), 76-76.

191. Steiner, M., Zur Kenntnis des Phosphatkreislaufes in Seen. Die Naturwissenschaften 1938, 26, (44), 723-724.

192. Huisman, J.; Matthijs, H.; Visser, P., Harmful Cyanobacteria. 2005; Vol. 3. 
193. Standardization, I. O. f., ISO 15681-2 Water Quality-determination of orthophosphate and total phosphorus by flow analysis (CFA)-part2. In 2003.

194. Standardization, I. O. f., ISO 15681-1 Water Quality-determination of orthophosphate and total phosphorus by flow analysis (FIA) -part1. In 2005.

195. J. Tarapchak, S.; M. Bigelow, S.; Rubitschun, C., Overestimation of Orthophosphorus Concentrations in Surface Waters of Southern Lake Michigan: Effects of Acid and Ammonium Molybdate. 2011; Vol. 39, p 296-304.

196. Tarapchak, S. J., Soluble Reactive Phosphorus Measurements in Lake Water: Evidence for Molybdate-enhanced Hydrolysis. Journal of Environmental Quality 1983, 12, (1), 105-108. 197. Baldwin, D. S., Reactive "organic" phosphorus revisited. Water Research 1998, 32, (8), 2265-2270.

198. Denison, F. H.; Haygarth, P. M.; House, W. A.; Bristow, A. W., The Measurement of Dissolved Phosphorus Compounds: Evidence for Hydrolysis During Storage and Implications for Analytical Definitions in Environmental Analysis. International Journal of Environmental Analytical Chemistry 1998, 69, (2), 111-123.

199. Wahab, M. F.; Anderson, J. K.; Abdelrady, M.; Lucy, C. A., Peak distortion effects in analytical ion chromatography. Analytical Chemistry 2014, 86, (1), 559-566.

200. Zhang, Y.; Lucy, C. A., Effect of injection matrix concentration on peak shape and separation efficiency in ion chromatography. Journal of Chromatography A 2014, 1371, 177183.

201. Pappoe, M. K.; Naeeni, M. H.; Lucy, C. A., Bromate peak distortion in ion chromatography in samples containing high chloride concentrations. Journal of Chromatography A 2016, 1444, 57-63.

202. Hudak, P. F.; Sanmanee, S., Spatial patterns of nitrate, chloride, sulfate, and fluoride concentrations in the woodbine aquifer of North-Central Texas. Environmental Monitoring and Assessment 2003, 82, (3), 311-320.

203. King, R.; Bonfiglio, R.; Fernandez-Metzler, C.; Miller-Stein, C.; Olah, T., Mechanistic investigation of ionization suppression in electrospray ionization. Journal of the American Society for Mass Spectrometry 2000, 11, (11), 942-950.

204. Slingsby, R. W.; Pohl, C. A., Approaches to sample preparation for ion chromatography sulfate precipitation on barium-form ion exchangers. Journal of Chromatography A 1996, 739, (1), 49-55.

205. Tikhomirova, T. I.; Krokhin, O. V.; Dubovik, D. B.; Ivanov, A. V.; Shpigun, O. A., Chromatographic Determination of Silicon and Phosphorus as Molybdic Heteropoly Acids with Preconcentration. Journal of Analytical Chemistry 2002, 57, (1), 18-23.

206. Buldini, P. L.; Mevoli, A.; Quirini, A., On-line microdialysis-ion chromatographic determination of inorganic anions in olive-oil mill wastewater. Journal of Chromatography A 2000, 882 , (1), 321-328.

207. Dahllöf, I.; Svensson, O.; Torstensson, C., Optimising the determination of nitrate and phosphate in sea water with ion chromatography using experimental design. Journal of Chromatography A 1997, 771, (1), 163-168.

208. Wu, J.; Yu, X.; Lord, H.; Pawliszyn, J., Solid phase microextraction of inorganic anions based on polypyrrole film. The Analyst 2000, 125, (3), 391-394.

209. Hassenteufel, W.; Jagitsch, R.; Koczy, F. F., Impregnation of Glass Surface Against Sorption of Phosphate Traces. Limnology and Oceanography 1963, 8, (2), 152-156. 
210. Ryden, J. C.; Syers, J. K.; Harris, R. F., Sorption of inorganic phosphate by laboratory ware. Implications in environmental phosphorus techniques. Analyst 1972, 97, (1160), 903-908. 211. Latterell, J. J.; Timmons, D. R.; Holt, R. F.; Sherstad, E. M., Sorption of orthophosphate on the surface of water sample containers. Water Resources Research 1974, 10, (4), 865-869.

212. Dalas, E., Phosphate adsorption at the porous glass/water and $\mathrm{SiO} 2 /$ water interfaces. Journal of Colloid and Interface Science 1990, 134, (2), 299-304.

213. House, W. A.; Denison, F. H.; Armitage, P. D., Comparison of the uptake of inorganic phosphorus to a suspended and stream bed-sediment. Water Research 1995, 29, (3), 767-779.

214. Chen, J.; Li, Y.; Li, D. P.; Huang, Y.; Zhu, P. Y., [Distribution of Phosphorus Forms in the Overlying Water Under Disturbance with the Addition of Algae]. Huan jing ke xue= Huanjing kexue 2016, 37, (4), 1413-21.

215. Altundoğan, H. S.; Tümen, F., Removal of phosphates from aqueous solutions by using bauxite. I: Effect of $\mathrm{pH}$ on the adsorption of various phosphates. Journal of Chemical Technology \& Biotechnology 2002, 77, (1), 77-85.

216. Dalas, E.; Koutsoukos, P. G., Phosphate adsorption at the porous glass/water and SiO 2/water interfaces. Journal of Colloid And Interface Science 1990, 134, (2), 299-304.

217. Jarvie, H. P.; Withers, J. A.; Neal, C., Review of robust measurement of phosphorus in river water: Sampling, storage, fractionation and sensitivity. Hydrology and Earth System Sciences 2002, 6, (1), 113-132.

218. Stainton, M., Errors in Molybdenum Blue Methods for Determining Orthophosphate in Freshwater. 2011; Vol. 37, p 472-478.

219. Worsfold, P.; McKelvie, I.; Monbet, P., Determination of phosphorus in natural waters: A historical review. Analytica Chimica Acta 2016, 918, 8-20.

220. Baken, S.; Regelink, I. C.; Comans, R. N. J.; Smolders, E.; Koopmans, G. F., Iron-rich colloids as carriers of phosphorus in streams: A field-flow fractionation study. Water Res 2016, 99, 83-90.

221. Sinaj, S.; Mächler, F.; Frossard, E.; Faïsse, C.; Oberson, A.; Morel, C., Interference of colloidal particles in the determination of orthophosphate concentrations in soil water extracts. Communications in Soil Science and Plant Analysis 1998, 29, (9-10), 1091-1105.

222. Hens, M.; Merckx, R., The role of colloidal particles in the speciation and analysis of "dissolved" phosphorus. Water research 2002, 36, (6), 1483.

223. Bradford, M. E.; Peters, R. H., The Relationship Between Chemically Analyzed Phosphorus Fractions and Bioavailable Phosphorus. Limnology and Oceanography 1987, 32, (5), 1124-1137.

224. Halmann, M.; Stiller, M., Turnover and Uptake of Dissolved Phosphate in Freshwater. A Study in Lake Kinneret. Limnology and Oceanography 1974, 19, (5), 774-783.

225. Ekholm, P.; Krogerus, K., Determining algal-available phosphorus of differing origin: routine phosphorus analyses versus algal assays. Hydrobiologia 2003, 492, (1), 29-42.

226. Van Moorleghem, C.; De Schutter, N.; Smolders, E.; Merckx, R., The bioavailability of colloidal and dissolved organic phosphorus to the alga Pseudokirchneriella subcapitata in relation to analytical phosphorus measurements. Hydrobiologia 2013, 709, (1), 41-53.

227. Liang, Y.; Blake, R. E., Oxygen isotope signature of Pi regeneration from organic compounds by phosphomonoesterases and photooxidation. Geochimica et Cosmochimica Acta 2006, 70, (15), 3957-3969.

228. Blake, R. E.; Alt, J. C.; Martini, A. M., Oxygen isotope ratios of PO4: An inorganic indicator of enzymatic activity and P metabolism and a new biomarker in the search for life. 
Proceedings of the National Academy of Sciences of the United States of America 2001, 98, (5), 2148-2153.

229. Elsbury, K. E.; Paytan, A.; Ostrom, N. E.; Kendall, C.; Young, M. B.; McLaughlin, K.;

Rollog, M. E.; Watson, S., Using oxygen isotopes of phosphate to trace phosphorus sources and cycling in lake Erie. Environmental Science and Technology 2009, 43, (9), 3108-3114.

230. Melby, E. S.; Soldat, D. J.; Barak, P., Synthesis and detection of oxygen-18 labeled phosphate. PLoS ONE 2011, 6, (4).

231. Baykov, A. A.; Anashkin, V. A.; Salminen, A.; Lahti, R., Inorganic pyrophosphatases of Family II - two decades after their discovery. FEBS Letters 2017, 591, (20), 3225-3234.

232. Cooper, W. T.; Llewelyn, J. M.; Bennett, G. L.; Salters, V. J. M., Mass spectrometry of natural organic phosphorus. Talanta 2005, 66, (2 SPEC. ISS.), 348-358.

233. Zhao, J.; Liu, X., Organic and inorganic phosphorus uptake by bacteria in a plug-flow microcosm. Frontiers of Environmental Science and Engineering 2013, 7, (2), 173-184.

234. Saiardi, A., How inositol pyrophosphates control cellular phosphate homeostasis? In Advances in Biological Regulation, 2012; Vol. 52, pp 351-359.

235. Feng, W.; Li, C.; Zhang, C.; Liu, S.; Song, F.; Guo, W.; He, Z.; Li, T.; Chen, H., Characterization of phosphorus in algae from a eutrophic lake by solution 31P nuclear magnetic resonance spectroscopy. Limnology 2019, 20, (2), 163-171.

236. Feng, W.; Zhu, Y.; Wu, F.; He, Z.; Zhang, C.; Giesy, J. P., Forms and Lability of Phosphorus in Algae and Aquatic Macrophytes Characterized by Solution 31P NMR Coupled with Enzymatic Hydrolysis. Scientific Reports 2016, 6, (1), 37164.

237. Wenqiang, Z.; Baoqing, S.; Hong, Z.; Wenzhong, T., Characteristics of Phosphorus Compounds and Their Effects in Sediments of an Eutrophic Chaohu Lake, China. CLEAN-Soil, Air, Water 2015, 43, (4), 544-550.

238. Packa, V.; Maedler, S.; Howell, T.; Bostan, V.; Diep, N.; Tooley, R.; Furdui, V. I., Unbiased Measurement of Phosphate and Phosphorus Speciation in Surface Waters.

Environmental Science \& Technology 2018.

239. de Ceballos, B. S. O.; König, A.; de Oliveira, J. F., Dam reservoir eutrophication: A simplified technique for a fast diagnosis of environmental degradation. Water Research 1998, 32, (11), 3477-3483.

240. Vega, M.; Pardo, R.; Barrado, E.; Debán, L., Assessment of seasonal and polluting effects on the quality of river water by exploratory data analysis. Water Research 1998, 32, (12), 3581-3592.

241. Reisenhofer, E.; Picciotto, A.; Li, D., A factor analysis approach to the study of the eutrophication of a shallow, temperate lake (San Daniele, North Eastern Italy). Analytica Chimica Acta 1995, 306, (1), 99-106.

242. Parinet, B.; Lhote, A.; Legube, B., Principal component analysis: an appropriate tool for water quality evaluation and management-application to a tropical lake system. Ecological Modelling 2004, 178, (3), 295-311.

243. Simeonov, V.; Stratis, J. A.; Samara, C.; Zachariadis, G.; Voutsa, D.; Anthemidis, A.; Sofoniou, M.; Kouimtzis, T., Assessment of the surface water quality in Northern Greece. Water Research 2003, 37, (17), 4119-4124.

244. Olsen, R. L.; Chappell, R. W.; Loftis, J. C., Water quality sample collection, data treatment and results presentation for principal components analysis - literature review and Illinois River watershed case study. Water Research 2012, 46, (9), 3110-3122.

245. Toronto and Region Remedial Action Plan. In Toronto, Ontario: 2015. 
246. Estepp, L. R.; Reavie, E. D., The ecological history of Lake Ontario according to phytoplankton. Journal of Great Lakes Research 2015, 41, (3), 669-687.

247. Don River Watershed Plan. In Conditions, S. W. Q.-R. o. C., Ed. Toronto and Region Conservation.

248. Poulton, D. J.; Griffiths, M.; Ontario. Ministry of the, E., Toronto waterfront general water quality, 1976-1983. Ministry of the Environment: 1986.

249. Howell, E. T.; Chomicki, K. M.; Kaltenecker, G., Patterns in water quality on Canadian shores of Lake Ontario: Correspondence with proximity to land and level of urbanization. Journal of Great Lakes Research 2012, 38, 32-46.

250. Huang, R.; Tang, Y., Speciation Dynamics of Phosphorus during (Hydro)Thermal Treatments of Sewage Sludge. Environmental Science \& Technology 2015, 49, (24), 1446614474 .

251. He, Z.; Cade-Menun, B. J.; Toor, G. S.; Fortuna, A.-M.; Honeycutt, C. W.; Sims, J. T., Comparison of phosphorus forms in wet and dried animal manures by solution phosphorus-31 nuclear magnetic resonance spectroscopy and enzymatic hydrolysis. Journal of environmental quality 2007, 36, (4), 1086.

252. Turner, B. L.; Cheesman, A. W.; Godage, H. Y.; Riley, A. M.; Potter, B. V. L., Determination of neo- and D-chiro-inositol hexakisphosphate in soils by solution 31P NMR spectroscopy. Environmental science \& technology 2012, 46, (9), 4994-5002.

253. Zhu, Y.; Wu, F.; He, Z.; Guo, J.; Qu, X.; Xie, F.; Giesy, J. P.; Liao, H.; Guo, F., Characterization of organic phosphorus in lake sediments by sequential fractionation and enzymatic hydrolysis. Environmental science \& technology 2013, 47, (14), 7679-7687.

254. Feng, W.; Li, C.; Zhang, C.; Liu, S.; Song, F.; Guo, W.; He, Z.; Li, T.; Chen, H., Characterization of phosphorus in algae from a eutrophic lake by solution 31P nuclear magnetic resonance spectroscopy. Limnology 2018, 1-9.

255. Hautman, D. P.; Munch, D. J., Method 300.1: Determination of inorganic anions in drinking water by ion chromatography. EPA: Ohio 1997. 